\title{
Viewing America's Energy Future in Three Dimensions
}

EDITED BY

L. Louis Hegedus and Dorota S. Tenple

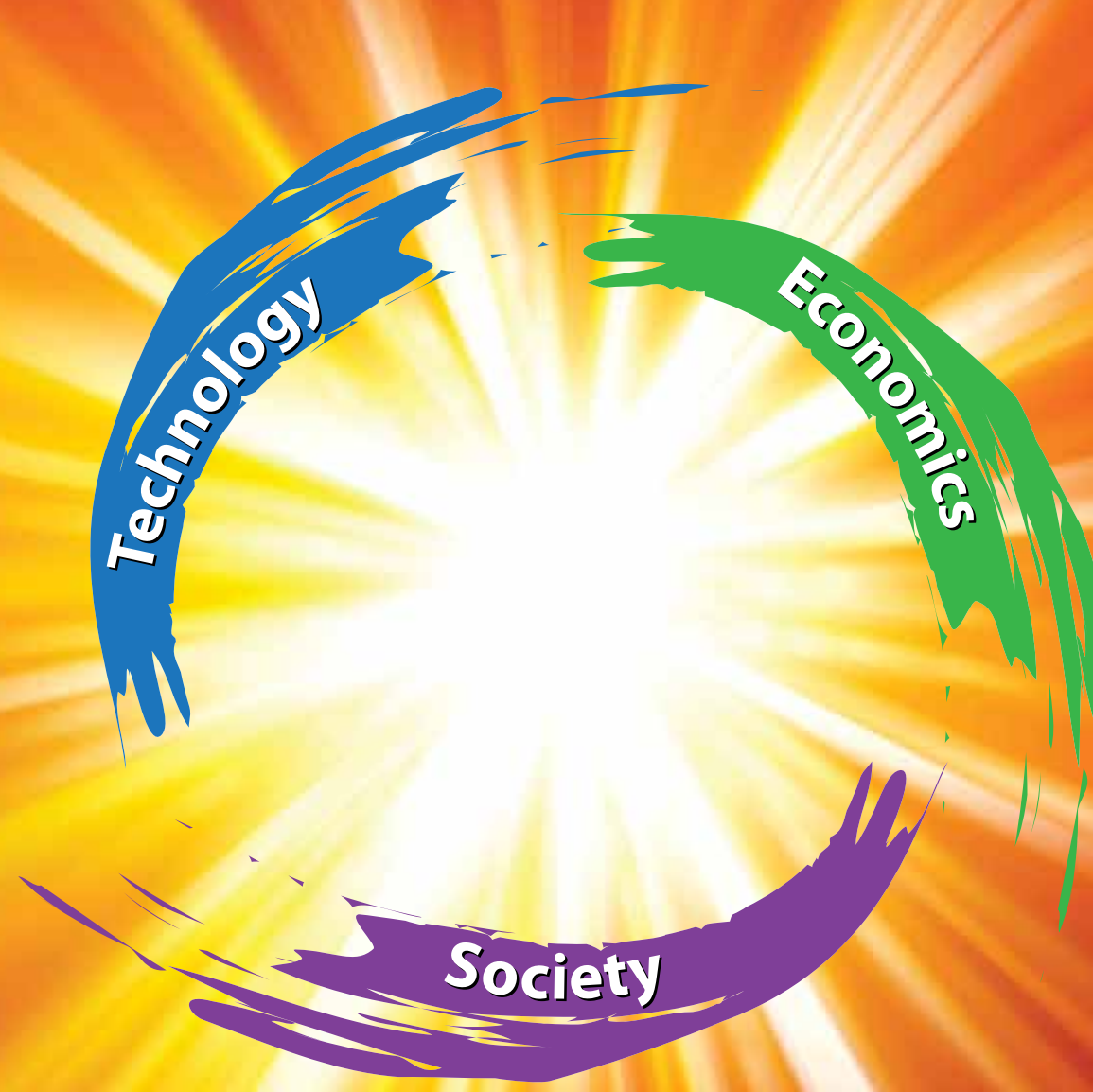

\section{CONTRIBUTING AUTHORS}

Robert H. Beach, Phillip C. Cooley, Allen P. Dufffer, Michael P. Gallaher, L. Louis Hegedus, Markus Lesemann, Toby H. Moore, Edo D. Pellizzari, and Dorota S. Temple 



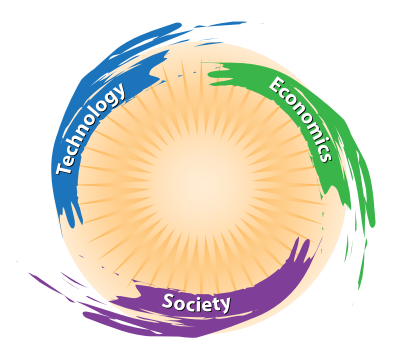

\title{
Viewing
}

\section{America's Energy Future in Three Dimensions}

\author{
EDITED BY \\ L. Louis Hegedus and Dorota S. Temple
}

CONTRIBUTING AUTHORS

Robert H. Beach, Philip C. Cooley, Allen P. Duffer,

Michael P. Gallaher, L. Louis Hegedus, Markus Lesemann, Toby H. Moore, Edo D. Pellizzari, and Dorota S. Temple 
C2011 Research Triangle Institute. RTI International is a registered trademark and a trade name of Research Triangle Institute. The RTI logo is a registered trademark of Research Triangle Institute

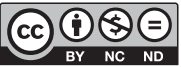

This work is distributed under the terms of a

Creative Commons Attribution-NonCommercial-

NoDerivatives 4.0 license (CC BY-NC-ND), a copy of which is

available at https://creativecommons.org/licenses/by-nc-nd/4.0

/legalcode.

Library of Congress Control Number: 2011934380

ISBN 978-1-934831-05-2

RTI Press publication No. BK-0006-1106

https://doi.org/10.3768/rtipress.2011.bk.0006.1106

www.rti.org/rtipress
The RTI Press mission is to disseminate information about RTI research, analytic tools, and technical expertise to a national and international audience. RTI Press publications are peer-reviewed by at least two independent substantive experts and one or more Press editors.

RTI International is an independent, nonprofit research institute dedicated to improving the human condition. We combine scientific rigor and technical expertise in social and laboratory sciences, engineering, and international development to deliver solutions to the critical needs of clients worldwide.

This publication is part of the RTI Press Book series.

RTI International

3040 Cornwallis Road, PO Box 12194, Research Triangle Park, NC 27709-2194 USA

rtipress@rti.org

www.rti.org 


\section{Contents}

Preface $\quad$ v

Acknowledgments vi vi

Chapter 1. Introduction 1

Chapter 2. Energy Technologies 5

Chapter 3. Energy Economics 25

Chapter 4. Societal Dimension of America's Energy Challenge $\quad 47$

Chapter 5. Future Research Needs 79

$\begin{array}{ll}\text { References } & 91\end{array}$

Appendix. America's Energy Future: Technology and Transformation-Excerpts of Interest for Societal Research 101

$\begin{array}{ll}\text { About the Authors } & 107\end{array}$

$\begin{array}{ll}\text { Index } & 109\end{array}$ 


\section{Figures}

Figure 2.1. US energy use in quads, 2008

Figure 2.2. US carbon dioxide emissions in million metric tons, 2008

Figure 3.1. Coal prices (in 2005 dollars), 1949-2009 27

Figure 3.2. US proved oil reserves, 1900-2008 28

Figure 3.3. US oil consumption and oil prices, 1973-2010 29

Figure 3.4. US oil production and oil imports, 1920-2010 30

Figure 3.5. Natural gas wellhead prices, 1976-2010 31

Figure 3.6. Uranium $\left(\mathrm{U}_{3} \mathrm{O}_{8}\right)$ prices, 1988-2010 32

Figure 3.7. ADAGE model structure 45

Tables

Table 4.1. Distribution of preferences about energy sources, 2007 (percent) 64

Table 4.2. Major oil exporters to the United States, $2008 \quad 69$

Table 4.3. Major coal-producing states, 2008 


\section{Preface}

This monograph resulted from research and discussions conducted by the RTI International Energy Grand Challenge Working Group, which formed in 2009 within the framework of the RTI Fellows Program's Grand Challenge Initiatives. These initiatives confront major, urgent challenges facing the United States (and, indeed, humanity) that can benefit from the kind of integrated, multidisciplinary analysis that a diverse, independent research institute like RTI can provide.

The Energy Grand Challenge Working Group consisted of representatives of RTI's technology, economics, and social science research functions who set out to explore the energy challenge as an intersection of three domains: technology, economics, and societal factors. Although, from the beginning, ours was an integrative approach, we have relied on the expertise of group members in their respective disciplines. In the energy technology domain, the group and the writing were led by L. Louis Hegedus; in the economics domain, by Robert H. Beach; and in the societal factors domain, by Toby H. Moore.

The objective of this work was to help frame the ongoing discussion of America's energy future in the context of all three dimensions-technology, economics, and social sciences-and to draw attention to research needs pertaining to the intersection of the societal factors domain with technology and economics. We hope that the proposed research will identify tools and techniques for not merely overcoming, but in fact harnessing, societal forces for the creation of a better energy future for our nation.

L. Louis Hegedus and Dorota S. Temple, Editors

Research Triangle Park, North Carolina, USA

June 2011 


\section{Acknowledgments}

We acknowledge many valuable discussions with RTI staff members. We thank David F. Myers for his role in initiating this project, James A. Trainham for valuable discussions, RTI Press former Editor-in-Chief Kathleen N. Lohr for her involvement and support during the preparation of the monograph, and Vikram Rao (of the Research Triangle Energy Consortium) for his interest in the study and insightful comments. Finally, we express our gratitude to the RTI Executive Leadership Team for initiating and supporting the Grand Challenge Initiatives of the RTI Fellows Program. 


\section{Introduction}

The late Richard Smalley, Nobel Prize-winning chemist and codiscoverer of a new allotropic form of the element carbon (buckminsterfullerene, $\mathrm{C}_{60}$ ), which prompted the onset of the nanotechnology wave, delivered a much-quoted presentation in 2003 on humanity's top ten problems for the next 50 years. ${ }^{1}$ He concluded that the most important issue and, therefore, the greatest challenge facing humanity is energy. In order of declining significance, the other problems were water, food, the environment, poverty, terrorism and war, disease, education, democracy, and population. All the challenges that follow energy are influenced and often dominated by energy; conversely, many of these other challenges have important implications for how the energy challenge may best be addressed.

At least three major viewpoints define how the US energy challenge is considered. Some view it primarily through climate-change considerations, related to carbon dioxide $\left(\mathrm{CO}_{2}\right)$ accumulation in the atmosphere and its actual or anticipated consequences. Others view it through the issues of energy security, pertaining to imported oil and related security and defense challenges, while yet others view the energy challenge primarily through its economic contexts, such as oil prices and price instabilities, impact on the US economy, trade balance, and impact on US currency.

Associated with these viewpoints are many additional concerns, including sustainability (how long the world's oil, natural gas, uranium, and coal supplies will last); globalization (the impact of rapidly growing energy demand in developing countries and the related economic, political, and environmental issues); regulation and taxation (how the government should respond to the energy challenge); politics (local and national constituencies, party ideologies); public preferences (impact of energy considerations on the quality of life and standard of living, or perceived balance between convenience and environmental responsibility); and the status and potential of technological developments (the balance between technologies that are available now, those that will be available in the near future, and those that may become longer-term "game changers").

The US National Academies Committee on America's Energy Future set out to study the title subject upon its formation in 2007. Its objective is to "inform policy makers about technology options for transforming energy production, distribution, and use to increase 
sustainability, support long-term economic prosperity, promote energy security, and reduce environmental impacts."2(p1) A series of reports resulted from the work, including America's Energy Future: Summary of a Meeting; ${ }^{3}$ America's Energy Future: Technology and Transformation; ${ }^{2}$ and Real Prospects for Energy Efficiency in the United States. ${ }^{4}$ Also of significance to our analysis is a recent National Research Council report, Hidden Costs of Energy: Unpriced Consequences of Energy Production and Use. ${ }^{5}$

We can group the issues considered in these reports into three main categories: technological, economic, and societal considerations. America's Energy Future: Technology and Transformation ${ }^{2}$ concludes that of these three, the "weakest link" is an insufficient understanding of the societal dimension. Accordingly, the report makes extensive calls for more data, analysis, and recommendations from the societal research disciplines. It concludes that "mobilization of the public and private sectors, supported by sustained long-term policies and investments, will be required for the decades-long effort to develop, demonstrate, and deploy these technologies."2(p1)

The report emphasizes the need to consider "policy and societal factors that would enhance or impede technology development and deployment"2(p10) and observes that a "study on energy conservation would require, for example, an in-depth understanding of how societal, economic, and policy factors affect energy consumption." ${ }^{2(p 33)}$ It refers to a "behavioral gap" that hinders the introduction of energy-efficient technologies, despite their economic advantages, and calls for continuing research to understand this gap more fully so that strategies can be devised for closing it.2(p50) Other societal research needs listed in the report include land use considerations in siting renewable technologies, opportunities for incentivizing businesses and the public, and opportunities for energy education. (For a collection of report excerpts pertaining to the societal dimension, see the appendix.)

The committee's call for the societal analysis of the US energy equation has motivated us to address this important topic and thereby provide a societal research-focused complement to the National Academies' technology-focused effort. Our approach recognizes the complexity of the problem, manifest in the intricate interactions among the technological, economic, and societal dimensions of the energy challenge. Consequently, we realize that the societal dimension should be discussed not in isolation but in its integrated, holistic context, at its intersection with technology and economics. For this purpose, we formed an interdisciplinary team of investigators at RTI International, an independent research organization with expertise in all three key dimensions of the energy problem. 
Energy technology and energy economics are necessary, although not sufficient, conditions for solving the energy conundrum; the sufficient condition derives from the societal dimension. Before developing the arguments grounded in the societal dimension, we provide, in Chapters 2 and 3, an overview of energy technologies and energy economics, respectively.

We discuss energy technologies in terms of their infrastructure, as the National Academies' report did. In our description of energy infrastructure, we point to those aspects that couple strongly with economics and social science knowledge gaps that need to be filled by new research. Similarly, we discuss energy economics in its technological and social context, establishing the basis for next discussing the societal dimension.

After we examine energy technologies and energy economics, in Chapter 4 we identify and describe our current understanding of the societal issues associated with the US energy challenge. We highlight the technological-economic-societal intersection and identify new social research needs in Chapter 5. These research opportunities are expected to drive progress at two levels: first, they may stimulate the development of improved or new tools, techniques, and recommendations to overcome the societal barriers identified in the Academies' report; second, and perhaps even more important, they may help identify additional opportunities for harnessing social forces to accelerate progress toward a rational energy future. 



\section{Energy Technologies}

Technology is based on the application of the laws of nature, which are immutable. Superimposed on technology are the conditions of economics (nothing can be implemented that cannot be funded) and societal driving forces and constraints. In the discussion of energy technologies, we highlight societal concerns as appropriate.

\section{Energy Infrastructure}

We discuss energy technologies according to the energy infrastructure they serve. A nation's energy infrastructure is its collection of resources, facilities, equipment, and systems for the exploration, extraction, conversion, storage, distribution, and use of primary and secondary energy sources.

Energy technologies can be defined as the intellectual property (patents and know-how) that are required to operate the energy infrastructure. All energy technologies have some common characteristics; these have to be considered when comparing the technologies or when technology preferences and technology portfolios are discussed. These common characteristics include their thermodynamic, operating, and material efficiencies; capital and operating costs; scale and scalability (modularity); environmental, health, climate, political, security, defense, and market risks and impacts; technological and market maturity; economic, resource, and environmental sustainability; and the trajectory and slope of their evolution, including their potential for breakthrough developments.

The US energy infrastructure is famously depicted in energy flow charts published yearly by the Lawrence Livermore Laboratory of the US Department of Energy. ${ }^{6}$ Figure 2.1 is the 2008 US energy flow chart on which our discussion throughout this chapter is based.

In 2008, the United States used 99.2 quads of energy from the primary energy sources shown in Figure 2.1. (One quad equals 1015 British thermal units, or BTUs). Of the 99.2 quads of energy, 7.28 (7.3 percent) came from renewable sources-solar, wind, hydroelectric, geothermal, and biomass; 83.39 (84.1 percent) came from fossil fuelsnatural gas, coal, and petroleum (crude oil); and 8.45 (8.5 percent) came from nuclear 
Figure 2.1. US energy use in quads, 2008
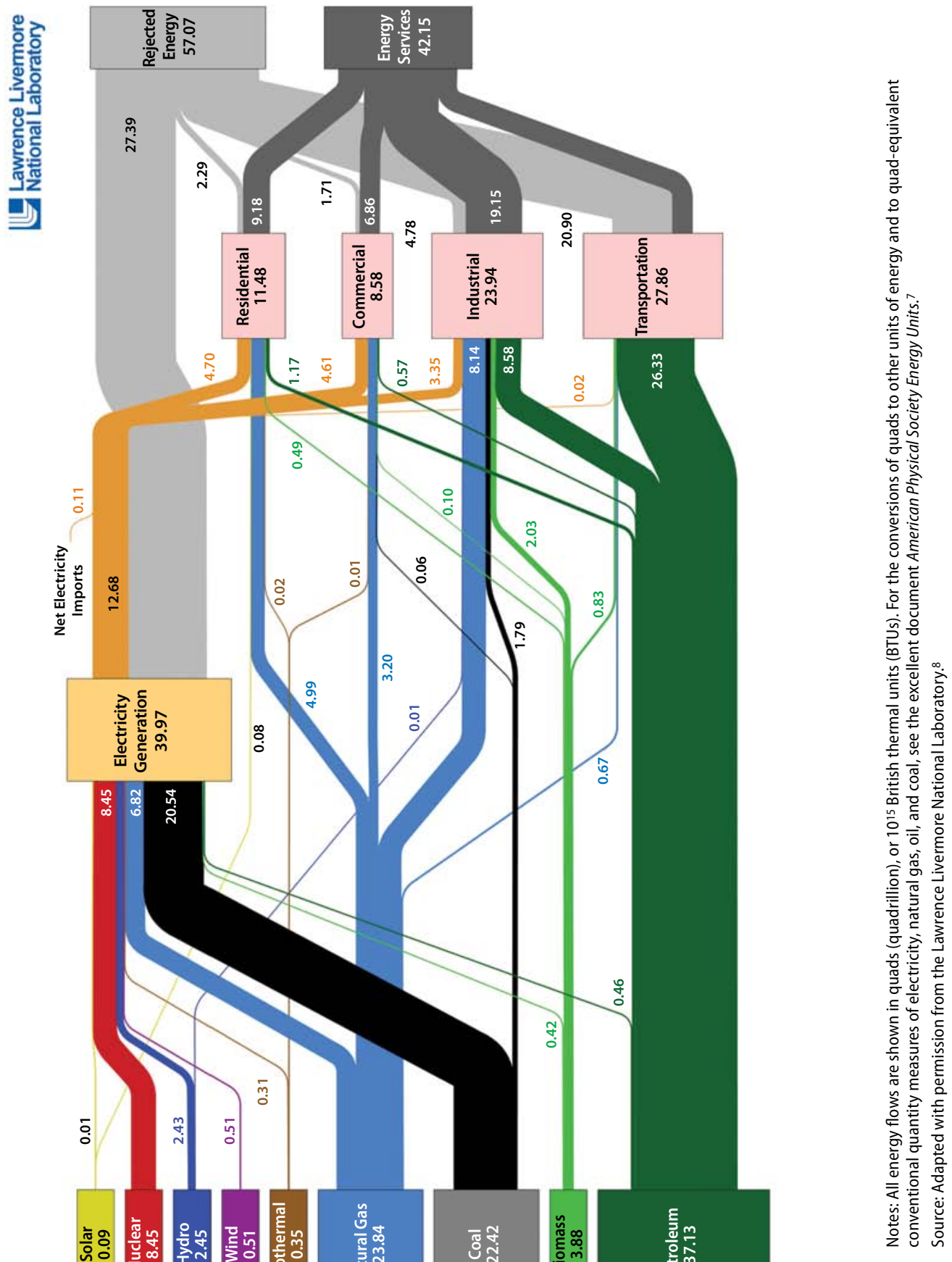
energy. Biomass, counted as a renewable source, contributed 3.88 quads (3.9 percent), 21 percent of which went for transportation. Approximately one-third of the total US energy consumption came from imported sources.

Some notable facts about the primary US energy sources:

- Despite all efforts to expand the use of renewable sources (solar, hydroelectric, wind, geothermal, and biomass in Figure 2.1), they remain a small proportion of sources overall (7.3 percent).

- All of nuclear power and 91.6 percent of coal are used to generate electricity.

- Transportation consumes 70.9 percent of the petroleum used in the United States.

- Almost all energy imports are petroleum; in 2009 about 62 percent of petroleum and petroleum products consumed in the US came from imports.

- Only 2.8 percent of natural gas is used for transportation.

\section{Energy Sources}

In this section we discuss the key US energy source technologies. They each have a large literature that is extensively cited in the National Academies reports. ${ }^{2-5}$ Unless stated otherwise, the numerical data quoted in this chapter are from the US Department of Energy's Energy Information Administration database. ${ }^{9}$

\section{Sustainable Energy Sources}

A number of primary energy sources are sustainable (i.e., considered inexhaustible or renewable). Among these sustainables are hydroelectric, geothermal, solar-thermal, solarelectric, wind-electric, wave-electric, and biomass energy sources.

\section{Hydroelectric}

Hydroelectric energy generation (2.45 quads in 2008, 2.4 percent of the total) depends on suitable geography; it is perceived to be almost fully developed in the United States.

\section{Geothermal}

Geothermal energy is feasible at volcanic locations, such as the edges of tectonic plates in California and Iceland. It can generate electricity by means of steam turbines or provide heating. About 0.3 percent of the world's electrical generating capacity comes from geothermal plants, with a global generating capacity of more than 10 gigawatts (GW). The largest geothermal generating site in the world is the Geysers, north of San Francisco, where 22 plants have a combined capacity of 1,517 megawatts (MW). Proposed novel 
geothermal technologies include hot (steam) wells drilled to a depth of up to 10 kilometers; this technology, if realized, would mitigate the current geographic limitations.

\section{Solar}

Solar energy ( 0.09 quads in 2008, 0.09 percent of the total) has a high but declining levelized cost (combination of capital and operating expenses, expressed as the cost of a unit quantity of energy) due to high capital expenses; therefore, to be competitive today, it requires government subsidy or needs to find niche, less cost-sensitive applications.

Solar technologies are either solar-electric or solar-thermal; solar-electric technologies involve crystalline silicon (efficient but expensive), thin film (less efficient but also less expensive), and amorphous silicon (cheapest but inefficient). Solar-thermal technologies involve nonfocused sunlight for heating water or focused sunlight to generate high temperatures that can be used directly (steam turbines) or indirectly (via pyrolysis of agricultural waste into syngas, a mixture of hydrogen and carbon monoxide, followed by catalytic processing into solar biofuels).

Challenges of solar energy include intermittent operation (requiring energy storage) and the need to operate at sunny, often remote locations (requiring a "smart grid" that would compensate for the uneven spatial and temporal distribution of this form of electricity). The solar plant's footprint is a function of solar irradiation intensity and of the areal efficiency of the solar cells or solar collectors.

\section{Wind}

Some of the challenges of wind energy ( 0.52 quads used in 2008, 0.5 percent of the total) are similar to those of solar energy. Both are capital intensive, intermittent, and often remote, and at present both require subsidies, energy storage, and a smart electric grid. Some issues with wind energy are associated with changing the landscape, as wind turbines tend to be huge installations, or that they interfere with birds and other wildlife, such as bats. Additional challenges include the need for addressing reliability and maintenance requirements, such as periodic cleaning to remove debris, life expectancy, and recyclability of the structures and components.

The suitability of locations for developing wind energy varies significantly across the earth's surface. Like solar, wind energy is intermittent; most of the power is derived during relatively brief periods of high winds. Wind speeds change with the seasons and may or may not correspond to peak electricity demands, e.g., in the southwest United States, wind speeds tend to be low during the hot summer months, when air conditioning drives the demand for electricity. Conversely, in the United Kingdom the demand for power 
is highest in the winter, when wind speeds there are also at their peak. Because of this temporal and geographic variability, wind power is a complementary energy source to traditional sources and needs to be integrated into the power grid in coordination with other forms of electrical generation.

\section{Tidal and Wave}

In theory, tidal and wave energy offers an inexhaustible source of mechanical energy that can be converted into electricity by means of electric generators. The first tidal power plant was built in France in the early 1960s (La Rance, 240 MW). High capital costs and geographic site limitations constrain the development of this primary source of electric energy.

\section{Biomass}

Biomass (3.88 quads in 2008, 3.9 percent of the total) represents a significant but complex and, by its nature, somewhat limited opportunity to contribute to the US energy balance equation. Involved are biomass-based fuels and gasoline admixtures (ethanol), and biodiesels based on chemically processed vegetable oils. Some of the complexity comes from the present-day primary source of bioethanol (subsidized corn), which can compete with food needs, or from complex performance issues (e.g., biodiesels and vegetable oil-based aviation fuels have to conform to complex chemical, shelf-life, and physical property standards previously established for petroleum-based fuels). Biomass-based fuels are categorized as renewables in that they involve a short-term carbon cycle: plants incorporate $\mathrm{CO}_{2}$ taken from the atmosphere (with sunlight as the energy source) to form plant material such as sugars and cellulose, which can serve as feedstocks for liquid fuels. Although biomass is renewable, the actual renewal of biomass-based primary energy sources is predicated upon human involvement to renew them via agricultural activities.

Intense research is underway to use agricultural waste for producing fuels. Agricultural wastes are mostly cellulosic and require complex (thermochemical, catalytic, enzymatic, or pyrolitic) processes to convert them into intermediates that can be processed into fuels. Some plans call for harnessing the sun's focused thermal energy to provide the gasification temperatures. All plant-based processes are limited by land availability and by the economic collection radii (currently perceived to be about 40 miles around the fuel plant, depending on the particulars of fuel source, conversion process, and the resulting energy carrier). Some biomass-based energy conversion processes are viewed as being net energy producing (despite the needs of plowing, seeding, fertilizing, harvesting, and collecting), and they are also viewed as $\mathrm{CO}_{2}$-neutral in that they tend to recycle $\mathrm{CO}_{2}$ from the atmosphere via photosynthesis. 


\section{Depletable Energy Sources}

Most of the United States' conventional energy sources are depletable; they include the fossil fuels coal, oil, and natural gas, as well as nuclear energy.

\section{Coal}

The United States has hundreds of years' worth of coal (22.42 quads in 2008, 22.6 percent of the total) at current rates of consumption. Coal is the most important commodity carried by rail, at about 44 percent of Class I rail tonnage; about two-thirds of US coal shipments are by rail. Ninety-two percent of coal is used for electricity generation; 51 percent of US electricity is generated by burning coal.

Coal is central to the current energy debate. The nation's ability to address this primary energy source intelligently will significantly affect the US energy future. Although coal is abundant, cheap, and domestic, it is beset with some major externalities (we discuss these unaccounted-for costs further in Chapter 3). These externalities include pollution in the form of sulfur and nitrogen oxides, mercury emissions, and about 300,000 tons of ash per $\mathrm{GW}$-sized power plant per year, assuming 10 percent ash content of the coal. ${ }^{10} \mathrm{In}$ addition, coal-fired power plants are the most prolific sources of $\mathrm{CO}_{2}$ emissions, both in absolute terms and on the basis of tons per kilowatt-hour $(\mathrm{kWh})$; therefore, these plants are implicated in the atmospheric accumulation of this greenhouse gas. Furthermore, openface coal mining, a method widely employed in the United States today, has a significant environmental and ecological impact.

Given coal's importance, it is no wonder that major efforts are underway (political, economic, scientific, engineering) to deal with its challenges. Among these efforts are increasingly complex and expensive methods to control flue gas emissions, thermodynamically more efficient boiler and generator technologies (including so-called combined cycles with higher overall thermodynamic efficiency), and projects aimed at concentrating and storing ("sequestering") $\mathrm{CO}_{2}$ emissions. Sequestering $\mathrm{CO}_{2}$ is associated with increased capital and operating costs of electricity, a significantly derated power plant capacity, and as of yet unresolved storage technologies and storage site liabilities, so its viability has not yet been established.

Further complicating coal's role is the fact that the two largest developing economies, China and India, are also heavily coal fueled. This fact poses unresolved political issues regarding the contribution of these countries to potential global $\mathrm{CO}_{2}$-reduction programs, not to mention the clouds of pollution (e.g., sulfur oxides, mercury) that were detected traveling across continental boundaries (e.g., from China to California). 
So far it has been economical to control pollutants (mostly sulfur and nitrogen oxides) in the flue gases of coal-fired power plants. However, the economics of $\mathrm{CO}_{2}$ sequestration (separation, concentration, storage) will have to be compared with the economics of alternative ways of reducing $\mathrm{CO}_{2}$ emissions, such as increased reliance on other primary energy sources (more nuclear, more natural gas, more solar, more wind) or energysaving technologies in the energy-consuming sectors such as industrial, construction, and transportation. Given the recently discovered large potential US natural gas reserves (shale gas), ${ }^{11}$ it is likely that many of the newly constructed power plants will be fueled by natural gas, followed in time by a mix of natural gas and nuclear.

Oil

In 2009 the United States used about 22 percent of the world's oil output: of this, 72 percent of US oil consumption was for transportation and about 22 percent for industrial purposes, including the manufacture of chemicals. Only 1 percent was used in electricity generation. US domestic oil production peaked in 1970 (at 9.6 million barrels per day) and is now in decline. Oil imports grew to exceed domestic production beginning in 1993. In 2009 about 61 percent of US oil consumption was from imports, and a significant, although not dominant, portion of the imports came from countries with challenging economic, political, national security, or military issues (Middle East, Africa, South America). As of this writing, we are witnessing political upheavals in the Middle East, some in the major oil-producing countries. These events will surely impact oil supply security and oil prices and price stability, as well as the fate of alternative energy technologies.

Foreign oil reserves are increasingly owned by national corporations that are controlled by governments. Some of the main oil transportation routes from the Middle East (35 percent of the world's oil passes through the Strait of Hormuz, and 34 percent passes through the Strait of Malacca) require military protection, a heavy cost burden to the US taxpayer.

Twelve percent of the known domestic US oil reserves exist under lands protected by environmental laws and, therefore, are not currently accessible for production.

Oil is a commodity, traded on major commodity markets, and its price has been fluctuating wildly. Oil prices, in general, are far above typical exploration, extraction, and transportation costs, reflecting in part the combination of risks involved. Oil quality and ease of extraction have been gradually declining, necessitating an increasing degree of "secondary recovery," which involves various chemical, thermal, or physical ways of 
stimulating the reservoirs, or advanced drilling techniques such as deep-water offshore drilling and horizontal drilling. Finally, very large oil reserves are available from oil shale, but it is expensive to process with the use of conventional technologies and is beset with potential environmental liabilities. It is unlikely that all oil resources will be fully exhausted before more of our transportation infrastructure switches to other energy sources for propulsion.

Oil-fueled transportation has depended on the internal combustion engine, a device that is substantially limited by the inefficiency of the Carnot thermodynamic cycle (interestingly, the Carnot cycle would be quite efficient if internal combustion engines could operate at much higher temperatures, but such internal combustion engines are currently perceived to be beyond practicality). The ongoing large effort to replace the Carnot cycle with electric propulsion is aimed at mitigating our dependence on oil, freeing the use of more of that substance for alternative, more efficient, and higher-valued uses, such as the manufacture of chemicals, plastics, and pharmaceuticals.

\section{Natural Gas}

In contrast to oil, natural gas is not easily portable across oceans. Its cryogenic storage and transportation are commercially viable but expensive and therefore limited. However, natural gas can be safely and economically transported and distributed by continental pipelines. Relatively speaking, it is a cleaner source of thermal energy. For the same amount of electricity produced, a natural gas-fired power plant emits about half of the $\mathrm{CO}_{2}$ emissions that a coal-fired power plant emits, with no ash content, no mercury emissions, and much lower emissions of sulfur oxides and nitrogen oxides. Natural gas is also an important raw material for the chemical industry. Although natural gas is a primary energy source, it is also suitable for conversion into secondary energy sources or energy carriers, such as hydrogen, methanol, gasoline, or dimethyl ether (proposed as a diesel fuel).

In a mid-2009 assessment, 12 the Potential Gas Committee upgraded the 2008 potential US natural gas resources from the 2006 levels by about 39 percent. This upgrade resulted, in part, from the development and demonstration of technologies that can economically recover natural gas from abundant shale gas deposits. The recently developed shale gas technology involves horizontal drilling into the shale and the multistage hydraulic fracturing of the shale to release the natural gas.

The US Department of Energy published a review of recent US shale gas developments. ${ }^{11}$ Two of the largest shale gas fields are the Marcellus Shale, spreading over 
the states of West Virginia, Pennsylvania, and New York, and the Barnett Shale in Texas. With the revised US reserves, at current consumption rates the United States has about 100 years' worth of natural gas left. This development is new and has not yet been fully analyzed by the energy planning community. Nevertheless, most recently constructed or currently planned new fossil-fueled power plants in the United States already rely on natural gas rather than coal. Some of the societal concerns surrounding shale gas involve groundwater pollution.

\section{Nuclear}

Nuclear energy ( 8.45 quads in 2008, 8.5 percent of the total) is carbon free and nonpolluting if properly managed. Current nuclear power plants employ uranium 235-fueled fission piles. The U-235 isotope makes up about 3 percent by weight of the uranium reserves, and the rest is the isotope U-238. As of early 2010, the United States had 104 operating nuclear reactors, with 1 under construction and 9 planned; in comparison, the worldwide figures, including the United States, are 438 operating, 54 under construction, and 148 planned. ${ }^{13}$ The 2011 Fukushima Daiichi nuclear reactor crisis will undoubtedly affect reactor safety designs and operating practices, new reactor construction costs, and public attitudes about nuclear energy.

The United States uses the open fuel cycle: after about 4 percent of the energy content of the fuel rods is exhausted, neutron absorbers are formed that require the removal and replacement of the spent fuel. In the open fuel cycle mode, the spent fuel is then stored indefinitely, leaving about 23 tons of waste per GW-sized power plant per year, as compared with the 300,000 tons of ash from coal combustion as mentioned earlier.

Several countries employ a closed fuel cycle, which involves the reprocessing of the spent fuel (extracting and reusing the unspent U-235 and the fission product plutonium). This technology improves U-235 utilization by up to about 30 percent and leaves behind significantly less, although more radioactive, nuclear waste (about 3 tons per GW per year) than the open fuel cycle, but at current uranium prices, it is uneconomical.

Reprocessing is currently discouraged by the United States, primarily because of the fear of proliferation: it leaves open the opportunity to isolate the fission product plutonium, which is susceptible to abuse. A number of countries, such as Canada, Sweden, Finland, Spain, and South Africa, share the United States' position. Nuclear fuel reprocessing is allowed or practiced in several countries, including France, the United Kingdom, India, Japan, and Russia. In 2006 the United States proposed a Global Nuclear Energy Partnership (GNEP) of 25 countries to develop and deploy advanced fuel-cycle 
technologies to improve nuclear fuel utilization and to reduce nuclear waste, without the risk of nuclear proliferation. A National Academy of Sciences report reviewed the international options for addressing issues related to reprocessing. ${ }^{14}$ The report advised against reprocessing, and the United States has subsequently canceled the GNEP's domestic component.

From the beginnings of nuclear power to 2010, approximately one-third of the world's spent light-water reactor fuel has been reprocessed commercially; the remaining spent fuel is stored on reactor sites, including onsite at US nuclear power plants. ${ }^{15}$ At current rates of consumption and at current uranium prices, reserves have been estimated to last for about another 50 years. 16

Breeder reactors use both U-235 and U-238 in their fission fuel cycle. They could extend uranium supplies by a factor of about 50, perhaps into the next millennium. Developmental issues surrounding the breeder reactor option include safety (require the development of materials that can reliably resist radiation damage) and cost.

As nuclear power generation became established after the 1950s, the size of reactor units grew from $60 \mathrm{MW}$ to more than 1,600 MW. The high capital cost of large nuclear reactors is driving some interest in developing smaller units. (The International Atomic Energy Agency defines "small" as less than $300 \mathrm{MW}$ of electric power, but in general, today $500 \mathrm{MW}$ may be considered an upper limit for "small".) These smaller reactors may be built independently or as modules in a larger complex, with capacity added incrementally as required. Many smaller nuclear reactors have been built for naval use; this engineering expertise may be applicable to commercial development.17,18 A 2009 assessment by the World Nuclear Association concluded that 43 to 96 small modular reactors may be operating by 2030, but none in the United States. 19

Two major longer-term efforts are underway to use nuclear fusion, instead of fission, for energy generation; the fuel is a mixture of the hydrogen isotopes deuterium and tritium, which, as parts of water occurring in nature, promise an essentially inexhaustible supply. Because no structural material can survive the reaction temperatures, the practical implementation of nuclear fusion requires confining the reaction volume to isolate it from the reactor's walls.

In France, an international, large-scale demonstration project aims to show the possibility of using fusion to produce commercial energy. The International Thermonuclear Experimental Reactor, ITER, project will employ a reactor called Tokamak (after a Russian phrase meaning "a toroidal chamber with magnetic coils"). Tokamak is based on the magnetic confinement of the reaction volume. 
A fusion project is also underway at the US Department of Energy's Lawrence Livermore Laboratory. This project employs laser-ignited inertial confinement of the reaction volume.

These efforts, although critical for humanity's longer-term energy future, will likely take several decades to achieve commercial utility.

The social issues associated with nuclear energy include safety and security considerations (fuels processing or reprocessing, reactor operation, and spent-fuel transport and storage). These social concerns have abated somewhat in recent years given the increasing problems with coal (ecology, environment, and climate) and oil (supply security and sustainability, national security, trade balance, price instability, and more recently, environment and ecology). The 2011 Fukushima Daiichi nuclear reactor crisis is likely, however, to affect public attitudes regarding nuclear energy and increase the social concerns pertaining to reactor safety.

\section{Carbon Dioxide Generation}

A significant component of energy-related issues and decision-making processes is represented by concerns about the potential impact of $\mathrm{CO}_{2}$ emissions on the climate.

Based mainly on US government and National Academies sources, the following discussion below briefly examines the Earth's carbon balance, followed by the related climate considerations.

The atmosphere contains about 750 gigatons (GT, billions of metric tons) of carbon, according to the diagram of the carbon cycle published on NASA's Earth Observatory web page. ${ }^{20}$ We can translate this number into $2,750 \mathrm{GT}$ of $\mathrm{CO}_{2}$ by multiplying $750 \mathrm{GT}$ by the $\mathrm{CO}_{2} / \mathrm{C}$ molecular weight ratio of $44 / 12$. This $2,750 \mathrm{GT}$ of $\mathrm{CO}_{2}$ in the atmosphere increases each year by about $12.1 \mathrm{GT}$ ( 0.4 percent). This increase arises from the difference between 796.0 GT CO $\mathrm{CO}_{2}$ emissions-26.1 GT, or 3.3 percent, of which are attributed to human activities-and the $783.9 \mathrm{GT}$ that are reabsorbed or consumed. ${ }^{20}$

The principal global anthropogenic $\mathrm{CO}_{2}$ contributors are fossil fuel combustion and cement production (20.2 GT) and deforestation (5.9 GT). ${ }^{20}$ Their sum (26.1 GT) exceeds the net $\mathrm{CO}_{2}$ accumulation in the atmosphere $(12.1 \mathrm{GT})$, implicating human activity as a primary causal factor of the $\mathrm{CO}_{2}$ accumulation. The various primary energy sources affect $\mathrm{CO}_{2}$ generation from human activity in various degrees. The $2008 \mathrm{US} \mathrm{CO}_{2}$ flow chart is shown in Figure 2.2.

The major source of anthropogenic $\mathrm{CO}_{2}$ is coal used to generate electricity (33 percent), followed by oil-fueled transportation ( 32 percent). Other anthropogenic components, not 
Figure 2.2. US carbon dioxide emissions in million metric tons, 2008
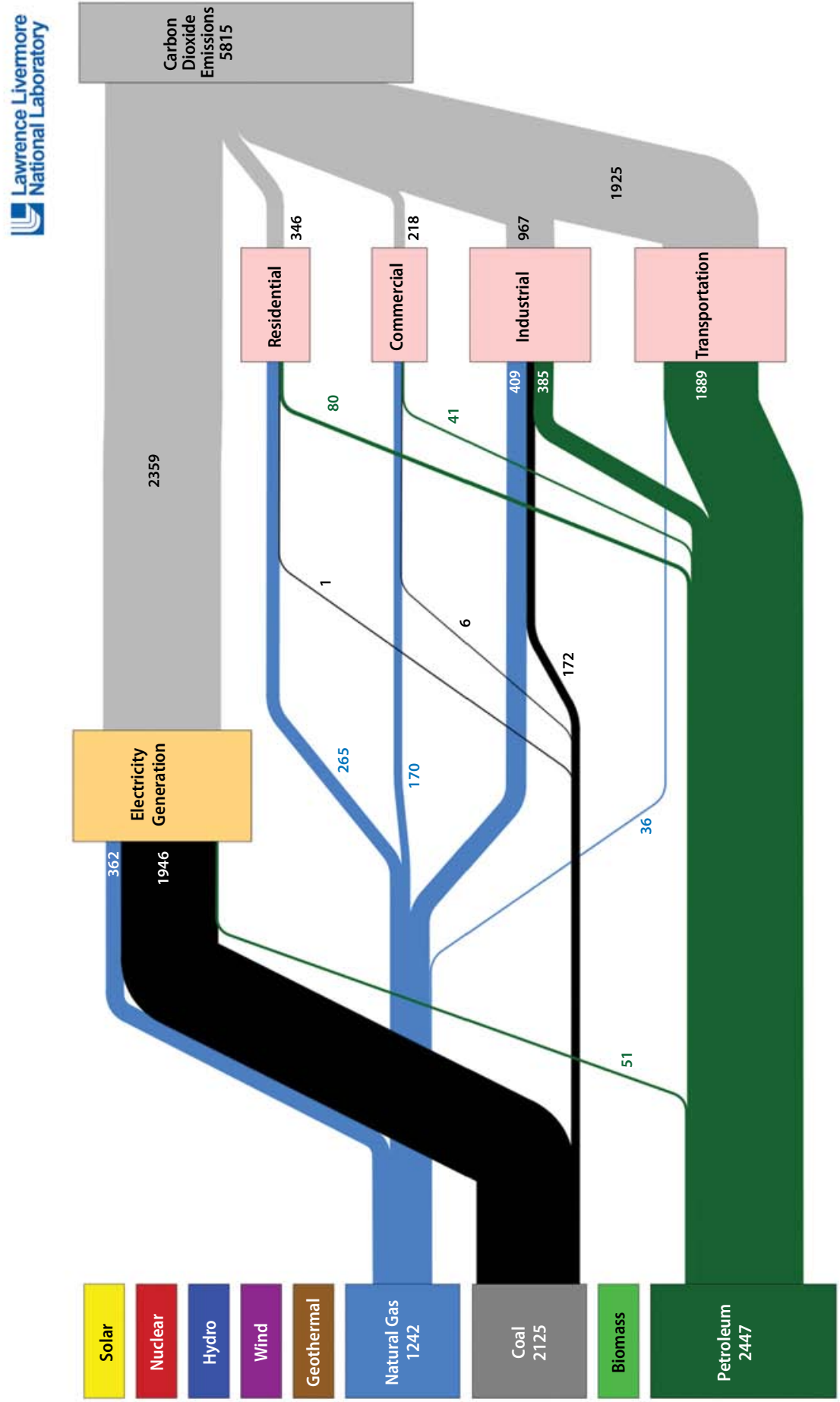

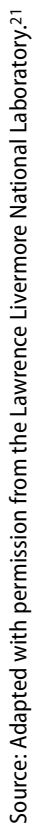


directly related to energy, are increased agricultural activity and deforestation. Renewable primary energy sources and nuclear energy are $\mathrm{CO}_{2}$-free, and biofuels are perceived to be $\mathrm{CO}_{2}$-neutral because they use solar energy to incorporate some of the $\mathrm{CO}_{2}$ content of the atmosphere into plant material (e.g., cellulose, lignin, and sugars). As mentioned before, natural gas, on a unit electrical energy basis, has about half of coal's $\mathrm{CO}_{2}$ burden.

The future of the US energy infrastructure may be closely tied to the outcome of a cluster of $\mathrm{CO}_{2}$-related climate change issues. (A concise summary of these, with key data, explanations, and a list of reference reports, is available from the US National Academies. ${ }^{22}$ ) Considerations include the amount and rate of $\mathrm{CO}_{2}$ accumulation in the atmosphere; its causes; its past, present, and anticipated future effects on climate; the evolution of climate itself; projected future climate change scenarios; the effects (positive and negative) of climate changes on humans and on nature; and human interventions to suppress adverse climate change effects, with their prospects, costs, and consequences.

The science of climate change is complex. Its predictive ability relies to a significant extent on a feedback mechanism and on scenario modeling. ${ }^{23}$ Although the model predictions have been accepted by the majority of scientists and by the national academies of seven large industrial nations, such models carry uncertainties about the nature, size, and time scale of the effects predicted. ${ }^{24}$ They also carry uncertainties about the nature, intensity, costs, and feasibility of proposed national and global efforts to mitigate these predicted effects.

Notwithstanding any uncertainties in the time scale and impact of $\mathrm{CO}_{2}$ accumulation on climate, and the projected effects of those changes on humans and the rest of nature, there are strong reasons for reducing $\mathrm{CO}_{2}$ emissions in the short-term, supporting timely and decisive action. Beyond producing $\mathrm{CO}_{2}$, using coal and imported oil is associated with additional important and urgent concerns. These concerns include technological challenges (e.g., clean coal, safe deep-water drilling), economic challenges (e.g., supply, access, reserves, price, price stability, globalization, trade balance, cost and availability of capital, risk of capital), and social challenges (e.g., defense, security, environment, ecology, sustainability, globalization, foreign policy). These challenges are sufficiently significant and urgent to require timely action regardless of the time scale and outcomes of climate change considerations. Reducing the use of coal and imported oil is, of course, consistent with the climate change-based call for reducing $\mathrm{CO}_{2}$ emissions as well. 


\section{Energy Generation, Distribution, and Storage}

Energy carriers are secondary energy sources, converted from the primary energy sources. They include electricity and petroleum- and natural gas-based fuels, which are discussed below, as well as biofuels, hydrogen, methanol, and dimethyl ether.

\section{Electricity}

The technologies for mainstream electricity generation are mostly well established and are based on rotating generators driven by turbines (coal, natural gas, nuclear, hydro, tidal, geothermal, or wind). Photovoltaic electricity requires extensive conditioning if it is to be coupled with the electric grid. Both solar- and wind-based electricity generation depend on the development of smart electric grids, which would compensate for the uneven spatial and temporal distribution of these forms of electricity: plants may not be located close to the users of the electricity, and wind and sunshine are not continuous. The simultaneous deployment of wind and solar energy may provide symbiotic benefits at some locations with sustained nighttime winds. Besides requiring a smart electric grid, new wind and solar electricity may also challenge the capacity of existing electric grids. In the absence of the smart grid, or in complement to it, various storage technologies are being developed for solar and wind electricity. Beyond large conventional batteries, these include water reservoirs, pressurized air tanks, and chemically reacting energy storage systems ("flow batteries").

Much discussion surrounds the US electric grid's ability to absorb perturbations due to increasing demand, the grid's failures and failure propagation, and the addition of smart grids or smart-grid components to accommodate solar and wind electricity. The US Department of Energy has published a helpful smart-grid primer. 25

Although electricity can be readily efficiently distributed with good efficiency in highvoltage grids, efficient electricity storage represents a continuing challenge. Electricity usage is highly uneven in time and space, and power plants were designed to meet peak usage periods. Plug-in hybrid and all-electric vehicles, charged overnight, are expected to eventually act as effective "peak shavers." They depend on the development of low-cost, high-energy-density, high-power-density, safe, and sustainable rechargeable batteries. Of those, rechargeable lithium batteries appear to have the technological lead and will probably replace the nickel-hydrogen batteries currently used in gasoline-electric hybrids. 


\section{Fuels Based on Petroleum and Natural Gas}

As with generating electricity, refining petroleum to liquid fuels such as gasoline, diesel fuel, and aviation fuels is well established. These operations are running very close to their thermodynamic limits.

Natural gas can be chemically converted into liquid fuels by means of partial oxidation to syngas. The syngas can then be reacted by means of catalytic Fischer-Tropsch chemistry to form diesel fuel or gasoline via the methanol route. Because of the newly discovered US natural gas reserves and the resulting potential for low natural gas prices, the catalytic methanol-to-gasoline (MTG) technology, so far employed only in niche markets, may see a renaissance.

Natural gas can also be converted chemically to hydrogen, with $\mathrm{CO}_{2}$ as a by-product. This conversion would be the basis of the first phase of the hydrogen economy, followed eventually by water electrolysis via nuclear or solar electricity. Hydrogen could then be used to power fuel-cell vehicles; currently, several hundred fuel-cell-driven vehicles are operating in California (General Motors, Honda), Europe, and Japan. Perceived problems with hydrogen as an energy carrier include distribution, storage, and safety. All three problems have been addressed. Hydrogen can be distributed using a natural gas distribution network with locally generated hydrogen; the US Department of Transportation has approved hydrogen tanks that can hold 10,000 pounds per square inch and carry enough fuel for about 300 miles in a typical vehicle. Hydrogen fueling and hydrogen-fueled automobile traffic safety have been deemed to meet commercial requirements.

\section{Energy Utilization}

Energy utilization can be divided into residential, commercial, industrial, and transportation categories.

\section{Residential}

Residential use is primarily for heating, ventilation, and air conditioning (HVAC), lighting, and refrigeration. It is based mainly on natural gas and electricity, with about 10 percent coming from heating oil. The efficiency of residential energy uses has been the subject of many technology developments, regulatory activities, and some social research. Issues include the up-front cost of improvements or new construction and equipment 
technologies as compared with the resulting reductions in operating costs. The National Academies' energy-efficiency report ${ }^{4}$ highlighted some important points that require more societal research.

A number of significant energy-efficient residential construction and construction materials technologies have evolved in countries with historically high energy pricestypically in Europe and in Japan. Adaptation of these technologies involves many dimensions beyond technology and economics and includes esthetic, cultural, and habitual factors, requiring a better understanding of these factors. One significant energysaving opportunity will come from the phase-out of incandescent lighting, to be replaced at first by fluorescent light bulbs and thereafter with solid-state light bulbs based on light-emitting diode (LED) technology. All will come with appropriate spectral colors for residential, industrial, or commercial use.

\section{Commercial}

The commercial use of energy is similar to residential uses (HVAC and lighting), but with more use for refrigeration. The energy efficiency of commercial buildings has greatly benefited from sophisticated window glass-coating technologies that filter and selectively control the transmittance of visible, infrared, and ultraviolet light. Commercial lighting has pioneered the use of low-energy light sources (fluorescent and solid-state) to replace incandescent light bulbs.

\section{Industrial}

Industrial energy use, in terms of primary energy sources, comprises 14 percent electricity, 34 percent natural gas, 36 percent oil, and small quantities of biomass and coal. The largest industrial use of electricity is for sodium chloride electrolysis to manufacture chlorine and sodium hydroxide, two large-volume industrial chemicals.

Industrial manufacturing operations have always depended heavily on their energy expenditures and, thus, have a history of energy-saving innovations. The chemical industry is the largest energy consumer in the manufacturing industries, both for electricity and for natural gas (as fuel and as feedstock for chemicals). High and volatile natural gas prices have been blamed for the loss of nearly 4 million manufacturing jobs in the United States between 2000 and 2010.26 


\section{Transportation}

Transportation use constitutes 28 percent of the energy consumption in the United States, and it is almost completely oil-based ( 95 percent oil, 2 percent natural gas, 0.1 percent electric). As we said before, about two-thirds of US oil is imported, and 32 percent of the US anthropogenic $\mathrm{CO}_{2}$ is produced from transportation. One of the great challenges for transportation is to reduce its dependency on oil. This issue is being addressed by reducing fuel consumption (smaller and lighter cars, more efficient engines, gasolineelectric hybrids) and by breaking the so far almost impenetrable boundaries between automobile transportation and electricity or natural gas.

The electricity-transportation boundary is being pierced by the introduction of plugin hybrids and all-electric vehicles. Plug-in hybrids are electrically propelled, with a gasoline engine that can be automatically turned on to recharge the battery but that is not mechanically connected to the drive train. (This is different from gasoline-electric hybrids, where electric- and gasoline-powered drive trains coexist.) Plug-in hybrid vehicles have a limited all-electric range, intended to cover the round-trip commuting range of most drivers (about 40 miles). Its gasoline engine serves as a range extender to perhaps 300 miles, making these cars suitable for longer trips as well, despite their small batteries. The initial charge, covering the needs of about 80 percent of commuters, is supplied via plugging into the electric network, mostly overnight, eventually also providing a loadleveling capability to the electric grid.

Mass-produced all-electric vehicles will eventually follow, pending battery developments. Technological development for electric vehicles is attracting dramatic worldwide activity. Issues include range, power, cost, safety, and speed and the availability of recharging. Electric batteries cannot be recharged instantly the way refilling a tank with gasoline can be accomplished, because of the very large electric currents that instantaneous recharging would require. One of the technological ventures involves developing standardized exchange terminals for electric vehicle batteries, where fully charged batteries can be inserted into the vehicle to replace the discharged batteries.

The natural gas-transportation boundary is, in part, being broken by hydrogen-powered fuel-cell vehicles. Although natural gas can be stored in portable high-pressure tanks just as hydrogen can and hydrogen will likely be generated from natural gas in a distributed fashion anyway, the hydrogen-powered fuel cell is thermodynamically more efficient than the Carnot cycle-limited internal combustion engine fueled by natural gas or hydrogen. Several fuel cell vehicle fleets are now running on most continents, and the vehicles seem to have evolved to deal with most requirements of performance, operability (including 
operation in cold climates), safety, and in many cases, durability. Cost is the major issue that is expected to become gradually more competitive because of the learning curves of large-volume production. Nevertheless, large-scale deployment of fuel cell-powered vehicles is probably more than a decade away.

In the shorter run, natural gas can be used directly to fuel internal combustion engines. Compressed or liquefied natural gas powers about 11 million vehicles in the world today. These vehicles are located mostly in countries where prices for natural gas prices are lower than for gasoline, primarily in Asia (e.g., Pakistan) and South America (e.g., Argentina), but also in some European countries (e.g., Italy). The number of natural gas-driven vehicles is growing rapidly. Challenges include building a fueling infrastructure and designing cars with sufficient trunk size to accommodate the natural gas tanks.

\section{Energy Savings}

Important to the US energy picture, rejected energy is the fraction of primary energy source content discarded during energy extraction, conversion, distribution, and use. Data from the US Energy Information Administration, graphically displayed by the Lawrence Livermore National Laboratory's energy information group (see Figure 2.1),8 suggest that rejected energy amounts to about 58 percent of the energy content of the primary energy sources.

Energy savings often prove to be the "low-hanging fruit" in reducing energy consumption, pollution, and $\mathrm{CO}_{2}$ emissions while also saving money. Therefore, they tend to be the highest priority of most short- and mid-term energy infrastructure restructuring proposals.

There are two distinct modes of energy savings: through energy efficiency and through energy conservation. The term energy efficiency refers to achieving the same objective while consuming less energy; this is typically a technology-dependent outcome (example from transportation: hybrid propulsion in contrast to conventional vehicle propulsion). The term energy conservation refers to achieving energy savings by compromising the objective itself while reducing energy usage; this is primarily driven by perceived or real need and related human behavior (example from transportation: less driving, smaller cars). These two modes of energy savings are of course overlapping in actual life, demonstrating yet again that energy technology, economics, and societal considerations are inseparable.

Three levels of technologies are pertinent to energy savings: technologies now in use (example from construction: incandescent lighting), technologies available now but not 
widely used (example from construction: fluorescent home lighting), and technologies under development (example from construction: LEDs for solid-state lighting). Again, implementation of a new technology is a complex function of technological, economic, and societal factors that, we argue, can best be understood in their integrated contexts, as the intersection of technology, economics, and societal factors.

The US National Academies Panel on Energy Efficiency Technologies, part of the America's Energy Future project, ${ }^{2}$ recently examined the energy savings potential of the United States. The study was restricted to energy efficiency, leaving energy conservation out of the analysis. This scope limitation opens possibilities for the analysis of energy conservation, especially by social scientists.

The National Academies' energy-efficiency report divides energy uses into three categories: construction, transportation, and industrial. The largest energy savings potential is in construction (insulation, lighting, heating, ventilation, air conditioning, and their integrated design and control). The report sets forth the remarkable conclusion that "if all the potential energy savings identified for residential and commercial buildings could be achieved" by 2020, the United States would not need any added electricity generating capacity. ${ }^{4(\mathrm{p} 2)} \mathrm{A}$ factor limiting the rate of implementation of energy-saving technologies is the long life cycle of buildings, demanding tough "replacement economics" from any new technologies.

In addition, the transportation category has significant technological potential remaining, ranging from advanced materials (lighter, stronger) to hybrid, plug-in hybrid, all-electric, and fuel-cell vehicles.

The third large energy-consuming category, industrial, is heterogeneous and complex. The major industrial energy consumers (aluminum, steel, chemicals) still appear to have untapped energy efficiencies; the implementation of these energy efficiencies is handicapped by the fact that large-scale industrial processes tend to have long life cycles (presenting challenging replacement economics if their capital has fully depreciated) and that energy consumption alone may not necessarily be their limiting economic dimension.

Energy savings are the result of complex interactions within the technologicaleconomic-societal intersection, involving both energy efficiency and energy conservation. The topic of energy savings represents new and intriguing opportunities for social science research with potential major impacts on the future of the US energy infrastructure. 



\section{CHAPTER 3}

\section{Energy Economics}

For any technology to become a viable component of the energy infrastructure, it must be economically sustainable. A wide range of alternative energy technologies exist, but fossil fuels are still the lowest-cost option based on current market prices. In addition, because energy in the United States is relatively inexpensive-with 2007 energy expenditures having accounted for less than 9 percent of the gross national product ${ }^{27}$ - energy efficiency initiatives have had difficulty gaining momentum.

One of the most important issues in considering the future of energy in the United States is determining how choices are made regarding the technologies that will be employed to meet growing energy demand. Market forces provide incentives for producing energy at the lowest cost while operating within the current public policy framework. However, in the presence of market distortions and impacts of energy production and consumption that are not reflected in the price to consumers, the market outcome will not necessarily lead to the most economically efficient mix of energy technologies. Consequently, at the heart of any discussion of our energy future are the following questions: What are the key factors influencing the cost of energy, specifically fossil fuels, in the United States, and to what extent do current prices deviate from the true social cost of these energy sources? For example, health and environmental externalities (unaccounted-for costs) and both implicit and explicit subsidies distort markets, leading to a suboptimal energy infrastructure from a societal perspective. It is vital to understand the magnitude of these effects and to consider the role of government policy in improving the economic efficiency of the United States' energy future.

Energy economics encompasses a broad range of issues tightly interwoven with technological and societal considerations. In this chapter, we present a brief overview of the economics of the primary energy sources; the externalities of energy production, conversion, distribution, and use; behavioral energy economics; the role of government; and the modeling of energy markets and policies. 


\section{Economics of Primary Energy Sources}

To provide background on recent developments in primary energy sources markets, we briefly review the historical relationships among reserves, production, consumption, and prices for the depletable energy sources discussed in Chapter 2 (coal, oil, natural gas, and uranium). We then assess the externalities of fossil fuel production and use.

As is true with most natural resources, reserves are defined in terms of currently available technologies for economical recovery and use. On this basis, the world is unlikely to ever literally run out of fossil fuels or uranium; more likely, the recovery of these energy sources will become expensive enough to stimulate the use of alternative energy sources. Prices provide important signals regarding scarcity and influence investment across alternative energy technologies. The introduction of policies that influence the net prices observed by producers and consumers (e.g., to account for externalities) will alter incentives and result in a shift toward those primary energy sources that have become relatively less expensive under the policy.

\section{Reserves, Production, Consumption, and Prices}

\section{Coal}

The US Energy Information Administration (EIA) estimates that the United States had a demonstrated reserve base for coal resources of 488 billion tons at the beginning of 2009. ${ }^{28}$ However, access to some coal is limited because of property rights, land use conflicts, and physical and environmental restrictions. In addition, the actual proportion of coal resources that can be recovered economically is affected by geologic features and the need to leave some coal as pillars to protect against mine collapse. In 2008, the average recovery rates for underground mines, surface mines, and overall were 57.9 percent, 90.1 percent, and 79.6 percent, respectively. ${ }^{29}$ Accounting for these accessibility and recovery factors, the most recent EIA estimate is that the United States had total recoverable coal resources of 261 billion tons at the beginning of 2009. Global recoverable coal resources were estimated at about 911 billion tons in 2007. Based on these estimates, current rates of production, and the current technology for production and mining, the ratio of global coal reserves to global annual production (reserves-to-production ratio) is approximately 130 years. ${ }^{28}$ The location and accessibility of these coal reserves suggest further tough choices for the United States in how far it is willing to go to recover this relatively cheap but environmentally problematic source of energy. 
Coal production has been growing at a slower rate in recent years, partly because of more stringent environmental regulations, which have greatly reduced interest in building new coal-fired plants. In addition to existing air quality regulations, the potential for regulations limiting greenhouse gas emissions is contributing to a reduced rate of expansion of coal-fired power plants.

Coal prices peaked in 1975, bottomed in 2000, and have risen over the past few years (Figure 3.1). However, in its 2010 Annual Energy Outlook, EIA projects flat to slightly declining prices between 2010 and 2035. ${ }^{31}$ In the event that policies limiting greenhouse gas emissions are implemented, coal prices are likely to decrease even more as coal demand is reduced.

Figure 3.1. Coal prices (in 2005 dollars), 1949-2009

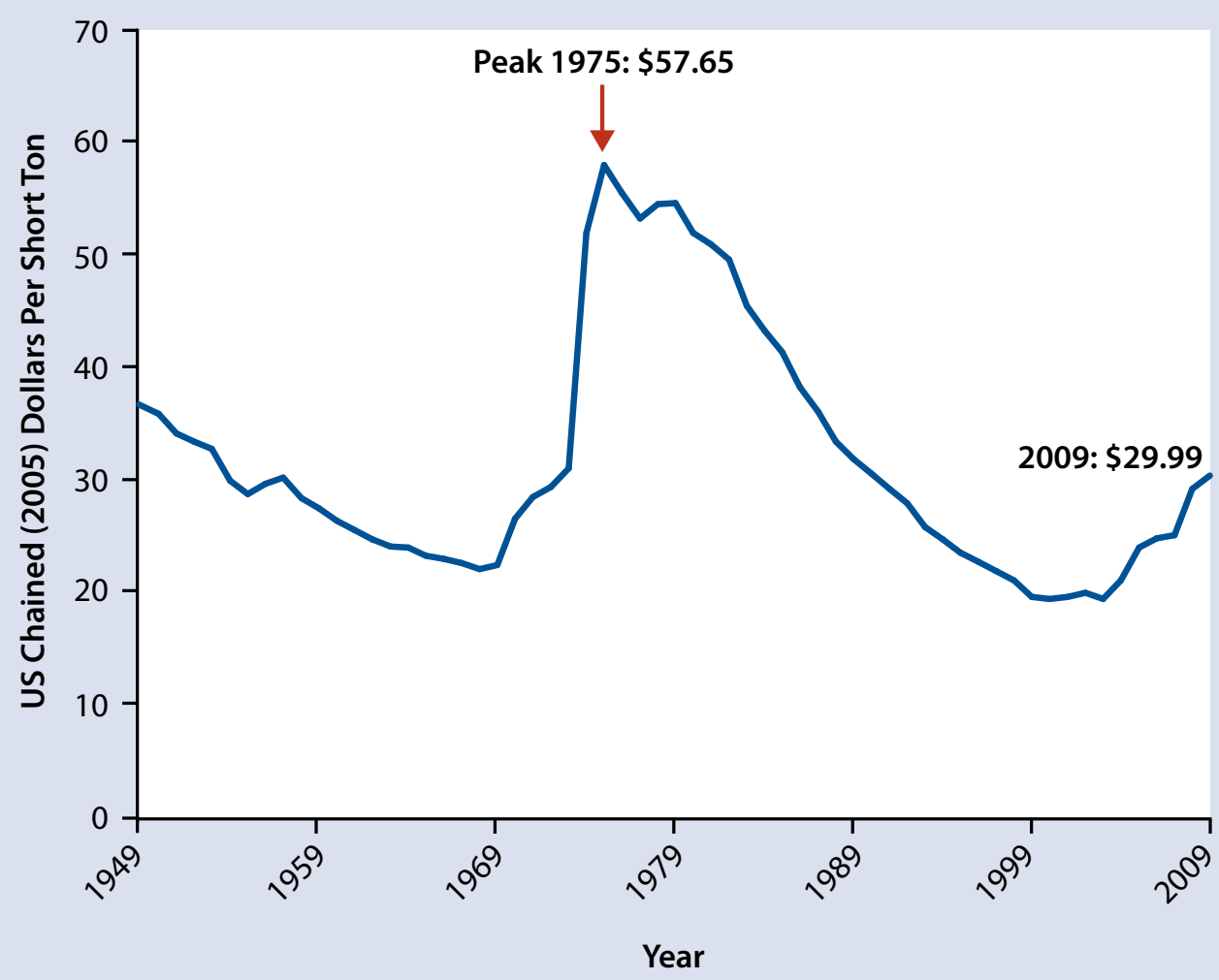


Oil

Proved US oil reserves peaked in 1970 (Figure 3.2) and have decreased since then. Domestic US oil production peaked in the same year.

The 1973 and 1979 oil crises resulted in a temporary decrease in US petroleum consumption, but then consumption steadily increased between 1983 and 2006 (Figure 3.3). The dramatic (and temporary) rise of oil prices in 2008 contributed to a recession, with a concomitant sharp decline in US oil consumption. Whether this

Figure 3.2. US proved oil reserves, $1900-2008$

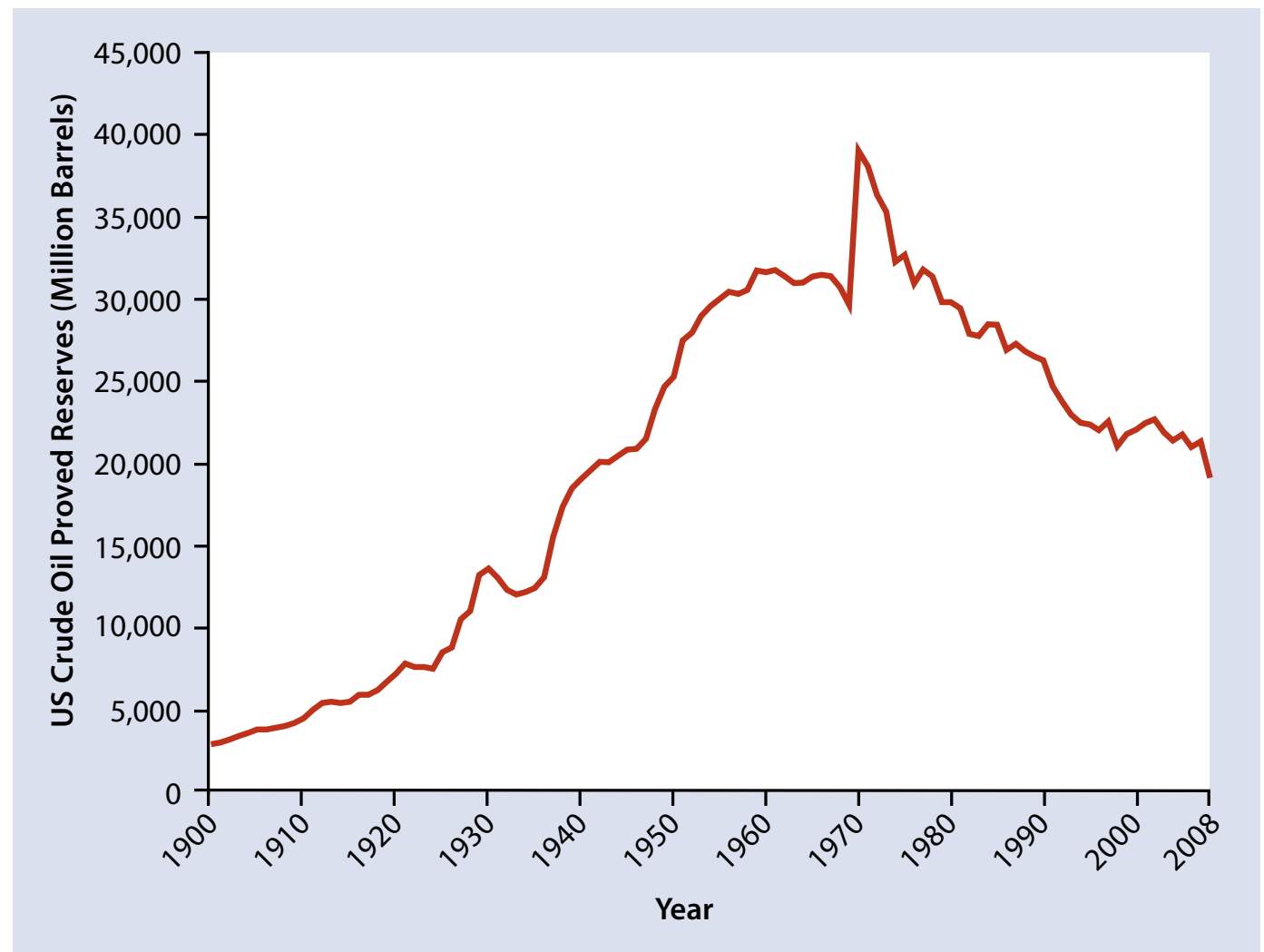

Source: Adapted with permission from the US Energy Information Administration. ${ }^{32}$ 
decline will be temporary and when the new trends for electric vehicles will start to affect petroleum consumption remain to be seen.

In summer 2008, US spot crude oil prices rose dramatically and briefly peaked at $\$ 147$ per barrel (not captured in the graph). By late December, they collapsed to $\$ 33$ per barrel, a price drop of a factor of almost 4.5. As of late October 2010, spot oil prices were hovering around $\$ 82$ per barrel. Such large price swings increase uncertainty and disrupt the economy.

Figure 3.3. US oil consumption and oil prices, 1973-2010

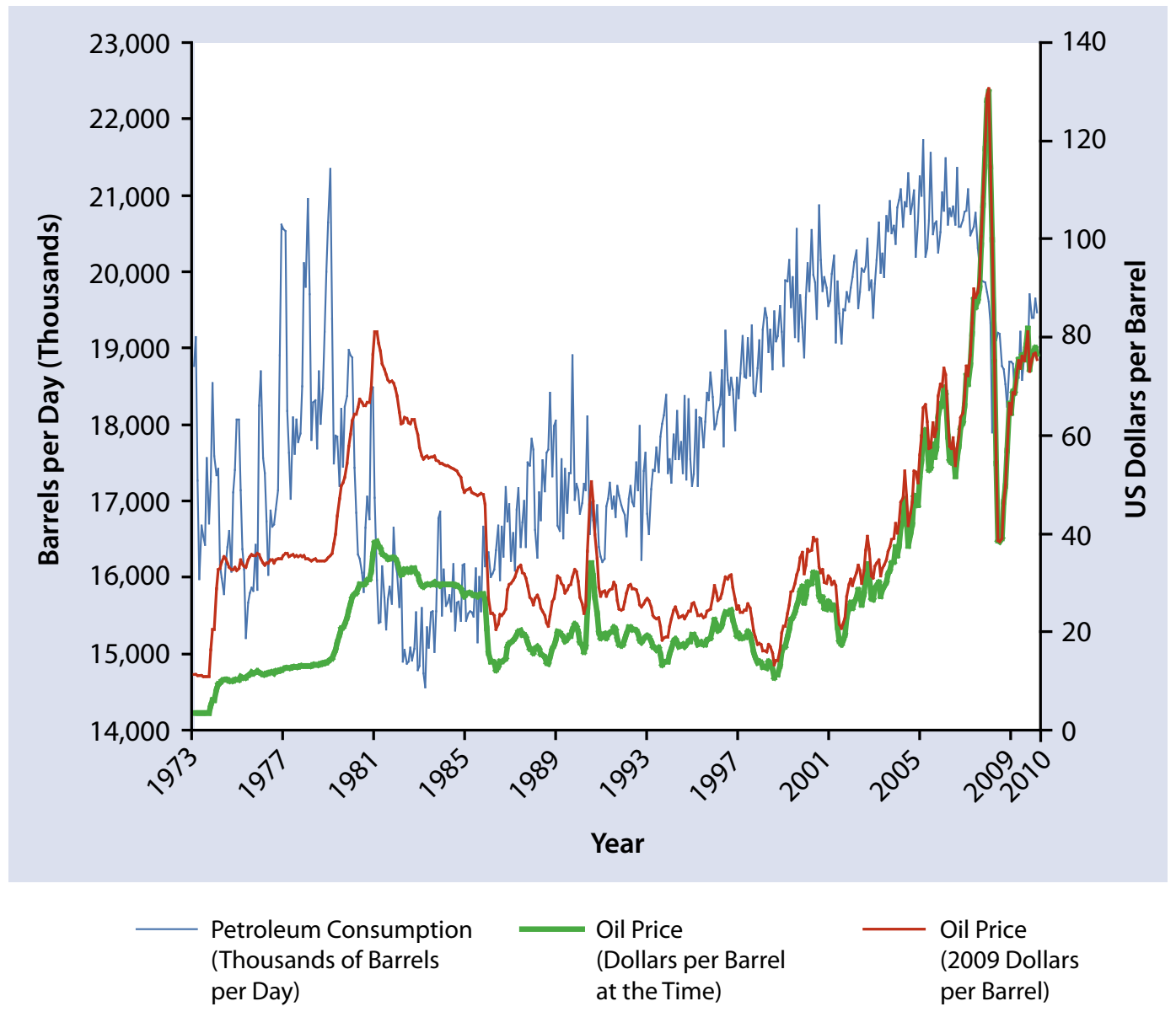

Source: Adapted with permission from Williams, c2006-2009, http://wtrg.com/prices.htm. ${ }^{33}$ 
In March 2010, the US trade balance was about $-\$ 40.4$ billion, composed of $-\$ 52.9$ billion in goods and $+\$ 12.5$ billion in services. Petroleum imports were $-\$ 24$ billion, representing 59 percent of the US negative trade balance in that month. As domestic oil production continues its decline, oil imports have continued their steep rise (Figure 3.4).

Figure 3.4. US oil production and oil imports, 1920-2010

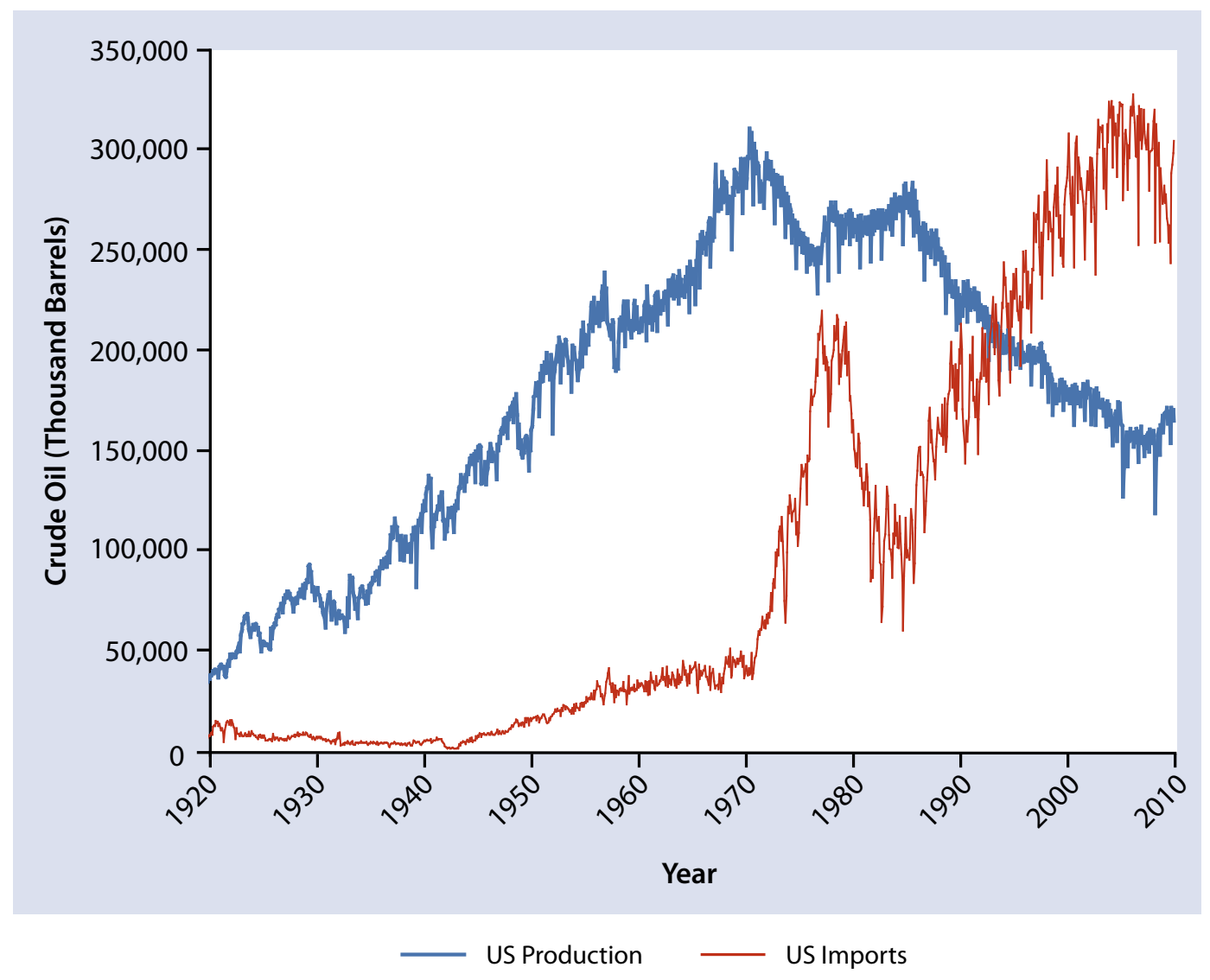

Source: Adapted with permission from the US Energy Information Administration..$^{34,35}$ 


\section{Natural Gas}

As discussed in Chapter 2, natural gas will likely play an increasingly important role as a transitional hydrocarbon fuel.

US prices for natural gas have a history similar to that of oil prices: they varied by a factor of nearly 6 over the decade from 2000 to 2010, as shown in Figure 3.5. Some of the large price swings occurred in the wake of deregulation-induced speculation (e.g., the 2000-2001 California energy crisis). Recent major upgrades in potential US natural gas reserves may contribute to improved stability in natural gas prices.

Figure 3.5. Natural gas wellhead prices, 1976-2010

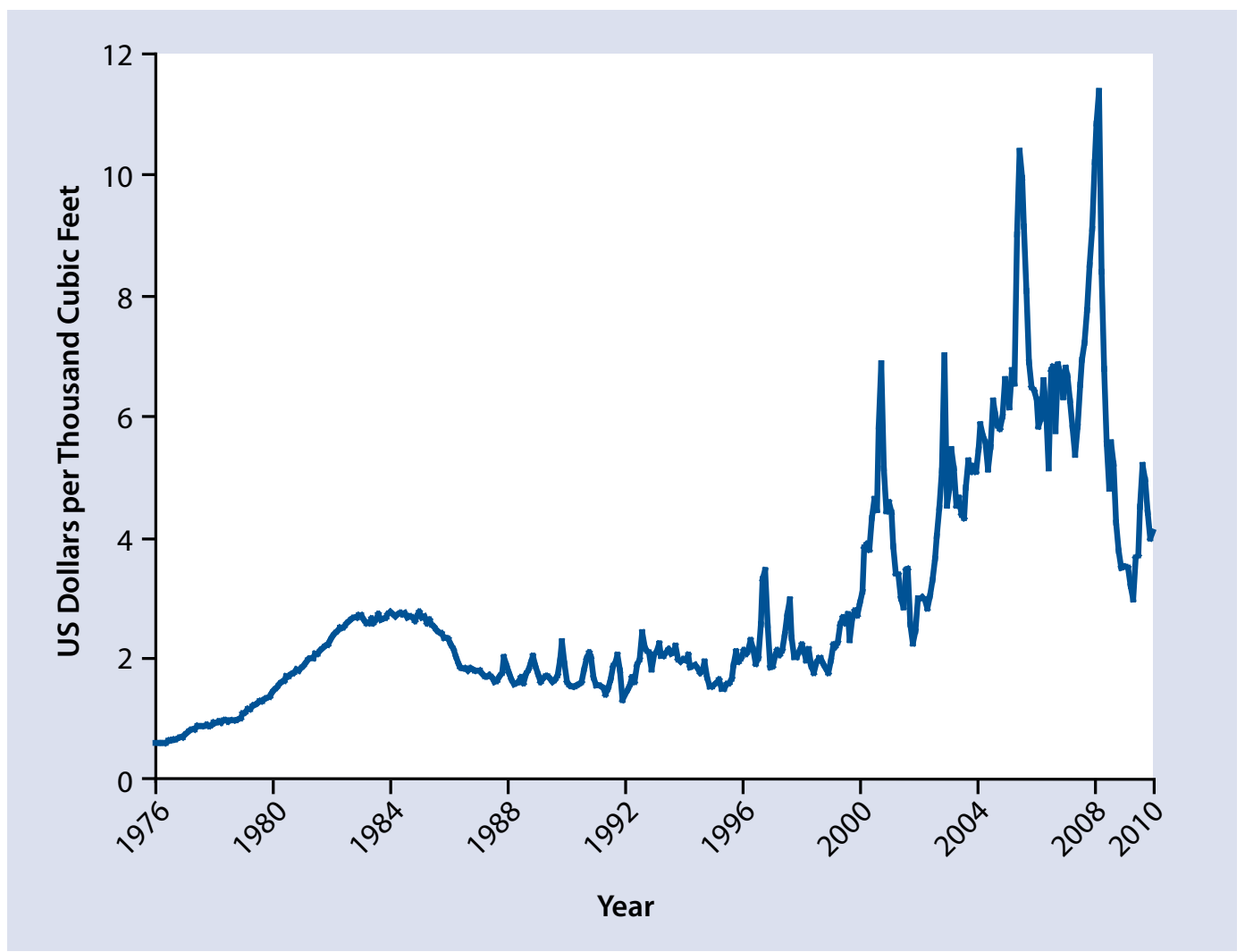




\section{Nuclear Energy}

Compared with fossil fuels, uranium is more readily available to more countries. The largest reserves are found in Australia, which has more than one-fifth of the world's total reserves; other large amounts of uranium are found in Kazakhstan, Russia, the United States, Canada, and South Africa. ${ }^{37}$ Currently, the availability of nuclear fuel imposes no limitation on nuclear power production, although such availability may later become a limiting factor. ${ }^{38,39}$ Moreover, the cost of nuclear fuel has not significantly affected the economics of nuclear energy, which is dominated instead by its high capital costs. ${ }^{40}$

Uranium prices (Figure 3.6) increased more than tenfold from June 2003 to May 2007. They have since declined substantially after briefly reaching a peak of $\$ 136$ per pound of $\mathrm{U}_{3} \mathrm{O}_{8}$ in 2007 (not captured in the graph). Nonetheless, 2010 prices remain about 3 times

Figure 3.6. Uranium $\left(\mathrm{U}_{3} \mathrm{O}_{8}\right)$ prices, 1988-2010

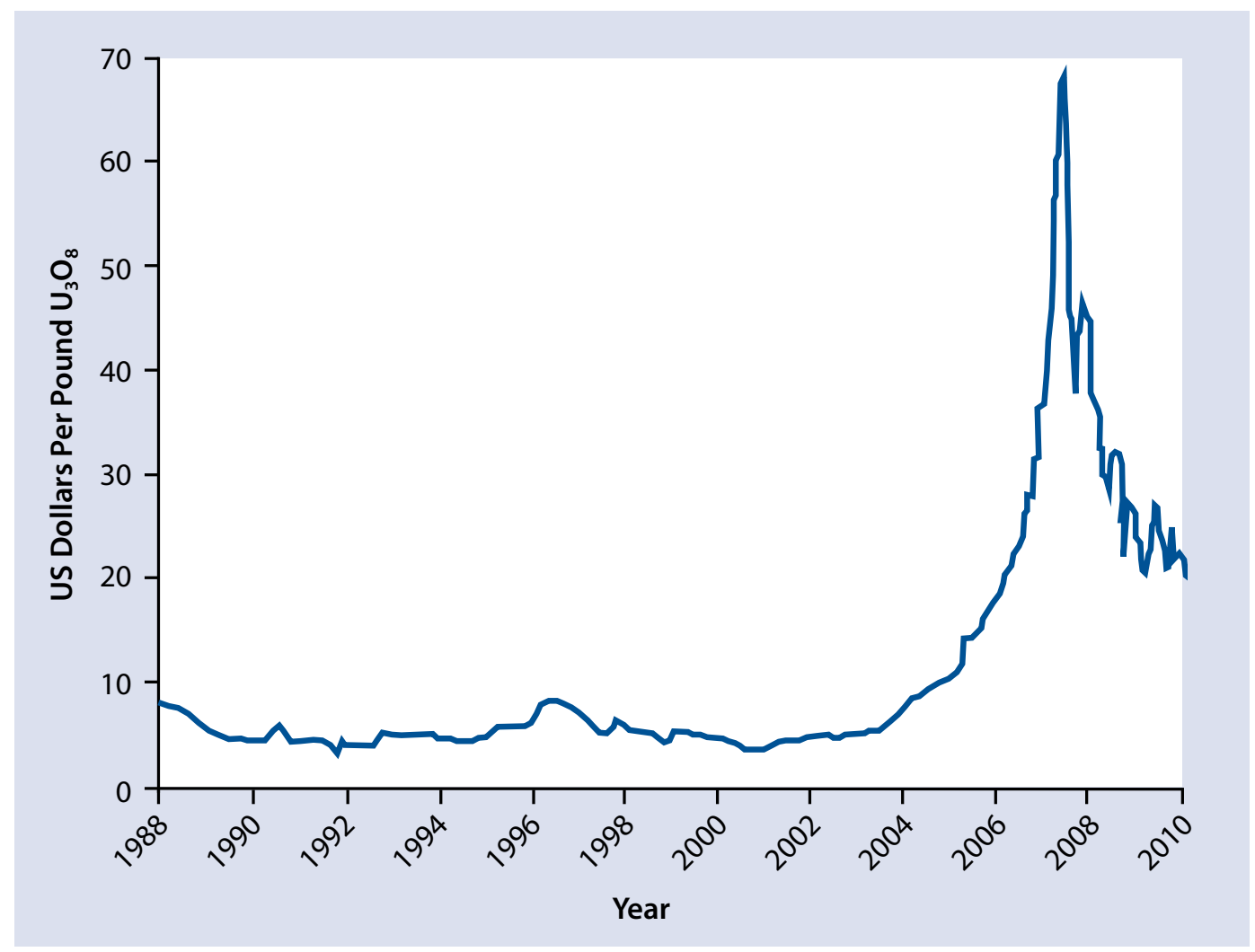

Source: Adapted with permission from the Ux Consulting Company. ${ }^{41}$ 
higher than the 1988-2003 average. There has been discussion of a potential "nuclear renaissance" in the United States and other parts of the Western world for the past decade. One way in which government support for greater nuclear development may manifest itself is through capital investment guarantees to protect against investment risks caused by potential fossil fuel and uranium price fluctuations. ${ }^{42,43}$

\section{Risks and Uncertainties}

Many kinds of uncertainties can substantially affect energy supply, which may cause disruptions in the supply chain and have a negative impact on consumer welfare through reductions in the availability of energy services. Some of these disruptions include the following:

- supply disruptions related to production safety, such as the 2010 Massey Energy mine explosion in West Virginia, which killed 29 miners, and the 2010 Deepwater Horizon offshore oil drilling rig explosion in the Gulf of Mexico, which killed 11 oil rig workers and caused a massive oil spill;

- natural disasters, such as hurricanes Katrina and Rita in 2005;

- price instabilities in commodity primary energy sources;

- oil crises in the form of coupled price and supply instabilities, such as the 1973 OPEC (Organization of the Petroleum Exporting Countries) oil embargo and the 1979 Iranian Revolution;

- international disputes, such as the 2006 Russia-Ukraine gas dispute and the 2007 Russia-Belarus oil dispute;

- sanctions, such as those currently in place against Iran and, earlier, against Iraq and Libya;

- terrorism, such as the terrorist attacks of September 11, 2001; and

- warfare in oil-producing regions, such as the 1990 Persian Gulf War and the 2003 Iraq War.

Nations can mitigate the impact of energy supply uncertainties by establishing strategic energy reserves. In the case of oil, for example, all 28 members of the International Energy Agency hold a minimum of 90 days' worth of their oil imports in strategic reserve. According to the US Department of Energy (DOE), the United States has 726.6 million barrels in its Strategic Petroleum Reserve (SPR) inventory as of November 30, 2010.44 
DOE indicates that the volume in the SPR is equivalent to 75 days' worth of imported oil. However, the United States fulfills its commitment to maintaining 90 days of import protection through a combination of the SPR and industry stocks.

\section{Externalities}

Externalities are the benefits or costs associated with market transactions that are not enjoyed or borne by market participants but affect the well-being of third parties outside the transaction. One of the most pervasive externalities is the environmental pollution created by energy extraction and consumption, where neither the energy producer nor the consumer bears the full social cost.

In the absence of externalities, market transaction costs and benefits to society equal the costs and benefits to the parties of the transaction. Thus, without externalities, the equilibrium price and quantity determined by the market maximizes both private and social net benefits. At quantities lower than the equilibrium, the value to consumers of an additional unit exceeds the cost of producing that unit, so there are gains to expanding production. Conversely, at quantities higher than the equilibrium level, the marginal cost of production exceeds the marginal value to consumers. In this case, without externalities any interventions in the market reduce total net benefits to society by moving the market away from the free market equilibrium. However, in cases where externalities do accompany market transactions, the free market equilibrium results in levels of economic activity above or below the socially optimal level. Market participants, in these situations, have no incentive to take into account these effects on third parties or the society at large. This supports a rationale for government intervention to improve total welfare by instituting policies that cause the effects on third parties to be considered.

When a negative externality occurs, the costs to society of additional production and consumption, or the marginal social cost, exceed the private cost, or the price of the good or service. In other words, the privately optimal level of production and consumption exceeds the socially optimal level. Consequently, proponents of a carbon tax argue that taxing society for the pollution externality is a way to bring fossil fuel energy consumption closer to its socially optimal level.

Conversely, with a positive externality, the marginal social benefit, which accrues to society through the additional production and consumption, exceeds the marginal private benefit, or the price of the good or service. In this situation, the resulting privately optimal level of production and consumption is too low relative to the socially optimal value. 
Government intervention can place a value on the externalities by, for example, taxing those activities with negative externalities and subsidizing those with positive externalities. Such intervention causes individuals and firms to "internalize" the externalities and consider them when making their private decisions. A policy that led to complete internalization of all externalities would result in privately optimal market outcomes that are also socially optimal.

Recognition of the importance of the environmental externalities of market production and consumption in socially optimal resource allocation constitutes one of the foundations of environmental economics. Energy production from fossil fuels imposes major negative environmental and human health impacts through, for example, emissions of $\mathrm{CO}_{2}$, sulfur oxides, nitrogen oxides, fine particulate matter, and vapors of mercury, as well as deposits of heavy metals in coal ash and of coal ash itself. Without intervention, fossil fuel-derived energy use will exceed the socially optimal level because energy users will not internalize the pollution externalities. Consequently, the need to address the production of multiple pollutants during the combustion of fossil fuels makes the study of climate and other environmental policies affecting energy markets a major focus of energy economics.

Numerous regulations require controls on emissions from electricity producers and from transportation use. However, these emission controls have not targeted $\mathrm{CO}_{2}$ reductions, at least not at the federal level. This situation may change as the US government considers regulatory and legislative approaches to reduce greenhouse gas emissions over time. Because of their dominant role in $\mathrm{US} \mathrm{CO}_{2}$ emissions (see Chapter 2), energy production and consumption would be among the most affected sectors of the US economy, according to economic analyses of the impacts of US policy proposals that have been considered as of late 2010.45

Energy-related externalities were considered in the previously cited 2010 report of the National Research Council titled Hidden Cost of Energy: Unpriced Consequences of Energy Production and Use. ${ }^{5}$ The committee quantified the hidden (unpriced) effects of health damages from air pollution associated with electricity generation and motor vehicle transportation, estimating them at about $\$ 120$ billion per year. Because the committee believed that some damages could not be meaningfully quantified, this figure excludes potential damages from climate change, potential harm to ecosystems, the effects of mercury in the air from coal combustion, and risks to national security. The computed externalities, as well as any additional (not computed) negative effects on climate, 
ecosystems, and national security, indicate that petroleum-dependent transportation incurs a significantly higher societal cost than the at-pump fuel prices reflect.

Oil-related hidden costs were addressed by a 2007 report of the National Defense Council Foundation. ${ }^{46}$ Elements of its analysis, in 2005 figures, included

- oil-related defense expenditures of $\$ 49$ billion per year,

- loss of current economic activity, in terms of gross national product, due to capital outflow of $\$ 160$ billion per year,

- losses in tax revenues of $\$ 13$ billion per year, and

- job losses numbering about 830,000.

Greene and Ahmad of Oak Ridge National Laboratory addressed hidden energy costs in a 2005 report. ${ }^{47}$ They calculated the costs of

- the transfer of wealth from the United States to oil-producing countries,

- the potential economic loss due to oil prices being elevated above competitive market levels, and

- disruption costs caused by sudden, large oil price movements.

According to their estimate, oil dependence cost the US economy $\$ 3.6$ trillion (in 2000 dollars) from 1970 to 2005.

\section{Behavioral Energy Economics}

Market prices provide consumers of energy resources with incentives to choose privately optimal levels of energy efficiency and energy use. Maximizing economic efficiency of energy use, which would maximize net benefits to society, does not generally imply maximizing energy efficiency. Energy efficiency refers to the quantity of energy used per unit of output. Although changes in production and consumption that reduce energy use per unit output may reduce energy costs, they are likely to require increases in the use of other inputs per unit of output (e.g., capital, labor, and materials).

Changes to reduce energy use per unit of output come at a marginal cost that is expected to increase as energy efficiency improves and it becomes increasingly difficult and costly to further increase energy efficiency. A large literature reasons that private economic decisions related to energy production and consumption may not result in economically efficient outcomes. ${ }^{48}$ For example, consumers may not be fully informed of alternatives or their cost-effectiveness, or they can be shortsighted or capital constrained. Markets may not lead to efficient outcomes in the presence of market failures, such as 
resulting from imperfect information, or in the presence of externalities, such as those concerning the environment. In addition to market failures, private decision making may lead to "behavioral failures" that lead to deviations from cost-minimizing behavior. ${ }^{49}$

Consumers may be relatively unresponsive to price changes in their use of residential energy, particularly electricity, in part because they lack or ignore information on the quantity of energy being used by individual devices in their homes. Therefore, provision, or clearer articulation, of information about these externalities to consumers may reduce the environmental externalities of energy production and consumption.

Few consumers know what primary energy sources are used to generate the electricity they use or how much energy is used to manufacture the products they purchase, let alone what the associated emissions, environmental, and health impacts are. One strategy for educating consumers is to place information about life-cycle emissions on consumer products so that consumers can consider emissions associated with alternative products as part of their purchase decision.

Behavioral failure refers to systematic biases in decision making that lead to too little investment in energy efficiency with respect to the cost-minimizing level. The argument for the presence of behavioral failures in energy markets comes largely from the literature of cognitive psychology to help explain private decision making. As described in the National Academies' report, three primary sources of potential behavioral failures have been applied to energy efficiency ${ }^{4}$ : prospect theory, bounded rationality, and heuristic decision making.

Prospect theory suggests that consumers evaluate potential gains and losses in their welfare with respect to a reference point, usually the status quo. It also argues that changes in welfare from a loss of a given magnitude are greater than changes associated with a gain of an equivalent magnitude. This phenomenon could lead to greater resistance to behavioral change than theories of rational cost-minimizing behavior imply when there is uncertainty regarding the welfare outcome.

Bounded rationality and heuristic decision making both rely on consumers' facing cognitive limitations that may lead to deviations from pure rationality; however, empirical evidence is limited on behavioral failures as related to energy use and energy efficiency. Consequently, whether cognitive limitations lead to systematic biases in decision making and, if so, whether such biases would lead to under- or over-investment in energy efficiency remain unclear. Much more research is required before the United States can understand and eventually harness the behavioral economics of the energy conundrum. 


\section{Role of Government}

An important question related to energy economics is what role should government fill in developing and deploying new energy technologies. Throughout history, US administrations have taken approaches ranging from nearly "hands off," as when they allowed industries to self-regulate safety and environmental standards, to much more active regulatory stances, as when they mandated renewable-energy portfolios.

The government has far-reaching responsibilities in managing the country's energy markets. The role of a national energy policy is to address US energy planning, generation, transmission, and use.

Governmental responsibilities include the following:

- appropriately regulating commercial energy activities;

- regulating energy efficiency and emission standards, including those affecting climate change;

- issuing instructions for government-owned energy-sector assets and organizations;

- conducting geological surveys;

- funding and conducting basic and applied energy research;

- regulating taxes, exemptions, and subsidies associated with energy generation, conversion, and use;

- enacting security and foreign policy measures such as treaties, alliances, and trade agreements; and

- if necessary for security, providing for military presence or even conducting warfare.

State, regional, and municipal government entities often have their own regulations. Typically, these regulations are coordinated with, or consistent with, regulations at the federal level.

Policy issues often transcend scientific, technological, or even economic considerations such as protection of jobs in certain industries or geographic locations. These considerations have to be implemented in the context of a democratic society. (Contemplating how energy-related policies may evolve in nondemocratic societies is interesting: Although their governments may be freer to enact far-reaching energy policies, they are also more exposed to potential catastrophic failures associated with rapidly mandated or misdirected shifts in energy technologies.) 


\section{Energy Subsidies}

Energy is a highly subsidized commodity throughout most of the world. In few countries do energy consumers pay what most economists would consider the full social cost of energy. Most governments invest heavily in energy research and development (R\&D) and in energy infrastructure development. Funded from the general tax base, these investments typically are not reflected in the final price of energy; instead, the final price arises from capital costs, depreciation, and variable operating costs, with externalities remaining unaccounted for.

A significant part of the US defense budget can be viewed as an energy subsidy not reflected in the price of imported energy. A key mission for the US military is to provide energy security by minimizing worldwide production disruptions and protecting shipping lanes to ensure the flow of oil and gas imports. These costs may not be fully allocated among the beneficiary countries.

Another important consideration concerns subsidies. Coal, oil, natural gas, and uranium are converted to energy carriers, such as electricity and fuels, in large-scale processes with established capital and operating economics, as well as established ratios of fixed to variable cost components. Alternative energy technologies, based on renewable (often low-cost and inexhaustible) energy sources, tend to result in levelized energy costs heavily dominated by the capital component, as exemplified by solar and wind energy farms. Because of the long time span required for such investments in alternative energy to break even, they represent a significant investment risk. Governments can mitigate this risk by using subsidies, tax breaks, tax exemptions, and investment guarantees. Nonselective subsidies make alternative energy sources and energy efficiency options less cost-competitive, whereas selective subsidies (e.g., of specific alternative energy technologies) may have undesired or unanticipated consequences. A recent example for the unintended consequences of selective subsidies has been the hotly debated effect of corn-derived ethanol subsidies on food prices.

\section{Regulation}

The government also fulfills a major role in the regulation of energy markets, largely because of the presence of numerous key externalities in this sector, as described earlier. These externalities argue strongly for public intervention in energy markets to improve economic efficiency, ensure energy availability, maintain public safety, manage the tendency toward local natural monopolies in electricity transmission, and ameliorate pollution concerns. 
Numerous regulations substantially affect both current and future energy markets with competing interests, often with fundamental tensions between short-term and long-term goals. In addition, a mix of regulations may focus on encouraging efficiency (e.g., energy efficiency standards) or on increasing energy supply (e.g., mandated use of advanced renewable transportation fuels). The many existing regulations interact in complex ways to influence private incentives for energy exploration, investment in $\mathrm{R} \& \mathrm{D}$, conservation, mitigation of environmental impacts, and other aspects of energy production and consumption.

In recent years, several state governments have moved to require the use of renewable energy for electricity generation through renewable portfolio standards. California has instituted a low-carbon fuel standard for transportation fuels. The federal government also promulgated a rule requiring an increased use of renewable transportation fuels that began in February 2010, which will significantly accelerate the use of renewable fuels between 2010 and 2022. When the rule is fully phased in, volume requirements will reach 36 billion gallons of renewable transportation fuels per year.

Recent discussion has addressed further increases in corporate average fuel efficiency (CAFE) standards for new vehicles.

A primary goal behind many of these policies is to reduce US dependence on imported energy sources and reduce greenhouse gas emissions. In addition, these policies may affect emissions of "criteria" air pollutants (the six identified by the Clear Air Act are ozone, particulate matter, carbon monoxide, nitrogen oxides, sulfur dioxide, and lead) and additional hazardous air pollutants.

Another set of potential regulations aims to reduce $\mathrm{CO}_{2}$ emissions. Because energy use accounts for most US $\mathrm{CO}_{2}$ emissions, any policy mandating their reduction is expected to have substantial effects on the future size and structure of the energy sector and on the mix of energy sources employed. Thus, enacting a US $\mathrm{CO}_{2}$ reduction policy could be expected to have substantial influence on the future use of energy sources (coal versus natural gas versus renewable energy) and energy use itself (investments in energy efficiency versus behavior change).

\section{Technology Development}

The theoretical basis for government's role in market activity lies in the concept of market failure. As mentioned before, market failure is typically attributed to monopoly power, imperfect information, externalities, and public goods. For example, the balance between 
monopoly power and economics of scale is continually being assessed through antitrust legislation. Explicitly asserting market failure to justify government's role in R\&D activity, however, is a relatively recent phenomenon in public policy.

Market failure, particularly technological or innovation market failure, results from conditions that prevent organizations from fully realizing or appropriating the benefits created by their investments. This situation happens when conditions prevent the R\&Dinvesting firm's full appropriation of the benefits from a marketable technology developed through the $\mathrm{R} \& \mathrm{D}$ process.

Patents are one of the more viable mechanisms for helping innovators reap the benefits of their research. Nevertheless, patents are imperfect and, typically, other firms in the market or in related markets will realize some of the profits from the innovation. Consequently, the R\&D-investing firm will calculate that the marginal benefits it can receive from a unit investment in $R \& D$ will be less than what could be earned if all benefits could be fully appropriated. As a result, an underinvestment in R\&D ensues with respect to what would have been optimal from a social perspective. Stated another way, the R\&D-investing firm may determine that its private rate of return fails to exceed its private "hurdle" rate (i.e., the firm's minimum acceptable rate of return); it may, therefore, decide against undertaking socially valuable $R \& D$ if it is not economically valuable for the company. The result may be a shift of R\&D investments into second-best technological solutions from the societal perspective.

Several factors can lead to a firm's perception that its expected rate of return will fall below its hurdle rate: 50

- High technical risk may cause market failure because, even when the firm is "successful," the private returns may fall short of the private hurdle rates.

- High technical risk can relate to high commercial or market risk when the requisite $\mathrm{R} \& \mathrm{D}$ is highly capital-intensive. The investment may require too much capital for a firm to feel comfortable with the outlay; therefore, the firm may not make the investment, even though both it and society might have benefitted more if it had.

- Many R\&D projects are characterized by a lengthy time interval until a commercial product reaches the market.

- Not uncommonly, the scope of potential markets is broader than the scope of the individual firm's market strategies, so the firm may not perceive economic benefits from all potential market applications of the technology. 
- The evolving nature of markets requires investment in combinations of technologies that, if currently extant, would reside in different, nonintegrated industries.

Because such conditions often transcend the R\&D strategy of individual firms, such investments will likely remain unrealized.

- In some situations, the technology may make assignment of intellectual property rights difficult.

- Industrial structure can raise the cost of market entry for applications of the technology.

- In some situations, the complexity of a technology makes buyer-seller agreement about product performance costly.

These factors, individually or in combination, can create barriers to innovation and, therefore, because of the technological market failure, lead to a private underinvestment in $\mathrm{R} \& \mathrm{D}$. As a result, frequently a role for government is to support the development of technologies that have large spillover benefits (e.g., by providing information that will be valuable to numerous parties and will lower their costs of further R\&D and commercialization) or are characterized by high risk but high potential return.

The main criticism aimed at government-supported $\mathrm{R} \& \mathrm{D}$ is that the government is then picking the next generation of technologies. Because resources are limited, the government develops and implements criteria by which it selects technologies and processes to fund. The question remains, however: Does the government have better information than the private sector on the potential success, both technical and economic, of technological alternatives? The persistence of this question has meant that the role of government has traditionally been focused on basic, precompetitive R\&D, from which knowledge spillovers are noncontroversial. Basic R\&D has historically been considered to have many attributes of a public good; hence, there is a clear role for government in promoting the optimal social level of basic $\mathrm{R} \& \mathrm{D}$.

In the past, the government has hesitated to venture into areas of applied research that are too close to commercialization of technology. However, this hesitance has been eroding in recent years because of concerns that, without government funding, the movement of new technologies from the laboratory or university to commercial products will end in the "valley of death" (i.e., the time span of negative cash flow in the life cycle of a technology). 51 


\section{Modeling Energy Markets and Policies}

When energy companies consider future investments or policy makers propose new regulations for energy markets, they typically turn to energy modelers to evaluate the potential impacts of their decisions. Energy modelers generally develop and apply models that combine information from a wide variety of disciplines, such as chemical and mechanical engineering, geology, transportation, and agriculture. They predict how markets may respond to changes in conditions. These models of the energy sector and, in some cases, the entire economy are useful tools in policy investigations because they can start from known conditions in energy markets, add new information on technologies or regulations, and evaluate how the future may look.

Energy models vary significantly in their focus and capabilities. Broadly speaking, the models can be characterized as either top-down or bottom-up. Top-down models tend to concentrate on macroeconomic drivers in energy markets and on interactions between energy and the rest of the economy. Meanwhile, they sacrifice details about the specific technologies that produce and consume energy. Bottom-up models have more of an engineering orientation and focus on representing individual technologies to the extent feasible in what is still an aggregated framework. However, they are less suited for an examination of forces driving overall energy supply and demand. Some efforts have been made to combine these modeling techniques; research on the best methods of integrating the two approaches continues.

The Stanford Energy Modeling Forum (EMF) has conducted numerous collaborative exercises among modelers to evaluate the predictions of energy models and how they can vary across individual models. Published literature from this process explored the possible economic effects of US, European, and international climate change mitigation policies. ${ }^{48}$ Other EMF projects have explored issues such as global natural gas or petroleum markets.

The US Energy Information Administration (EIA) uses the National Energy Modeling System (NEMS). NEMS combines several detailed modules representing specific aspects of energy markets to estimate future energy demands as a function of expected changes in economic growth and technological development. NEMS also helps formulate responses to requests from federal government agencies for policy analyses.

The US Environmental Protection Agency (EPA) Climate Change Division uses a combination of the bottom-up Integrated Planning Model of electricity production ${ }^{52}$ and two top-down macroeconomic models: the Intertemporal General Equilibrium model ${ }^{53}$ 
and RTI's Applied Dynamic Analysis of the Global Economy (ADAGE) model ${ }^{54}$ (see text box for additional description of ADAGE). This combination of models has been used in EPA responses to congressional requests for legislative analyses.

Some elements of these models, and the underlying drivers of their predictions, are inherently uncertain. Many of the findings depend on expected economic growth. Similarly, analysts must make assumptions about the costs and availabilities of energy production technologies on the basis of the best available engineering data. For example,

\section{ADAGE Integrated Model Structure}

ADAGE is a dynamic computable general equilibrium (CGE) model capable of investigating economic policies at the international, national, US regional, and US state levels. CGE models such as ADAGE combine economic theory and empirical data to estimate policy effects, while accounting for all interactions among businesses and consumers.

ADAGE typically solves in 5-year time intervals from 2005 to around 2050 and can be used to explore dynamic effects of many types of energy, environmental, and trade policies. Of particular note is its ability to investigate climate change mitigation policies at a range of geographic scales.

ADAGE is designed with an integrated, modular structure (see figure at right ). Each module relies on different data sources and has different geographic scopes, but all have the same overarching theoretical structure. The internally consistent, integrated framework connecting ADAGE's modules allows its components to use relevant policy findings from other modules with broader geographic coverage, while avoiding computational issues that preclude solving for all US states and world nations simultaneously.

The comprehensive framework of ADAGE begins with the international module. Based on Global Trade Analysis Project (GTAP) data, this component of ADAGE allows the model to conduct international policy investigations of any group of nations included in its database. After the GTAP data and economic/energy forecasts from EIA enter the model structure, policies can be examined.

From these studies, findings on prices of traded goods and, in the case of climate change mitigation policies, greenhouse gas permit prices can be passed to the US Regional Module (based on IMPLAN economic data and EIA energy data). 
estimated macroeconomic impacts of climate policies depend critically on assumptions about advanced electricity generation technologies, such as nuclear energy and "clean coal" with carbon capture and storage. These types of data are always subject to debate, but energy-sector models may help decision makers evaluate a range of assumptions that capture most of the possible outcomes and provide information on the potential differences in direction and the relative magnitude of impacts under alternative scenarios.

\section{Figure 3.7. ADAGE model structure}

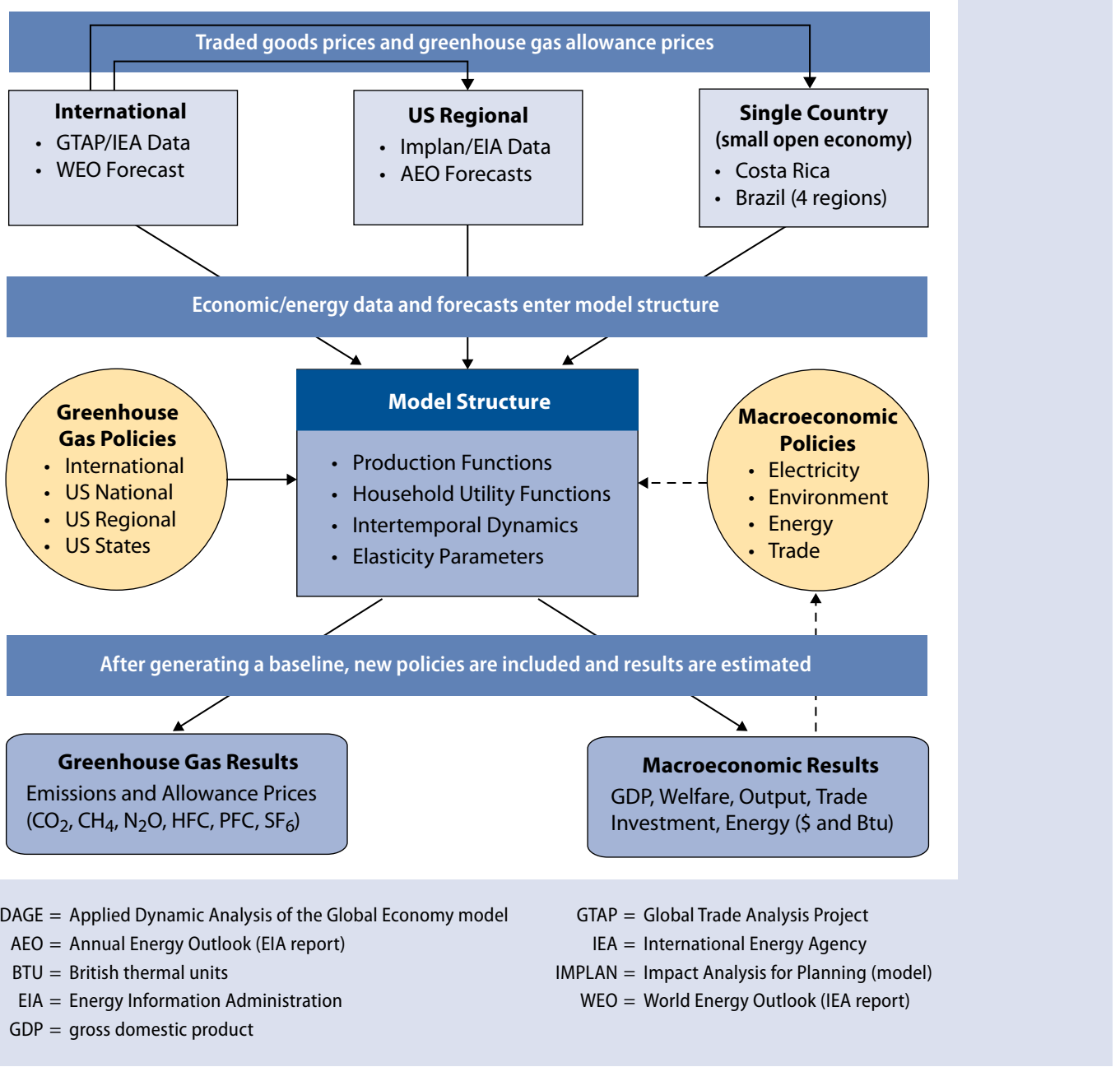


Although considerable improvements in our ability to model energy markets have been made over time, there remain many uncertainties regarding consumer preferences and behavior and room for substantial improvement. For example, as discussed in Chapter 2, transportation is responsible for about one-third of all energy consumed in the United States, with personal vehicles representing about 60 percent of that total. Factors influencing the choices of personal vehicles remain poorly understood. Such choices often depend on factors other than the economic cost of transportation, which makes analyzing them in macroeconomic models problematic. Modeling and predicting transportationrelated energy economics become even more complicated when energy-sector models have to incorporate plug-in hybrid or electric vehicles not yet in widespread use. Such issues could be informed by collecting additional survey data about consumer preferences.

Other choices by households remain equally unexplained in current energy modeling. Energy efficiency, in particular, is considered an important tool for meeting future energy goals and complying with possible climate policies. Engineering cost data can help specify technological options for efficiency improvements with relative ease, but adoption of these technologies is not well understood. Similarly, additional information would have to be collected to inform energy models with respect to consumers' possible reactions to new kinds of technologies - such as smart electric grids-necessary to improve energy efficiency.

Energy economics and modeling has made considerable strides in recent years in improving our understanding of the inherent trade-offs associated with alternative energy sources available at different prices, levels of supply risk, and externalities. However, much remains to be learned about human behavior and development of public policy. In the following chapter, we examine social dimensions of the energy challenge facing the United States that are not well understood. An improved understanding of these issues will provide valuable insights into consumer decision making, development of public policy, and energy model structure and parameterization. 


\section{Societal Dimension of America's Energy Challenge}

The Mojave Desert in California is among the premier locations in the United States for solar and wind energy plants. Its high rates of peak sunshine and proximity to power transmission lines and population centers spurred hundreds of millions of dollars in investments at the end of the twentieth and the beginning of the twenty-first centuries. Power companies making these investments sought to supplement their traditional fuelburning plants with renewable sources.

Yet in late 2009 ambitious plans to build 13 more wind and solar "farms" in the Mojave Desert appeared to be scuttled by the opposition of environmentalists and some of the state's elected officials. They called further development of energy plants, even "clean" energy like solar and wind, a threat to the desert's landscape and ecology. The conflict divided the environmental movement and aggravated traditional battles between developers and ecologists. ${ }^{55}$

Meanwhile, union leaders seeking to secure construction jobs for their members supported the development and opposed liberal elected officials whom they normally support. Equally subject to such ironies, conservatives opposed to government spending found themselves at odds with other conservative business interests looking to the government for critical investment in technology or tax relief to support fledgling enterprises.

Like the controversies over the Mojave Desert site, the choices confronting the United States will be socially, politically, and economically complex. As discussed in Chapter 2, alternative energy technologies such as wind and solar power have enormous potential and have been developed into viable alternatives for generating electricity and for other uses. Because they do not directly contribute to pollution or $\mathrm{CO}_{2}$ emissions, and do not raise energy security concerns, they are far less prone to the externalities problems detailed in Chapter 3. Wind and solar plants must, however, be deployed in specific places and communities, where (as illustrated above) competing values and complex politics can frustrate even the most compelling technical achievements. 
Studying the way forward in meeting the country's energy challenges means developing a better understanding of the social contexts in which individuals and institutions make energy decisions. The nation has a great deal of information about the energy infrastructure and technologies, and energy economics are well developed. What is lacking is an organized evidence base about people's attitudes and behaviors with respect to options for energy use. Little is known, for instance, about how sociodemographic factors, cultural or religious views, or developments outside the United States influence the choices that people or organizations in this country make about energy.

This chapter sets forth what is already known about this third dimension to America's energy future: the social constructs and societal activities that interact with both technology and economics to give us the energy infrastructure that we have today and the options for tomorrow. We first cover largely domestic issues, such as public opinion and engagement; we also examine the complex geopolitical considerations that influence US actions in both the public and private sector. Finally, we raise a broad set of considerations involving social justice and ethics. Then, in Chapter 5, we lay out a research agenda to fill the many gaps in our understanding of the societal factors so crucial to achieving progress and making sensible personal and policy choices in the years ahead.

\section{Further Examples of the Impact of Societal Factors}

The Mohave Desert account at the outset of this chapter is but one illustration of the interplay of technology, economics, and social factors in fostering, or in this case impeding, efforts to expand America's energy options. It is by no means the only example, however.

For instance, efforts in the early 2000s were under way to build a wind farm off Cape Cod, a 24-square-mile project that would be the country's first offshore wind power plant. These efforts were challenged in early 2010 when the National Park Service declared Nantucket Sound eligible for listing on the National Register of Historic Places. The Park Service was responding to a request from two Massachusetts Native American tribes. The tribes claimed that the turbines would interfere with tribal rituals for welcoming the sun as it rose across the sound and would disturb the tribes' burial grounds. ${ }^{56}$ In short, decisions about energy sources may be made in a social context with deep historical roots, one involving long-established ethnic and religious rights.

The history of nuclear power in the United States provides another example of the complex interactions among technology, subsidies, externalities, uncertainties, and issues concerning public perception and imperfect information. Technical innovation and 
economic feasibility, discussed in Chapters 2 and 3, have not sufficed to ensure nuclear power's development as a primary source of power in the United States.

Nuclear research and development was funded by the government originally for military purposes. As with many defense technologies, use in commercial applications was a spillover benefit to society. The promise of power "too cheap to meter" made nuclear power attractive from both an economic and an energy security perspective. However, social concerns over safety significantly increased construction and operating costs, and difficulties in locating new plants because of environmental and "not in my backyard" issues led to a decline in the industry.

No new plants in the United States were constructed for three decades. However, in 2010 new plants were being built in Europe, and proposals for new reactors were being generated in the United States. Seemingly, social attitudes were converging with advances in technology and realities of the costs of alternative fuel sources to enable nuclear power proponents and energy companies to move ahead in this sector.

The most controversial element of nuclear power remains waste management, and this issue, too, entails technical, economic, and social factors. Two competing waste management approaches exist. One involves open fuel cycle and the other closed fuel cycle (reprocessing) technologies, discussed in Chapter 2.

In 1997 the United States officially banned the reprocessing of spent fuel from nuclear reactors. At the time, the government cited two main reasons for the ban. First, reprocessing may generate weapons-grade fuel (plutonium) and could lead to nuclear proliferation or terrorism. Second, US reprocessing historically had proven to be environmentally dangerous because of radioactive contamination.

Over the past 30 years, however, France and other countries have shown that reprocessing can be environmentally safe. No security breaches have occurred with any weapons-grade fuel, but the waste still presents a security risk, and the reprocessed material is concentrated and more difficult to manage. The lack of commercial technology for constructing a viable breeder reactor (discussed in Chapter 2) prevents realization of the full economic benefits of reprocessing.

Consequently, no clear technological or economic winner has emerged in the reprocessing debate. The US nuclear industry has little incentive to pursue breeder reactor technology, because the federal government subsidizes existing waste management practices. In addition, politically charged issues surrounding nuclear proliferation, terrorism, public safety, and the environment support the status quo and make change difficult. 
The US open fuel cycle system will likely continue, on the promise of future development of a long-term, cost-effective system to manage unprocessed nuclear waste. However, the solution of storing waste at Yucca Mountain in Nevada, which has been extremely controversial, is currently on hold; moreover, the Yucca Mountain site may already be too small to hold the existing US stockpile of high-level waste. Consequently, US nuclear power plants continue to rely on on-site waste storage. Similarly, France and other European countries will likely continue with their own system, on the promise of eventual commercial viability of breeder reactors.

Another example of the importance of societal factors in the energy debate is the explosion on April 20, 2010, of the Deepwater Horizon semisubmersible oil rig 41 miles offshore Louisiana in the Gulf of Mexico, which resulted in 11 deaths and a massive oil spill. Offshore drilling represents a true technical, economic, and societal dilemma. The technology is complex at depths of 5,000 feet and beyond, the oil-drilling definition of "deep." However, failure to exploit offshore oil might lead to even higher levels of use of imported oil, exacerbating the related military, security, and economic issues.

These kinds of low-probability, high-consequence disasters cannot be completely avoided (airline disasters come to mind as an analogue). Government control of deepwater offshore drilling operations is only partially effective, because the government is neither fully familiar with the technology nor in possession of the required equipment and manpower. Perhaps the most likely outcome of the Deepwater Horizon catastrophe will be a resumption of deep-water offshore drilling after substantial tightening of both company practices and governmental regulations, coming after multibillion-dollar damages, corresponding claims, and their economic consequences. The outcomes of this disaster will be the result of not only economic and technical factors, but also societal choices and contexts.

These examples suggest only some of the ways that our energy options will be constrained as much by the way society operates as by the way science operates. For this reason, researchers must understand the following:

- how much members of the public know about present and future energy choices and the impacts of those choices, and how they obtained that knowledge;

- how world and market developments influence public opinion;

- how energy politics operates domestically and in American foreign policy;

- how public policy can influence individual behavior, and vice versa; and 
- how the United States can better prepare for whatever future energy infrastructure the country develops, including better understanding the homeland security implications of our energy future.

We explore these concepts here by examining public attitudes, knowledge, and opinions on energy options available to the United States, or possibly available in the near future, and the domestic and geopolitical contexts in which energy decisions are made. We also investigate the research possibilities related to energy shortages, which are taken up again in Chapter 5. The United States has met its past energy challenges with relatively little permanent disruption to its social and economic development. This record of success offers encouragement that the nation will solve the current crisis, but it is not a guarantee.

\section{Broad Agreements in Public Opinion}

Americans' attitudes toward energy are rooted in broad agreement on three concurrent concepts:

1.instability of supply, or the notion that domestic supplies of currently used energy sources are inadequate, forcing the United States into reliance on unstable foreign sources;

2. scarcity, or the notion that global supplies of fossil fuels are intrinsically limited and that the horizon for the depletion of reserves of key fuels is fast approaching; and

3. environmental impact, or the notion that the consumption of fossil fuels is the source of environmental degradation, ranging from the health effects of air pollution to effects of $\mathrm{CO}_{2}$ emissions on climate.

On none of these points are Americans unanimous: each is contested, sometimes vigorously. Some Americans believe that increased oil drilling or other strategies can help the United States achieve energy independence, while some Americans think that the decline of fossil fuel supplies is not a crisis, because other fuels will rapidly develop to replace fossil fuels well before fossil fuels are exhausted. Moreover, Americans continue to debate global climate change. Even where disagreement persists, these three issues have nonetheless entered the American public mind in a profound, lasting way.

\section{Instability of Supply}

Americans have witnessed how the uneven distribution of fossil fuel resources across different countries has influenced America's foreign relations for more than a century. It has had an acute impact since at least the OPEC oil embargo in 1973 to 1974, which 
was in response to Western support of Israel in the Yom Kippur War. The 1979 oil crisis stemming from the Iranian revolution followed.

The political situation in the Middle East, centered on the questions of the PalestinianIsraeli coexistence and the rise of Islamic fundamentalism, is inextricable from the United States' need to secure the country's access to oil fields in Arab countries. Rivalry between the United States, Russia, and China for regional and international influence is tied as well to energy access. Although the United States can rely on considerable domestic fuel supplies, particularly coal, it is far from self-sufficient.

The specter of a sudden energy crisis arising from a world event, such as the outbreak of war or a terrorist attack, hovers over American attitudes toward energy sources and policy. The concern has, in fact, influenced societal perspectives for several decades, reinforcing the notion that the United States' access to energy is highly contingent, even fragile, and therefore in need of safeguarding. Consequently, US taxpayers assume a heavy burden for the large military expenditures associated with guaranteeing the safety of oil production and transportation and with protecting the public from terrorism.

\section{Scarcity}

Regardless of the location of energy reserves, for decades both policy makers and the public have recognized that economically and ecologically accessible supplies of fossil fuels are finite. Although debate persists over how long supplies will last, many experts perceive that reserves could be exhausted in the near future. In 1956, Shell Oil geologist M. King Hubbert, in a controversial paper, ${ }^{57}$ predicted that American domestic production of oil would peak in 1970, a forecast that turned out to be correct (Figure 3.4 in Chapter 3 illustrates this point). Hubbert's modeling techniques have been extended, with varying results, to the global oil supply. Many experts trying to predict peak global oil production have placed the high point between 2010 and 2020; some optimists, perhaps most notably Cambridge Energy Research Associates, ${ }^{58}$ place the peak beyond the year 2030.

Corollaries to peak oil can be found for coal and natural gas. Peak coal production in the United States is predicted to occur in the 2030s; however, peak coal energy output may already have occurred because of the depletion of higher-quality coal reserves. Peak natural gas is harder to estimate because of the lack of certainty over gas reserves and the recent upgrade of natural gas resources, described in Chapter 2.

Although these timelines differ, nearly everyone agrees that economically recoverable fossil fuel reserves are limited. Perceived and real oil supply shortages, combined with 
rapidly growing oil demand in developing economies such as those in China and India, have contributed to extreme oil price fluctuations (plotted in Figure 3.2 in Chapter 3). These fluctuations have, in turn, resulted in huge economic dislocations and uncertainty; they likely contributed to the US recession beginning in 2008 .

\section{Environmental Impact}

The third major consideration underpinning the modern energy challenge implicates fossil fuels in an array of threats to the environment. Most immediate is the threat to public health through degraded air, water, and soil. At its extreme, concern over the environmental impact of fossil fuels has brought into question the ability of the planet to sustain continued human activity.

The health impacts of environmental pollution have only recently been understood. They come from many sources. Some health impacts arise from manmade disasters such as oil spills or nuclear plant failures, as in Chernobyl in 1986, for example. In 1952 a "killer fog" in London attributed to the burning of dirty fuels killed more than 4,000 people.

Other sources of pollution are continuous rather than catastrophic. For example, motor vehicle emissions are thought to be among the primary causes of a rise in asthma cases, particularly among young children..$^{59}$ Bronchitis, various upper respiratory infections, heart attacks, and other maladies are also associated with air pollution. Coal mining threatens water supplies, particularly if the coal is taken through strip mining, which can also leave barren soil prone to erosion. Together, one study estimated that air, water, and soil pollution account for 40 percent of worldwide deaths each year. ${ }^{60}$ More indirectly, cheap energy contributes to the increasingly sedentary lifestyle of many people in the industrialized world, giving rise to growing rates of obesity and related chronic health effects.

Pollution from the production and consumption of fossil fuels also poses economic risks, such as managing the public health effects of pollution. The externalities of energy production and consumption create other widespread risks as well. Oil spills such as that from the Deepwater Horizon explosion in 2010 threaten fisheries and other industries, including tourism. The cost of securing overseas sources of energy burdens the American economy, as does the price volatility that marks the international oil market.

Interactions between energy markets and other sectors of the economy are enormously complex. Moreover, developing accurate assessments of the relative life-cycle emissions of alternative energy production technologies is quite difficult and, therefore, frequently misrepresented or misunderstood. For example, biofuels are typically assumed to have 
zero net emissions from combustion, but expanded use of biofuels in the transportation sector will likely require large quantities of agricultural and forest feedstocks, which require energy to produce. Producing an agricultural crop for use as a bioenergy feedstock requires energy for fertilizer production and pesticide production, transportation fuels for use in tractors and other equipment, and energy for transporting feedstocks to renewable energy facilities. All these activities result in $\mathrm{CO}_{2}$ emissions that at least partially offset the reduction in emissions associated with biofuels. In addition, fertilizer application and other agricultural activities contribute to emission of non- $\mathrm{CO}_{2}$ greenhouse gases.

Beyond these emissions, important effects on commodities and land markets occur as commodity prices change in response to demand for bioenergy feedstocks. One of the more difficult-to-assess elements of large-scale production of feedstocks for renewable energy is the net effect of expanded biofuels production on global land use. Of particular interest are the land types and quantity that might be converted to agricultural production in response to higher global commodity prices. For example, agricultural conversion of tropical forests, which store large quantities of carbon per acre, releases large quantities of $\mathrm{CO}_{2}$.

Perhaps most significantly, widespread-although by no means unanimousviewpoints warn that the consumption of fossil fuels is accelerating greenhouse warming of the Earth. Even if domestic reserves sufficed for US consumption and if global reserves lasted for several more centuries, the predictions of climate change theory suggest that the country will remain under considerable pressure to change its energy practices. Theories of human-generated climate change tend to piggyback on more widespread acceptance of the dangers of airborne pollutants and the even wider acceptance of environmentalism.

\section{Environmental Movement}

Three concepts-instability, scarcity, and environmental impact-form the basis for much of American knowledge of and opinion on contemporary energy issues. This broad social agreement has helped fuel the rise of one of the more successful post-World War II social movements in the United States: a broad-based environmental movement that has influenced energy policy debates and effected legislative and social successes across parties and ideologies.

The success of the environmental movement is ubiquitous. It is found, for example, in laws such as the various Clean Air Acts of 1955, 1963, 1967, 1970, 1977, and 1990 and the Endangered Species Act of 1973. Other ramifications include the setting aside 
of considerable amounts of conservation territory; changes in American consumer behavior, such as increased recycling; and the development of hybrid automobiles. The environmental movement has become so fundamentally a part of everyday modern American life that its genesis as an actual social—and political-movement is sometimes forgotten.

Despite the successes of the environmental movement, its actual impact on the energy choices of American society can be overstated. Fuel efficiency in cars, for example, has improved only slightly, as the demand for larger and more powerful automobiles has kept pace with technological improvements in fuel efficiency; from 1990 to 2006, average passenger car fuel efficiency in the United States increased from 20.3 miles per gallon to only 22.4 miles per gallon. ${ }^{61}$ Total US $\mathrm{CO}_{2}$ emissions in 2007 reached the highest levels ever, up 17 percent from 1990, and they are forecasted to continue to increase. ${ }^{62}$ The environmental movement, for all its success in recent decades, has had a limited impact on energy consumption. Moreover, its tenets remain in uneasy tension with America's dominant free market ideology and with views about individual liberties.

Moving forward to meet the energy and environmental challenges outlined here will force choices on the American population. As consumers, Americans will have to choose between pursuing energy conservation (consuming less) and investing in energy efficiency (consuming differently). How we choose to mix these two ways of confronting energy shortages will prove critical in shaping American society in the twenty-first century. As citizens, we will be asked to weigh the different values we place on the environment and the economy as well as on individual choice and societal constraint. We will also debate the role of government in effecting the energy infrastructure transformation. Understanding the ways that American society will approach these choices is critical to understanding America's energy future.

\section{Divisions in Public Opinion}

Measuring public opinion on energy options and the environmental impact of the public's energy choices has interested researchers and policy makers for decades. Our understanding of societal attitudes, however, remains piecemeal. The lack of regular, large-scale, scientifically designed survey projects has left the literature on the public's views somewhat incoherent. Nonetheless, a review of the scholarly and popular literature suggests some important conclusions. 
At least three widely recognized divisions exist in the American population with regard to general attitudes toward energy choices:

1. a marked generation gap, as young people have proven more sympathetic to energy conservation and the exploration of alternative sources than their parents or grandparents;

2.clear socioeconomic divisions, which affect how people consider energy policy and their own attitudes and behaviors; and

3. geographic divisions within the United States, both between different regions of the country and between rural and urban residents, with the western states having been at the center of disputes in recent decades.

\section{The Generation Gap}

The generation gap in attitudes toward energy and the environment is somewhat more complicated than it may at first appear. Generally, young people repeatedly express more concern about the environment than older people do, but they express less concern about several specific energy topics. This difference reflects the different consumer role that young people fill in industrial societies. For example, a Eurobarometer survey in 2007 found that young people were less concerned than older people about the energy efficiency of appliances: more than one-third (36 percent) said they did not really care, compared with 14 percent to 17 percent of older cohorts. ${ }^{63}$ As people age and become more attuned to energy costs, their sensitivity to energy conservation often increases.

On energy itself, younger people tend to profess more "green" attitudes than their elders, although their definitions of green differ and change over time. For example, a Harris Poll on nuclear power in 2008 found that older Americans were more likely than younger Americans to support construction of new nuclear plants: more than 60 percent of people 63 years of age or older favored new plants compared with less than 40 percent of people ages 18 to $31 .{ }^{64}$

\section{Socioeconomic Divisions}

Attitudes on energy correlate, as one may expect, with income and education. Higher levels of income and education are associated with modestly higher support for energy conservation and alternative sources and support for governmental intervention to ensure environmental protection. ${ }^{65}$ Income clearly plays a role in the sensitivity of Americans to energy prices: working-class Americans feel more vulnerable to spikes in gas prices than wealthier Americans do. 
Rural and urban residents have divergent attitudes and behaviors as well. A series of studies extending back to the 1980s has sought to compare rural residents with their counterparts in urban areas. Results have been mixed. Some studies have argued that environmental concern is higher in cities, whereas others have disputed this conclusion. ${ }^{66,67}$ A 2005 study in Spain found high levels of environmental concern but low levels of pro-environmental behavior among both rural and urban residents. Although the samples differed considerably, the results suggested that people in rural areas experience environmentalism differently than people in cities. ${ }^{68}$

\section{Geographic Divisions}

Regions of the United States experience the energy crisis in disparate ways. Western states dominate fossil fuel production, generally have lower population densities, and have some additional political power relative to densely populated states as a result of equal representation in the US Senate. People in the colder Northeast show a higher sensitivity to heating-fuel prices than do people in the South. Different political cultures in the various US regions view debates on energy through quite different ideological lenses.

\section{Divisions in Public Action}

\section{Level of Engagement}

More generally, public opinion varies both in the amount of engagement with energy issues and in attitudes toward solutions. By extension, the extent of social action by individuals or organizations also differs. A 2009 Public Agenda cluster analysis of its survey data found that its respondents broke into four broad groups: ${ }^{69}$

1. The Disengaged (19 percent), who know little about the energy problem and are not worried about it.

2. The Climate Change Doubters (17 percent), who are equally or more knowledgeable about energy than other Americans but have doubts about global warming theories. They are conservative politically, favor expanded oil exploration and drilling, choose economic growth over environmental protection, and yet often still favor investments in alternative energy sources like solar and wind.

3. The Anxious (40 percent), who are worried about the energy future, particularly the prospects of higher prices.

4. The Greens (24 percent), who favor energy conservation measures, oppose environmentally questionable policy decisions such as offshore and Alaskan oil drilling, and are willing to pay more for renewable energy. 
The Public Agenda results suggest that Americans value the various components of the energy question differently. Some emphasize the long-term environmental impact, and others emphasize the immediate impact of energy costs on the household budget. As individuals or collectively, then, Americans will differ in the economic decisions they make or other steps they take to address energy problems.

\section{Level of Knowledge}

As the Public Agenda study suggests, the abundant statistical data on energy and the numerous studies of public attitudes obscure Americans' lack of knowledge that might inform their energy choices. The survey found that 39 percent of Americans could not name a fossil fuel, and even more could not name a renewable energy source. These results may be a combination of the lack of public knowledge and the quality of the survey design, however.

Almost one-third of respondents said that solar energy contributes to global warming. Again, this result may have derived from a poorly worded question: solar energy generation does contribute to global warming through the manufacturing process for solar panels. In addition, the question could be interpreted to mean the contribution of solar insulation to the greenhouse effect.

Finally, nearly two-thirds said that most of the United States' imported oil comes from the Middle East, a severe overestimate. Such misinformation may play a role in Americans' views about events well beyond our borders and contribute to support for military actions that have significant unintended consequences for present and future generations.

\section{Public's Preferences for Energy Sources}

Despite their gaps in knowledge, Americans view forms of energy in specific ways. Generally, they show enthusiasm for renewable forms of energy, such as solar and wind. They dislike the nation's reliance on oil and coal and look less favorably on other depletable energy sources, but they look favorably on natural gas and have starkly mixed feelings toward nuclear power.

\section{Renewable Energy Sources}

Sustainable energy is defined as any energy source that provides for current needs without compromising the ability of future generations to meet their own. Renewable energy, while sustainable by definition, is in addition perceived to be inexhaustible. Nevertheless, 
the magnitudes of all renewable sources are bounded by suitable climates, geographies, available space, and in some cases, water.

The world has seen a rapid growth in interest in renewable energy sources. As discussed in Chapter 2, these sources constitute a small but important amount of American energy capacity and are growing rapidly. In 2010, The New York Times reported that America's wind power industry increased capacity by 39 percent in 2009 alone. ${ }^{70}$ Although such increases start from exceedingly small amounts of capacity, and sustainable energy production does not contribute to air pollution and $\mathrm{CO}_{2}$ emissions, even these sources can pose significant environmental challenges.

\section{Solar Energy}

The most familiar renewable energy source is solar. Public perceptions about solar energy are nearly the opposite of attitudes toward coal and oil: solar energy is widely perceived as perhaps the foremost "clean" source of energy. The deployment of solar energy is increasing rapidly, as both absolute and relative costs fall. In 2008, according to the Solar Energy Industries Association, a trade group, US solar energy capacity increased 17 percent. $^{71}$ This increase included solar electric production, solar water heating, and other uses, such as swimming pool heaters and space heaters and coolers.

By 2025, according to one estimate, solar power could supply as much as 10 percent of the nation's energy needs. ${ }^{72}$ Survey after survey has found that solar is the most popular alternative energy source. A 2004 survey in California, for example, found that 87 percent of likely voters had a favorable opinion of solar energy production. ${ }^{73}$

Solar energy's popularity as a source of clean energy has not translated (at least not yet) into an economically viable option for many of the consumers who view it so favorably. Although solar energy's cost is declining fairly quickly, it remains expensive and dependent on tax breaks. If the externalities of carbon-containing fuels are not internalized, then solar will remain among the least cost-competitive alternative sources, although the economics are complex and solar production is highly site-dependent.

A Lawrence Berkeley National Laboratory study in 2009 found that average capacityweighted, pre-incentive installed costs (real 2009 dollars per installed watt) remained flat from 2008 to 2009 at $\$ 7.50 / \mathrm{W} .^{74}$ The cost to the consumer was actually higher in 2009 because of falling state subsidies; in California, for example, the state rebate declines as more solar systems are installed. ${ }^{75}$

The environmental impact of solar energy deployment is also not as straightforward as it may first appear. The potential impact on potable water resources is well recognized, 
particularly in wilderness parts of the American Southwest, where solar energy is most efficient. The large-scale deployment of solar panels in uninhabited areas may be less efficient than dispersed installations, for example, on the tops of buildings.

Less appreciated is the environmental cost of solar modules, both in their manufacture and in their eventual disposal. Manufacturing solar panels is an energy-intensive process that often relies on fossil fuels, although over the course of the life of the panel that cost is mitigated by the power that the panel produces. Making photovoltaic cells often requires using such harmful substances as cadmium and arsenic compounds, which present challenges for proper disposal.

\section{Wind Energy}

Like solar power, wind energy is a small but rapidly growing source that enjoys widely favorable ratings. Although harnessing wind energy for power has existed for millennia, deploying wind turbines to produce electricity has only recently become a viable alternative to fossil fuels: from 2005 to 2008 , power capacity from wind doubled. The World Wind Energy Association estimated that in 2008 wind generators produced 1.5 percent of the global consumption of electricity; for some individual countries wind now contributes significantly to fulfillment of electric power needs. ${ }^{76}$

Wind is also a popular alternative fuel for American consumers. Farhar found that wind trailed only solar power as the preferred energy source for consumers. ${ }^{77} \mathrm{Few}$ consumers, however, live near promising wind-generation sites. Wind generation itself produces no greenhouse gases. Although the impact of wind installations on the landscape prompts some opposition, some people report that they find wind generators aesthetically pleasing.

\section{Hydroelectric Power}

In addition to wind and solar power, Americans are at least somewhat familiar with several other renewable sources of energy. The principal one is hydroelectric power, a traditional source of electrical generation.

As we discussed in Chapter 2, water continues to supply a significant portion of the United States' electricity needs, and water is the world's most common renewable energy source. About 17 percent of the world's electrical supply comes from hydroelectricity. In the United States it accounts for almost 70 percent of the electricity generated from renewable sources and about 6 percent of total US electrical generation.

The main problems associated with further development of hydroelectricity are the shortage of appropriate sites in many countries, the environmental consequences of dam 
construction, and the economics of the enormous initial investment that hydroelectric projects require. Consequently, hydroelectric power has increased at a slower rate than other sources of electricity.

Worldwide, hydroelectric power generation was 73.6 percent higher in 2006 than in 1980, compared with 114.0 percent higher for fossil fuels and 289.0 percent higher for nuclear energy. In the United States, growth has been virtually nonexistent; the country produced only 1.4 percent more hydroelectric power in 2006 than in $1980 .{ }^{78}$ Virtually no chance exists for the resumption of large-scale dam construction in the near future in the United States.

China, by contrast, has seen dramatic growth and is now the world's largest producer of hydroelectric power. The world's largest hydroelectric project is the Three Gorges Dam on the Yangtze River.

Hydroelectric power generation is a mature technology that has met its limit in many countries because of societies' unwillingness to bear the environmental and capital costs of investment.

At the same time, hydroelectric power itself enjoys widespread popular support. Consumers prefer it as a source for their utilities, even over natural gas. Only about 15 percent of respondents in the Massachusetts Institute of Technology (MIT) study in 2007 wanted to reduce power from dams at all; almost 40 percent wanted to increase it. ${ }^{65}$ Hydroelectric power was seen as markedly more damaging to the environment than wind or solar, although still much less damaging than fossil fuels. ${ }^{65,77}$ The wording of MIT's questions about the popularity of hydroelectric power, however, likely makes isolating attitudes toward hydroelectric production from attitudes toward hydroelectric investment difficult.

The question of public knowledge and attitudes toward hydroelectric power, at least in the United States, may be largely moot because site and environmental factors constrain further development.

\section{Biomass}

Introduced in Chapter 2, biomass is a broad term that denotes the use of renewable biological material for the production of energy. The material could be forest or agricultural residue (e.g., stumps, barks, corn stalks, or husks) or plants grown specifically for use in energy generation.

Corn-based ethanol constitutes about 3 percent of the US automobile fuel supply, according to 2007 data. The United States allows up to 10 percent ethanol to be mixed into 
gasoline, and some states and cities mandate this mixture. The United States is the largest producer of ethanol in the world; ethanol production has increased tenfold since 1990, largely because of its fuel use.

Whether corn-based ethanol offers a truly renewable source of energy is questionable given that it requires tilling, fertilizing, harvesting, processing, and distributing. Certainly it substitutes for significant quantities of imported oil. The use of corn-based ethanol as a fuel admixture depends on significant agricultural subsidies. In addition, it has been implicated in increasing food prices and competition for food-producing agricultural land. Cane sugar-based ethanol, as is produced in Brazil, is not perceived to interfere with the food supply. Worldwide, substantial research is under way to develop an economically viable process for producing ethanol through the decomposition of cellulosic agricultural residue. Such a technology would affect agricultural markets less than corn-based ethanol production does.

Public knowledge and opinion about biomass are difficult to determine, in part because the term is so broad and can be used in so many contexts. What is clear is that biomass, through its link to agriculture, is more closely interwoven with the lives of more people than extractive fossil fuels or large-scale wind or solar generation. Because of the variety of environmental impacts of biomass fuel production, however, the economic viability and environmental sustainability of biomass efforts will depend on careful management of this method of fuel production.

\section{Geothermal Energy}

Geothermal energy, although less familiar, is well regarded by the American public. Farhar found that 71 percent of utility customers were in favor of geothermal energy production. This figure was lower than those for solar, wind, or natural gas but was in the mid-range for all energy options. ${ }^{77}$

\section{Depletable Energy Sources}

Of the traditional fossil sources of energy, oil and coal share the lowest public esteemnatural gas is viewed more favorably. Oil and coal, particularly coal, are associated with pollution, and oil incurs the additional implication of foreign dependence. Coal, oil, and natural gas account for 85 percent of the world's energy consumption. Each is a carbonbased fuel source heavily (although not equally) implicated in global climate change, and each is thought to have finite reserves. 


\section{Oil and Coal}

Oil accounted for an estimated 37 percent of global energy consumption in 2008. It holds a prominent place in most Americans' knowledge, perceptions, and opinions on energy, ${ }^{79}$ perhaps in part because of American drivers' sensitivity to oil prices. Unlike other energy consumption choices, gasoline reminds American consumers of price spikes whenever they fill up their tanks and see gas prices prominently advertised along streets and highways. Energy sources for electricity consumption remain hidden from view, but no one mistakes the source of fuel for their cars.

Coal, an even older energy source than oil, is the second-largest source of global energy, as discussed in Chapter 2. It is the leading source for generation of electricity. In 2006 coal supplied 129 quads of the global energy demand, compared with 169 quads from oil and 107 quads from natural gas. The share of global energy for coal has declined slightly over the past 40 years, from 29.2 percent in 1970 to 27.4 percent in $2006 .{ }^{78}$ Despite this share decline, the world still consumes more than twice as much coal each year as it did in 1970.

Two factors drive public attitudes toward oil and coal: price and the environment. Consumers have a close association with oil economics; when prices are high, interest in alternative fuels and concern over foreign policy spike, only to recede again with lower prices of gasoline. The close relationship that many consumers have with oil economics complements a direct sensory impression of oil as an unclean energy source. Although consumers may not breathe tailpipe emissions directly, and although few people nowadays change their own motor oil, most people directly experience oil and oil products in a way that is not true of coal, natural gas, or other energy sources. Similarly, liquid oil spills from wrecked tanker ships or offshore oil rigs have left a vivid mental image of oil as a pollutant in a way that gaseous pollutants, for example, generally have not.

Coal-fired electrical plants release harmful heavy metals, such as lead, mercury, nickel, tin, cadmium, antimony, and arsenic, into the atmosphere. Coal emits an estimated 0.963 kilograms of $\mathrm{CO}_{2}$ per kilowatt-hour of electricity generated from it, compared with 0.881 kilograms for oil and 0.569 kilograms for natural gas. For these reasons, most Americans perceive coal as a particularly "dirty" source of energy.

American consumers consistently rank coal among the least preferred sources of electricity. A 1999 review of utility market surveys found that coal ranked a distant last among both residential and commercial customers in their preferences for source of electricity. ${ }^{77}$ In addition, 69 percent of customers characterized themselves as somewhat or strongly opposed to coal, compared with 11 percent for natural gas; they ranked coal with nuclear power as the least preferred of sources. ${ }^{77}$ The poor image of coal has 
prompted a reaction from the coal and power industries, which promote clean coal technologies. The American Coalition for Clean Coal Electricity, for example, argues that advanced technologies make coal an economic and environmentally friendly choice for the near future. 80

Despite the "dirty" reputation of coal, the MIT survey in 2007 found that far fewer Americans wanted to increase oil usage than wanted to increase usage of any other energy source, including coal (Table 4.1). ${ }^{65}$ Only 7.8 percent of respondents wanted to increase the use of oil, a decline from the results of the same survey conducted in 2002, when 12.7 percent of respondents wanted to increase the use of oil. The difference between those wanting to increase oil and those wanting to increase coal (18.8 percent in 2007) may be attributable to Americans' recognition of domestic coal reserves and of the greater likelihood that oil has been imported from abroad. It may also reflect the notion of coal as a cheap energy source.

Table 4.1. Distribution of preferences about energy sources, 2007 (percent)

\begin{tabular}{lcccc} 
Energy source & Do not use & Reduce & Keep the same & Increase \\
\hline Coal & $6.6 \%$ & $47.7 \%$ & $27.0 \%$ & $18.8 \%$ \\
\hline Hydroelectric & $4.0 \%$ & $10.9 \%$ & $45.1 \%$ & $39.9 \%$ \\
\hline Natural gas & $3.5 \%$ & $26.5 \%$ & $38.8 \%$ & $31.3 \%$ \\
\hline Nuclear power & $11.3 \%$ & $28.0 \%$ & $25.0 \%$ & $35.7 \%$ \\
\hline Oil & $6.4 \%$ & $67.7 \%$ & $18.1 \%$ & $7.8 \%$ \\
\hline Solar & $2.7 \%$ & $7.5 \%$ & $13.1 \%$ & $76.8 \%$ \\
\hline Wind & $3.8 \%$ & $4.7 \%$ & $14.2 \%$ & $76.8 \%$ \\
\hline
\end{tabular}

Source: Adapted with permission from the MIT Center for Advanced Nuclear Energy Systems. ${ }^{65}$

Coal avoids the price awareness and the foreign policy implications of oil, but it carries an even heavier burden of pollution. Of all the sources of energy, coal has perhaps the worst public image in this regard. Its production and consumption are marked by negative associations, from the coal mine to the power plant. Coal mining results in local environmental degradation, whether it is mined by stripping the earth's surface or by tunneling beneath it. Mining coal produces huge amounts of waste, much of it toxic. Coal mining is associated in the public mind with terrible workplace conditions and with some of America's worst historical labor conflicts. Transporting coal is expensive, often costing more than mining it, which decreases coal's efficiency. 


\section{Natural Gas}

Like oil and coal, natural gas is a fossil fuel, but it has markedly better properties and public image. It is in many ways the obverse of coal: natural gas enjoys the widespread perception that it is a clean source of energy. This perception may be attributable in part to the successful marketing campaign of industry groups such as the American Gas Association, which touts it as "America's responsible energy choice" and sponsors' advertising natural gas as a clean alternative to petroleum.

With more than half the homes in the United States being heated with natural gas, people have a familiarity with it that they lack with coal. Natural gas is also mostly delivered and consumed without the consumer's ever seeing, smelling, or feeling it. Perhaps as a result, consumers rate natural gas nearly as high as solar and wind among their energy preferences. ${ }^{77}$

As discussed in Chapter 2, estimates of the probable US natural gas reserves were raised in 2009 by 39 percent. The new figure yields an estimated supply, at current consumption rates, that will last about 100 years. Consequently, natural gas seems increasingly likely to take significant additional market share from coal in electricity generation. Environmentalists have however raised concerns about the process of hydraulic fracturing, a highly effective method of natural gas extraction, as a potential source of contamination of the water supply. Undoubtedly this issue will continue to attract attention and may influence the society's attitudes regarding natural gas.

\section{Nuclear Energy}

Nuclear energy provides about 6 percent of global energy needs, although this amount varies greatly from country to country. In America, nuclear supplies 8.5 percent of our national energy consumption.

Nuclear is perhaps the most controversial of energy sources, and public opinion in the United States on nuclear energy is more complicated than for any other source. Opinions about it vary widely, and views may shift in positive or negative ways more easily than for other sources. To some, it is the most dangerous energy source, the producer of extremely toxic waste, and one vulnerable to catastrophic or even apocalyptic failures. To others, it is a potential source of clean and domestic electrical power generation far into the future.

The previously quoted 2007 MIT survey studied consumers' preferences about many alternative energy sources, from solar to hydroelectric. ${ }^{65}$ As shown in Table 4.1, nuclear power evoked the most divided response; more people (11 percent) advocated no future use of nuclear than advocated no future use of any other source. At the same time, almost 
36 percent wanted to see use increase. Moreover, fairly equal numbers wanted to use nuclear power "a lot" and wanted to reduce it "a lot." 65

Overall, nuclear power was preferred as a future energy source over only oil. The percentage of respondents who considered nuclear generation "very harmful" was higher than the percentage for any other source, even coal, but again, opinion was sharply divided: 28 percent responded that nuclear was only slightly harmful or not at all. ${ }^{65}$ The findings suggest that attitudes toward nuclear energy may be more malleable than opinions about other fuel sources.

\section{Public's Willingness to Pay}

The public attitudes and opinions we have surveyed frame the energy decisions that Americans will make on many public policy fronts in coming decades. Support for increased governmental investments in renewable energy technology, for example, will depend on the willingness of American voters to support such expenditures in the face of enormous and growing federal budget deficits. The role of coal and oil in America's energy portfolio will depend on the willingness of Americans to support mining and drilling operations that will become more complex and may change with respect to their impact on the environment as more readily accessible reserves are exhausted. Similarly, nuclear power will be very sensitive to the preferences of the American public.

As discussed in Chapter 3, decisions on energy use are often made through consumer choice, in which availability and price play major roles. Energy choices are not made in the abstract-Americans sort through options with the financial costs firmly in mind.

Some experiments and surveys have examined the willingness of Americans to pay more for sustainable energy. For example, Ansolobehere performed an experiment as part of the MIT survey on alternative energy sources. ${ }^{65} \mathrm{Half}$ of the sample formed a control group of 615 people who were given no further information. A quarter of the sample was assigned to one treatment group, and another quarter was assigned to a second treatment group. The treatment groups received information for seven energy source alternatives, from coal to solar power, about the supposed costs to a family of four; the difference between the treatment of the two groups was the stated cost of nuclear energy. ${ }^{65}$

The experimental results suggested that people misapprehend the costs of the various energy choices. The respondents tended to judge alternative sources such as hydroelectricity, solar, and wind as cheap and to think of fossil fuels as expensive, although the opposite is true. At the same time, they tended to estimate properly the relative costs of conventional fuels: they knew that coal is cheapest and oil is most expensive. 
When respondents received information about the true costs of energy, coal saw a marked increase in support; natural gas and oil a smaller increase; and alternative sources, such as solar and wind, a significant decrease. This experiment and others suggest that support for alternative energy sources stems not only from their association with zero emissions but also from a misapprehension of their costs.

Similarly, Farhar investigated utility customers' stated willingness to pay more for electricity that is renewable. ${ }^{77}$ Half of respondents indicated that they were "somewhat likely" or "very likely" to voluntarily pay more, whereas slightly less than half indicated an unwillingness to pay more. Farhar also cited "deliberative polling" studies, in which customers completed questionnaires before and after a weekend spent listening to presentations on energy and participating in discussions. The information caused only modest increases in the willingness of customers to pay more for renewable energy sources, but his results did indicate an increased willingness to pay small additional amounts. ${ }^{77}$

\section{Energy Conservation}

Study of the behavioral dimensions of energy consumption has focused on conservation, the willingness of people and organizations to use less energy in their daily lives, either on their own initiative or in response to stimuli such as government-financed tax breaks. Businesses and individuals may also practice energy conservation as a means of maximizing profit and economic security. Boosting energy conservation remains a central part of US energy and climate policy.

Conservation has had some notable successes. Recycling programs, which lower energy consumption through the avoidance of some production processes, are nearly ubiquitous. Widespread consumer education has promoted water conservation, fuel-efficient cars, and better-built homes that reduce the energy costs of cooling and heating.

Significant barriers prevent more widespread energy conservation. Consumers may find that the costs of researching and obtaining more efficient technologies outweigh realized energy savings. Various efforts at "eco-labeling," like the US Department of Energy's Energy Star program, seek to boost consumer knowledge of energy-efficient alternatives and the savings they may produce.

More problematically, technological improvements can increase energy consumption while increasing energy efficiency, a paradox formulated by an English economist William Stanley Jevons in $1866 .{ }^{81}$ Jevons observed that improvements in fuel efficiency in coalburning plants led to increases in the amount of coal consumed, largely because of the 
wider adoption of the new technologies. Proponents of energy conservation use Jevons' Paradox to assert the need for "green energy" taxes, which would keep the costs the same and recover the resulting savings for reinvestment, presumably in clean energy sources. Enabling consumers to increase their conservation lies at the heart of efforts to implement the smart electric grid, as described in Chapter 2, to augment the traditional one-way delivery of electrical power. Overlaying the current electric grid with digital feedback devices, including net metering, would allow for conservation measures, such as automatically running some appliances at off-peak times and turning off some uses at peak times. These automated adjustments would decrease reliance on expensive auxiliary power plants.

\section{Energy Politics and Geopolitics}

America's energy challenge is global. This fact has long been recognized in terms of the country's reliance on oil. Other forms of energy, both traditional and emerging, also have distinct political geographies, both domestically and globally. In this section we consider the linkage between public opinion and the US foreign and domestic policies.

\section{US Foreign Politics}

Oil

More than attitudes toward any other source of energy, attitudes toward oil are intertwined with complex questions of foreign policy, environmentalism, and big business. Multinational oil companies such as Shell and Exxon-Mobil have a brand awareness that nuclear, natural gas, or even coal companies do not match.

In addition, the price sensitivity of oil at the gasoline pump creates linkages in Americans' minds between world events and consumer pocketbooks. When, for instance, war breaks out in the Middle East, Americans are acutely aware of its impact on their commuting costs. Unlike the situation for electricity generation, where coal, natural gas, or nuclear power can be substituted as prime sources, little can currently be done for transportation to substitute for the primary fuel source, oil. Various fuels are available to heat a house, for example; at least until electrical vehicles become feasible, however, nearly everyone who drives will use gasoline.

The role of oil in complicating and, in some cases, driving American foreign policy is widely recognized. The United States imports more than half of its oil, making it heavily dependent on particular countries and regions to secure its supply. As shown in Table 4.2, 
six countries account for about twothirds of all oil imports. Approximately half of America's oil imports come from countries belonging to OPEC. Member countries of OPEC are Algeria, Angola, Ecuador, Iran, Iraq, Kuwait, Libya, Nigeria, Qatar, Saudi Arabia, United Arab Emirates, and Venezuela.

The fact that the United States imports oil from a much wider assortment of countries than the Arab nations of the Middle East is not
Table 4.2. Major oil exporters to the United States, 2008

\begin{tabular}{lc} 
Exporting country & $\begin{array}{c}\text { Percentage of US oil } \\
\text { imports }\end{array}$ \\
\hline Canada & $19.3 \%$ \\
\hline Saudi Arabia (OPEC Member) & $11.8 \%$ \\
\hline Mexico & $10.1 \%$ \\
\hline Venezuela (OPEC Member) & $9.2 \%$ \\
\hline Nigeria (OPEC Member) & $7.7 \%$ \\
\hline Iraq (OPEC Member) & $4.9 \%$ \\
\hline Source: Adapted with permission from the US Energy Information \\
\hline Administration.
\end{tabular}
widely recognized. Nearly two-thirds of Americans believe that most of the country's imported oil comes from the Middle East. In reality, only 10 percent of the US domestic consumption comes from the Persian Gulf (primarily from Saudi Arabia and Iraq, as shown in Table 4.2). About 29 percent of US domestic consumption comes from all the OPEC countries combined.

A similar lack of information fosters American attitudes toward the development of domestic reserves. For example, Americans tend to grossly overestimate the impact on self-sufficiency of measures such as offshore oil drilling or expanding oil production in Alaska. Alaska currently provides approximately 3 percent of US energy consumption.

\section{Coal}

Foreign policy with regard to coal is influenced by domestic policy. The domestic political geography of coal resembles that of oil. A few states dominate production (Table 4.3), although about 25 states produce at least some coal. This dominance leads to coal's importance to these states' elected officials and to considerably less importance to officials

\section{Table 4.3. Major coal-producing states, 2008}

\begin{tabular}{lcc}
\hline State & Short tons (millions) & Percentage of US total \\
\hline Wyoming & 467.6 & $39.9 \%$ \\
\hline West Virginia & 158.0 & $13.5 \%$ \\
\hline Kentucky & 119.9 & $10.3 \%$ \\
\hline Pennsylvania & 65.3 & $5.6 \%$
\end{tabular}

a Short ton is a unit of weight equal to 2,000 pounds ( 0.907 metric ton or 907.18 kilograms).

Source: Adapted with permission from the US Energy Information Administration. ${ }^{82}$ 
of other states; this disparity results in coal interests' predictably intense lobbying efforts at both state and federal levels, as well as the accompanying impact on campaign finances.

Geopolitically, America's relative self-sufficiency with regard to coal puts it in a situation that differs greatly from that for oil. Rising demand overseas through the 2000s pushed American coal exports to record levels. From 2007 to 2008 alone, exports increased 37.8 percent, a sign of the volatility of the international coal market. In 2008 the United States exported 81.5 million short tons while importing 34.2 tons, mostly from Colombia. As domestic coal production has shifted westward and as transportation costs and demand for low-sulfur coal have risen, importing low-sulfur coal by ship to power plants on the East Coast and in the Gulf of Mexico has become more cost competitive.

\section{Natural Gas}

Fifteen countries produce 84 percent of the world's supply of natural gas. Russia and the United States are the leading producers, each with about one-fifth of the global annual amount. US natural gas production remained flat between 1975 and 2005 but has been rising since, approaching its early-1970s peak.

The United States has proven reserves of 238 trillion cubic feet of natural gas, enough to last about 10 years if the country were completely reliant on domestic supplies. Recent estimates of future recoverable gas reserves, however, suggest much higher amounts (as mentioned earlier, recently revised estimates of probable US reserves are about 100 years at current rates of consumption). Russia's proven natural gas reserves are close to 7 times greater than those of the United States; Iran and Qatar also have vast reserves of the fuel. ${ }^{79}$

Transporting natural gas through pipelines has led to somewhat different geopolitics than the tanker route geopolitics of oil. Russia has engaged in disputes with Belarus and Ukraine over natural gas prices, creating worries that Europe's access to supplies may become endangered. Pipelines figure prominently in the geopolitics of Central Asia and the Caucasus, in particular.

Because of the transportation difficulties inherent in natural gas supply, pipelines and terminals are sometimes perceived as homeland security vulnerabilities. In 2007 al-Qaeda called for militants to attack oil and natural gas supplies, and some evidence suggests plots by the group to target liquefied natural gas (LNG) tankers. A 2007 report from the US Government Accountability Office focused on studies of the vulnerability of domestic LNG facilities and the impact of a terrorist attack on the surrounding population. ${ }^{83}$ The report concluded that the government must continue to strive for maximum safety measures for LNG facilities. These include positioning the facilities far away from densely 
populated areas to minimize the appeal of the target and the consequences of any mishap, accident, or sabotage.

\section{Nuclear Energy}

The United States generated 806 billion kWh of electricity from nuclear power plants in 2007 , about one-fourth of the world's total. Other leading producers of nuclear power were

- France, 418 billion kWh;

- Japan, 251 billion kWh;

- Russia, 148 billion kWh;

- South Korea, 136 billion kWh; and

- Germany, 136 billion kWh.

By comparison, the two most populous countries, China and India, had a combined production of only 79 billion $\mathrm{kWh}$. Nuclear generation provides approximately 18 percent of the United States' electrical needs, in contrast with 27 percent of Europe's. ${ }^{79}$ France, Belgium, and Slovakia obtain more than half their electrical supply from nuclear power.

Nuclear reactors represent some of the most sophisticated technology known to humanity. Splitting the atom was a milestone of scientific achievement, and modern nuclear reactors draw from a combination of advanced physics, chemistry, engineering, construction, and systems design. Even the limited deployment of nuclear power in the United States represents many billions of dollars of combined investment in research, construction, and operation.

Technological achievement and coordination required for the implementation of nuclear power are significant challenges, but those have not been the chief reasons that development of nuclear power as a source of electricity generation in the United States floundered. Instead, nuclear power development has been stymied by complex societal and socioeconomic processes. Concerns about nuclear production's impact on the earth's environment, its long-term safety, and its possible proliferation, while simultaneously increasing the cost of any new nuclear installation, guide the course of American nuclear policy development.

From essentially the same technological base, the United States and France have pursued remarkably different paths for their nuclear industries. The same can be said, to greater or lesser degrees, for the other forms of energy we have discussed. Even for still immature technologies, such as solar or wind energy, their success or failure will have as 
much to do with the societal contexts in which they are deployed as with humans' ability to maximize efficiency through better engineering.

Nuclear facilities remain a concern for homeland security because of the catastrophic damage that sabotage or attack could cause. The terrorist attacks of September 11, 2001, heightened fears that hijacked aircrafts could be flown into the cooling towers or containment areas of nuclear plants and release radiation, although industry trade groups dispute the likelihood that an airplane could penetrate the containment structure. Fears of proliferation and delivery of nuclear weapons material to nonstate entities-for the purpose of fabricating a "dirty bomb," for example-indirectly foster the perception that nuclear energy is implicated in global terrorism.

State-sponsored nuclear power, with its potential to provide weapons-grade material, is a unique foreign policy dilemma. The United States has sought to contain nuclear proliferation while encouraging nuclear power for peaceful uses-not always successfully. Recent crises with Iran and North Korea are prominent signs of the general struggle to contain nuclear power globally.

Nuclear power, long viewed with suspicion because of its potential for environmental destruction, is receiving another look because of rising concern about global climate change and increasingly uncertain supplies of fossil fuels. Some environmentalists are looking more favorably on nuclear power. Likewise, public opinion may change if energy prices rise or if, for example, electrical vehicles replace gasoline-powered cars on the nation's highways, which would increase demand for electricity.

\section{Wind and Solar Energy}

The politics of wind and solar power, unlike the politics of more traditional forms of energy, tend to be local (to the United States and, more specifically, to states, regions, and communities). With no intercontinental transport of the electricity, wind and solar power sources incur the problems of "not in my backyard" attitudes and the conflicting activities, policies, and politics that accompany such feelings. Even advocates of clean energy join protests over installation locations that are too close to either their own homes or fragile natural environments.

Increasingly, the environmental impact of wind generation's bulky spinning turbines has aroused local opposition. Birds and some mammals, particularly bats, may be at risk from wind generators. In fact, in December 2009 a federal judge halted expansion of a West Virginia wind farm because of its potential impact on endangered Indiana bats. ${ }^{84}$ Aesthetic and other concerns, as was the case with the Cape Cod wind farm mentioned 
previously, can also arouse local opposition. No other source of energy evinces such disparity between its broad general support and its local opposition.

Although large-scale wind developments dominate much of Americans' thinking about wind energy, small-scale generation, of less than $50 \mathrm{~kW}$ capacity, has long been part of the electrical system. It particularly affects people off the grid, those in isolated places, and people endeavoring to minimize their carbon footprint. Widespread adoption of a smart electric grid, described in Chapter 2, may make the installation of domestic wind generators on rooftops in some areas more attractive.

Internationally, the political geography of wind energy, like that of other sources, is highly variable. Supported by large governmental subsidies, wind is now responsible for

- 19 percent of stationary electrical generation in Denmark,

- 13 percent in Spain and Portugal,

- 7 percent in Germany and Ireland,

- 1.5 percent in the United States, and

- less than 1 percent in China.

The production of wind turbines is centered in the United States and China. China is investing substantially in manufacturing and innovation.

Solar power is not immune to geopolitics. China's massive investment in solar development and production has sparked US fears that the United States will lose clean energy jobs and technological leadership. Like other sources of energy, solar power is unevenly distributed over the earth's surface and even across the territory of large countries such as the United States. Climate and topography limit its utility in some places.

\section{US Domestic Politics}

Divisions like those delineated above have produced the expected partisan political divisions. Splits along political or ideological lines have an important impact on how the United States frames responses to its energy and climate challenges. Intensified partisanship over energy policy has entered the public consciousness, as evidenced by chants of "drill, baby, drill" at Republican rallies, when offshore drilling became an issue in the 2008 presidential election. Subsequently, the issue of offshore drilling has been immensely complicated by the 2010 Deepwater Horizon oil spill disaster.

Republicans have tended to be more skeptical of claims of human-induced global warming and the more aggressive remedies that have been proposed, although Republican 
attitudes toward climate change vary considerably. The environmental movement has tended to support Democratic candidates more often than Republican ones, but the Republican Party does have a strong conservation tradition dating back at least to President Theodore Roosevelt in the early twentieth century.

On energy policy, Democrats have tended to support the government's investment in alternative energy technologies, in part because of skepticism that market forces alone will produce timely viable options. Throughout the first decade of the 2000s, however, a consensus appeared to emerge that federal leadership in energy policy was needed. This consensus significantly departed from the state of affairs in the 1980s, when Ronald Reagan ran for office on a vow to disband the US Department of Energy.

The role of energy in determining voters' choices is inadequately understood. A growing body of literature addresses "green politics," and anecdotal information suggests that energy policy plays an important role in political campaigns. Nevertheless, we lack in-depth studies of the degree to which energy challenges influence Americans' choices at the ballot box.

\section{Energy and Social Justice}

Energy consumption and conservation enter into concerns about equity and social justice, particularly globally. They also enter into disagreements over equitable solutions to global climate change. These concerns and controversies have helped scuttle some ambitious attempts at a coordinated response.

The major disagreement is over the distribution of burden for environmental and conservation measures, such as reduction of $\mathrm{CO}_{2}$ emissions, across rich and poor countries. Developing countries contend that countries such as the United States, which consumes disproportionate amounts of energy per capita, should assume a higher share of the costs. They also contend that countries such as the United States should not hold developing countries to emission control targets that may impair their ability to develop economically and reduce poverty.

Western countries, meanwhile, have argued that nothing can be done about climate change if increases in gas emissions in the developing world overtake reductions in industrialized countries. This kind of dispute has stymied some attempts to reach an international agreement, including efforts made at the 2009 United Nations Climate Change Conference (commonly known as the Copenhagen Summit).

Domestically, social justice concerns often emerge in arguments opposing increases in the costs of energy, particularly gasoline, through additional taxation. Gasoline taxes are 
often characterized as regressive because they consume a higher proportion of the income of the poor than of the wealthy. Tensions also arise when, for example, home heating costs rise, disproportionately affecting the poor and those on fixed incomes, such as retirees. Finally, environmental justice advocates target the fact that many of the externalities of energy production and consumption, such as pollution and health problems, disproportionately burden poor and marginalized populations, such as racial and ethnic minority groups.

\section{Prospects of Energy Success and Energy Failure}

\section{Future Energy Options}

We probably cannot identify with much precision in 2011 the energy choices that will be available in 2050, 2100, or beyond. Particularly if the cost of energy rises, a host of other avenues may be feasible for developing practical alternative fuels. The willingness of Americans to support and adopt these emerging technologies may play a critical role in addressing energy needs in the United States.

Some of these potential sources of energy are almost mundane, such as the kinetic energy produced by human beings as they go through everyday motions. For example, the Shibuya Central Station in Tokyo installed mats beneath its turnstiles to capture the energy of people walking into the train station. The power produced suffices to light the station's light-emitting diode (LED) display boards and lights in the station's interior walls. ${ }^{85}$

One promising emerging power source is the fuel cell, which produces electricity from the chemical reaction of a fuel (e.g., hydrogen) with an oxidant (air). The concept of fuel cells originated in the nineteenth century. Their first uses were with the American space program in the mid-twentieth century. More recently, hydrogen-powered fuel cells have been successfully demonstrated with vehicle fleets, including automobiles and city buses.

California has aggressively pushed fuel-cell technology, operating a series of hydrogen fueling stations and working with auto manufacturers (Honda, General Motors) to put several hundred fuel-cell demonstration cars on its highways. In the summer of 2009, however, the Obama Administration canceled Department of Energy funding for developing hydrogen fuel-cell vehicles, citing the low likelihood that such vehicles would be practical in the next 10 to 20 years. The Administration also referred to the challenges of developing a national hydrogen fuel system. Nonetheless, fuel-cell research will continue. Whether fuel cells can be applied more widely or will remain a niche energy source remains to be seen. 
Another alternative energy source, ocean thermal energy conversion (OTEC), has received attention. It uses the temperature differential between deep and shallow waters to operate a heat engine. The first OTEC plant, built in Cuba in 1930, generated $22 \mathrm{~kW}$ of electricity. In 1974 Hawaii developed the Natural Energy Laboratory, one of the world's leading OTEC research facilities. To date, however, the large capital investments required for OTEC plants have prevented them from being cost-effective energy sources.

Tidal energy is another idea that has been around for hundreds of years. Tidal mills were in use in the Middle Ages and may date back as far as the Roman Empire. Despite this history, however, tidal energy is not in wide use in the world today, and its future remains uncertain.

The quest for new sources of energy, as distinguished from exploitation of current sources, will be undertaken, at least for the near future, in the middle of a fiscal crisis in Western industrialized democracies. Even in the best of circumstances, however, the ability of capitalist democracies to make public investments in long-term energy development remains open to debate.

With the pressing budget demands of the modern welfare state, investments in energy research may be curtailed. Planned or hybrid economies such as China may find themselves better positioned to make the necessary large capital investments in emerging energy technologies. China has demonstrated this possibility with its extensive investments in wind and solar power in recent years. Lacking the transparency of democracies, such countries may also make major missteps.

\section{The Prospect of Failure}

The search for solutions to America's energy challenges should be accompanied by a search for ways to prepare the country if these challenges cannot be fully addressed. These failures can be classified in various ways:

- Failures could be in the short term, as with the California electrical blackouts of 2000 and 2001 and the periodic shortages of gasoline due to embargoes or threats to the supply chain. These shortages disrupt local and national economies and represent a homeland security vulnerability.

- Failures could be in the medium term, as with the depletion of economically recoverable fossil fuel reserves before adequate development of alternative energy sources. These transitional shortages could cause instability on a global scale, because they would almost certainly occur unevenly across different countries. 
- Failures could be in the long term, if, for example, human societies must adapt to chronic energy shortages arising from increasing consumption, effects of climate change, and the failure to develop adequate sustainable energy sources.

One promising route for this research would draw from the burgeoning homeland security literature and examine the impact of energy crises through the lens of community resiliency. Community resiliency is defined as the ability of communities to prepare for and respond to natural and manmade emergencies, such as hurricanes, earthquakes, or terrorist attacks. This approach remains sensitive to two notions: first, that disasters do not affect all parts of society equally and, second, that preparedness is critical to mitigating the effects of traumatic events.

Modeling the impact of changing energy supplies on society is a complex undertaking, and the complexity increases as the time horizon moves away from the current situation. The United States may have the capital required to survive dramatic changes in its energy infrastructure, but other parts of the world appear more vulnerable.

For example, the post-World War II period has seen a dramatic increase in the productivity of agriculture - the so-called green revolution - which has seen yields rise significantly for a number of crops. This rise derives not only from genetic improvements in plants but from a heavy dependence on fertilizers, which are derived largely from fossil fuels. In developed countries, the mechanization of agriculture is similarly based on cheap energy. Critical questions involve the world's ability to feed itself if energy shortages occur, and the impact of these shortages on the international political order.

Domestically, energy shortage will almost assuredly affect different social and geographic parts of the country differently, on both the consumption and production sides of exchange. American states with large energy sectors, such as Wyoming, Alaska, and Oklahoma, will feel the changes in their state economies. Cold-climate states will experience changes in their vulnerability to price hikes on heating fuels. Working-class people and the poor will be more vulnerable to abrupt shifts in energy than the wealthy, and retirees will experience energy shortage differently from the young. Improving our ability to predict the geography and sociology of energy shortage will be critical to ameliorating its effects. 



\section{Future Research Needs}

When the Belgian Camille Jenatzy raced down a kilometer track near Paris in 1899 to become the first person to break the 100-kilometer-per-hour speed barrier, no one was surprised that he did so in an electric car. Lacking gear shifters and hand cranks, electric cars were easier to start and drive than their gasoline-powered rivals; moreover, they were quieter and less smelly. By the turn of the century, a fleet of electric taxis conveyed passengers around New York and other cities. Electric cars, despite their slower speeds and limited range, outnumbered gasoline cars across the country by almost 2 to 1 . Near the peak popularity of electric cars in 1911, The New York Times called them "ideal" because of their economy and cleanliness.

Electric cars were soon eclipsed by cars with internal combustion engines. Gasolinepowered cars were cheaper, were easier and faster to refuel, had longer ranges, and were soon to have electric starters. By the 1930s, they had established the dominance they enjoy to this day. The demise of the electric car and its modern prospects for a return offer a window onto the kind of cross-cutting research we advocate in this monograph. As emphasized at the outset and particularly in Chapter 4, the research gaps fall largely into the societal dimension of our three-part conceptual framework. Both energy technologies and (somewhat less expansively) energy economics have been explored in detail in past decades, but social attitudes and perceptions, knowledge, behaviors, and considerations of social constructs such as justice and ethics have had far less attention. We aim here to foster a change by delineating the questions that warrant investigation and the means by which such studies should go forward.

The example of automobiles illustrates some of the information gaps, but the general issues extend to the many ways we use energy in this country beyond transportation. The technological advances in gasoline-powered cars, and the corresponding problems in overcoming the limits of turn-of-the-century electric power, necessarily conditioned the prevalence of the internal combustion engine. Similarly necessary to our understanding is the economics of the two types of cars: Henry Ford's mass-production techniques cut the price of gasoline-fueled cars at the same time that the manufacturing costs of electric cars were rising. Improved technology and the economics of production and consumption favored the purchase of cars powered by gasoline. 
Nevertheless, Ford's decision to mass-produce gasoline and not electric cars was characterized as a close call. The early demise of electric cars followed primarily from the lack of availability of suitable battery technology; however, neither technology nor economics alone can explain why electric cars disappeared for almost a century and personal transportation became dominated by gasoline-powered cars. An understanding of the social contexts in which the two technologies were deployed is critical.

The United States was slow to electrify. It would be the 1930s before the country undertook serious rural electrification. Electricity for cars lacked standardization, with voltages varying widely. Being basically a waste product in the manufacture of kerosene for lamps, gasoline at the time was cheap. In addition, gasoline was easy to transport and to store; any general store could keep drums of gasoline for passing motorists.

Distribution of electricity, by contrast, would have to wait for immense governmental investment in infrastructure. Gasoline-powered cars may have been smellier, but consumers considered them almost pristine compared with the horses they were replacing. Moreover, the quickly rising popular fascination with long-distance road trips corresponded with the strengths of gasoline-powered automobiles. By contrast, the heavier electric cars often found the poor roads of the time impassable and had insufficient range for cross-country travel.

No less important, politics and public policy drove the rise of gasoline-powered cars and the concurrent environmental, foreign policy, and other externalities we have described in this monograph. The sweeping changes wrought by the car culture-the impact not only on the American landscape and the American economy, but also on the American environment-arose because of a combination of technology, economics, and social preferences and choices. All three dimensions play out in personal behaviors and public policy.

With vast improvements in technology, electric cars are emerging again. Since they are not yet economical, nor do they outperform their gasoline-powered equivalents, their initial market penetration is driven by social forces that value their low emissions, independence from imported oil, and high-tech features attractive to early adopters.

\section{Need for Multidisciplinary Energy Research}

Although not complete, our understanding of the technical and economic dimensions of energy production and consumption is fairly well advanced. Energy elements such as production and consumption rates and energy reserves and capacity are tracked with copious data and supported by significant investments of research funding. Even 
if projecting these into the future with precision remains difficult, we have sufficient knowledge to make at least reasonable estimates. For example, debate continues over exactly how much fossil fuel the earth contains and over humanity's ability to exploit it without damaging the earth's ability to sustain life, but we have largely in place the institutions and resources required to refine our estimates and increase the marginal efficiency of fossil fuel consumption.

Applying this technical and economic understanding to the United States' energy challenges, however, has yielded incomplete knowledge and solutions. The challenge in moving from the technical and economic emphasis to the social is considerable. However complex hard science and economics may be, the complexities of the social contexts in which the technologies and economies will be chosen and used exceed them.

Individual and community behavior and attitudes will frame and, in many cases, limit the nation's future energy options. Americans will have to make difficult choices among often competing concerns, such as environmental and ecological impacts, monetary costs, convenience, security of supply, sustainability, and social benefits. The outcomes will depend on the decisions and preferences of individuals as transmitted through their governments. Even the further development of energy technologies will depend on social context, in the form of public support for investments in basic and applied research and development. Knowledge about the hard science of energy outpaces our understanding of its social science contexts.

\section{Potential Research Topics}

Closing the gap between our hard science expertise and our understanding of social contexts will require contributions from several disciplines working with new sources of data and new methods. It will also require the synthesis of this new research and its integration with the technical and economic domains of energy research. In the work reflected in this monograph, we have reached some conclusions about research directions and topics, and we describe some possible research avenues. The following research areas and, in some cases, specific projects that we pose below illustrate some of the ways that America can move toward addressing its historic neglect of the social dimensions of energy.

\section{Addressing the Inadequacy of Public Knowledge}

What may be called "energy literacy," the public's everyday level of knowledge about energy options, is insufficient to support the informed choices that voters will be called 
on to make in the coming decades. A better understanding of how much Americans actually know and understand about energy uses, sources, and options will help identify which policy areas require better explanation to the public. Such information will enable educational programs or communication schemes to target their efforts more efficiently.

Researchers and policy makers also need a better understanding of how public opinion on energy is shaped. Economics is a major determinant, but it may not be the dominant one. Other questions need to be addressed: What other forces influence how people think about various energy options? What arguments are most persuasive? How do secular events like recessions, energy shortages, natural disasters, or international events influence energy opinion? How quickly or slowly do these impacts take hold, or recede, over time? Research into how public opinion is shaped will yield a better understanding of the forces that create the social contexts in which energy options are considered.; it will allow as well for better tailoring of public information campaigns.

To this end, we conclude that the United States should consider instituting an annual or biannual survey of public opinion on energy and knowledge of energy options. This objective could be accomplished either in conjunction with the Residential Energy Consumption Survey now conducted by the US Energy Information Administration or as a separate effort. It would institutionalize and standardize the issues addressed by various periodic private surveys, providing a neutral, unaligned source of public opinion data, complementing the surveys funded by advocacy or industry groups.

\section{Such a National Energy Opinion Survey could be guided by the following objectives:}

- Develop an understanding of how much Americans know about energy sources, technologies, alternatives, and their use.

- Identify effective ways to increase that knowledge where gaps exist.

- Monitor shifts in public opinion to clarify the immediate and longer-term challenges involved in developing public support for energy initiatives.

- Determine how energy economics and secular events shape public opinion, and estimate the rate at which such effects recede over time.

\section{Assessing the Acceptance of Alternative Energy Deployments and Their Impact on Society}

The rapid growth of alternative energy sources such as wind and solar electricity generation offers opportunities for studying the societal acceptance and environmental impact of the large-scale deployment of solar and wind technologies. How seriously will 
the phenomenon of "not in my backyard" restrict the available prime locations for both forms of sustainable electrical generation? How will their development affect the political geography of energy and climate change?

Infrastructure development of alternative energy sources has progressed far enough that both intensive and extensive studies of the impact of wind and solar installations are feasible. Conducting such work will yield information that will allow for better planning of future deployments. Local conflicts over the siting of renewable energy plants such as solar panels and wind turbines will almost certainly increase as these forms of energy are more widely deployed in coming decades. A better understanding of these conflicts and the government's potential role in mediating them will ease the deployment of energy facilities while helping protect the rights of local residents.

\section{Significant energy-efficient residential construction and construction materials}

technologies have evolved in countries with historically high energy prices-typically in Europe and in Japan. Whether the American society will be receptive to the introduction of these foreign alternative construction technologies remains unclear. Tracking adoption of such materials and technologies and clarifying the reasons for such technology diffusion (or lack of it) are important areas of future research.

The smart electric grid is a disruptive technology that will affect decisions about energy generation, distribution, and consumption by industrial, commercial, and residential consumers. The ultimate goal of the smart grid is to distribute electrical energy to consumers in a more efficient manner than is available today. Efficient energy distribution requires that utilities, governments, and organizations with an interest in energy conservation more fully understand consumer preferences, values, and decision making. Only then can they tailor communications programs, construction efforts, and the like most effectively.

The transportation segment will undoubtedly see further technology development. These technologies range from advanced materials (lighter, stronger) to hybrid, plugin hybrid, all-electric, and fuel-cell vehicles. The rate of conversion to such alternative technologies in transportation (or other energy uses) will be modulated by societal adaptation and acceptance. Future research can explore whether American society will adopt some, all, or none of these new technologies, and why. Adoption will clearly be determined by a combination of technological, economic, and societal forces; our focus here is on the social factors that are likely to play the biggest role in individual and organizational decision making. 
To aid the adoption of these new technologies, we need to have a better understanding of the externalities associated with the production and consumption of fuels. Because of concerns about petroleum's price stability, long-term availability, and negative externalities, considerable interest has been directed toward alternatives to petroleum transportation fuels. The externalities are associated with the effects of petroleum extraction, processing, and use on the environment and public health. Issues pertaining to the security of the petroleum supply complicate the picture. A fuller understanding of the externalities is essential in harnessing societal forces to support and implement an appropriate mix of alternative fuels that reflects the full impacts associated with production and consumption of each fuel.

The need to assess the societal acceptance and impact of alternative energy deployments opens the door to numerous research opportunities. Some of the examples that follow are focused on energy broadly defined; other are targeted to specific energy topics such as transportation, but the underlying questions can be generalized to a wide array of issues in this sector.

\section{Among the high-priority efforts, we recommend the following research:}

- Determine the underlying basis for conflicts emanating from the siting of renewable energy plants and the government's potential role in mediating them.

- Determine the role that esthetic, cultural, and habitual factors play in people's acceptance and adaptation of conventional, alternative, and future technologies. Differentiating consumer segments by sociodemographic characteristics of households with different behaviors and examining attitudinal and behavioral associations with such variables will be critical to this understanding. In addition, determining whether, for example, individuals tend to act more as individuals or as households may also be important, particularly if decision making power in households can be seen to reside, on average, with one or another member (such as mothers).

- Collect information (through, for example, the proposed National Energy Opinion Survey) to inform energy models with respect to consumers' expected reactions to new energy technologies and the perceived tradeoffs they might need to make relative to conventional (existing) technologies. Such technologies may be those introduced to improve the efficiency of energy generation, distribution, and consumption and include issues associated with the smart grid.

- Collect survey data about consumer preferences that can be used in modeling the economics of new types of transportation vehicles.

- Develop a methodology for estimating the externalities associated with selected alternative transportation fuels, such as biofuels, with the goal of comparing them with the externalities of petroleum-based fuels. 


\section{Understanding the Behavioral Economics of Energy Consumption}

As discussed in the previous chapters, the behavioral economics of energy consumption in a modern consumer society remains inadequately understood. In this area, numerous questions arise: How does America foster better energy decisions in an economy that seeks to increase consumption? What role do such practices as automatic bill paying and invisible metering have in insulating consumers from their energy choices?

Working from the National Academies' report and its conclusions on the inefficiencies in consumer behavior, the broad research issue can be framed as addressing ways in which the United States can improve the quality of market-driven decisions. Generating data for the analysis of this problem can provide decision makers with better options for reducing what appears to be an inherent contradiction between continued economic growth through the expansion of consumerism and a potential need to shift to a post-cheapenergy era. Among the specific areas to investigate are consumer behaviors related to energy savings, energy efficiency, and energy consumption information. As noted above, the externalities that influence consumption are also important to elucidate.

Energy savings are the result of complex interactions at the intersection of the technology, economics, and societal factors. Investigating and explaining public behaviors with respect to energy savings achieved through either energy efficiency or energy conservation (or both) opens up new and intriguing opportunities for social science research, with potential major impacts on the future of the US energy infrastructure.

A large literature focuses on energy efficiency and on the reasons that individual economic decisions may not result in economically efficient outcomes at the societal level. For example, consumers may not be fully informed of alternatives or their costeffectiveness, or they can be shortsighted or capital constrained. Markets may not lead to efficient outcomes in the presence of market failures, such as imperfect information; moreover, markets may not optimize outcomes in the presence of externalities, such as those concerning the environment. Nonetheless, the specifics of market failures as they apply to energy sources and uses are not yet well documented.

In addition to market failures, private decision making may lead to "behavioral failures." These may lead to deviations from cost-minimizing behavior (assuming that cost-minimization is the principal goal). More behaviorally oriented research is needed to understand the nature, magnitude, and reasons for these energy behavioral failures. Other questions are whether, from the point of view of consumers, they are, in fact, failures or instead represent informed, defensible choices that simply do not accord with conventional views about rational behavior. Such research must be done taking 
socioeconomic variables into account, insofar as education and income are likely to be prominent predictors of behaviors that involve the expenditure (or the saving) of money.

Residential energy consumers may be relatively unresponsive to price changes in their residential energy use, particularly electricity. This insensitivity to cost may arise, at least in part, because they lack or ignore information on the quantity of energy used by individual devices in their homes. Therefore, provision, or clearer articulation, of information about these externalities to consumers may reduce the environmental externalities of energy production and consumption.

We recommend that federal agencies support research that addresses the following issues:

- Determine and quantify the factors responsible for consumer behaviors regarding energy use and savings through choices reflecting efficiency and energy conservation.

- Determine the nature and magnitude of behavioral failures in private decision making that lead to deviations from cost-minimizing behavior.

- Assess how best to communicate to residential energy consumers the quantity of energy being used by individual devices to reduce the environmental externalities of energy production and consumption.

- Evaluate strategies for integrating the societal factors (e.g., society's preferences) into best practices for modeling energy demand and supply.

\section{Analyzing the Effects of Climate Change on Future Energy Production and Consumption}

The relationship between global climate change and energy has traditionally been framed as extending essentially in one direction: the consumption of fossil fuels must be reduced to limit $\mathrm{CO}_{2}$ emissions and, therefore, reduce the greenhouse effect. Considerable technical research has gone into the physical aspects of this proposition. Less well understood is whether consumers conceptualize the question in the same way and, for that matter, whether they understand such basics as the existence of a greenhouse effect or the relationship between that and $\mathrm{CO}_{2}$ emissions.

Also worth investigating are aspects of essentially the inverse of this problem: the effects of any future changes in climate on future energy production and consumption. For example, policy makers might want to know whether warmer temperatures lead to more energy demand through greater use of air conditioning or less demand because less heat is used. Improving our understanding of the effects of global temperature changes on our energy needs, on our ability to generate energy, and on energy use is crucial in researching the energy future. 


\section{In light of these issues we see the following research opportunities:}

- Assess the effects of climate change on energy consumption and future energy production needs based on the predicted impact of climate change on the environment. Research that is focused on the responses people make to supposed or real impacts of climate change might entail collecting data on people's ideas of what they might do, given different scenarios about climate change, and modeling these responses in various ways.

- Utilize the results of such "impact assessments" to direct the development of strategies that lead to an optimal portfolio of energy production and to programs that encourage consumers to make informed choices among energy sources.

\section{Understanding Energy Politics}

Researchers and policymakers lack a deep understanding of how energy politics works and how energy preferences intersect with broader questions of how voter preferences are formed. Political opposition, on many (and conflicting) fronts, remains an obstacle to solving America's energy challenges. Such opposition (or support) can take the form, for instance, of resistance to greater federal investment in new technologies or as local opposition to particular kinds of facilities. Research in both communities, and through nationally representative samples, that explores the factors that influence people's perceptions and choices would provide information helpful for decision makers. Such findings would enable them to better understand the policymaking climate in which energy options at the national, regional, or local level will be debated and decided. Such an understanding would contribute to a healthier, more transparent politics of energy.

The role of energy in determining voters' choices is inadequately understood. A growing body of literature addresses "green politics," and anecdotal information suggests that energy policy plays an important role in political campaigns. Nevertheless, we lack in-depth studies of the degree to which energy challenges influence Americans' choices at the ballot box.

\section{We recommend the following research initiatives:}

- Determine how energy preferences intersect with broader questions of how voter preferences are formed and whether such preferences differ by sociodemographic or other characteristics; such information gives policymakers a deeper understanding of how energy politics works and how best to reach voters with accurate, appropriate, and persuasive information.

- Conduct in-depth studies on the degree to which energy challenges influence Americans' choices at the ballot box. 


\section{Forecasting the Geopolitics of Energy}

The geopolitics of energy has long been understood to be unstable. The distribution of the primary energy sources is dramatically uneven across the surface of the earth and within its nation-states. The full impact of this instability and inequality is less well documented or understood.

Thus, we see a need for two related research avenues: (1) more extensive modeling of energy geopolitics per se and (2) integration of changes in energy production and consumption into these models. To prepare for America's future energy security needs, researchers must better predict how shifts in the global balance of power and shifts in energy supply and demand will change regional and global politics. Better data for both the nation and the world will be needed to populate such models with accurate and reasonably up-to-date facts, if they are to serve policymakers in a timely manner.

A switch to electric vehicles, their market being already in its nascent stages, will eventually cause changes to the commercial and small-business landscape of most American communities. For example, conventional gas stations may become obsolete, car repair shops may face extensive changes in the way they do business, and newer sites of power (e.g., plug-in sites for those vehicles) will emerge. Local economies will be changed when people no longer visit retail gasoline outlets, but instead recharge their cars at home or in settings established for this purpose. Exactly how these types of scenarios might play out, over what time frame, will be very important to clarify as both governments and entrepreneurs begin to make decisions of considerable economic and political consequence.

For examining these types of issues, we recommend undertaking two main research efforts focused principally on modeling. Each may entail multiple types of investigations, including basic data collection from individuals and organizations or institutions:

- Develop a model that predicts how shifts in the global energy supply and demand will affect global politics.

- Develop a corollary model that predicts shifts in local, especially urban, economies resulting from the introduction of alternative and new energy sources and technologies. 


\section{Exploring and Understanding the Relationships Between Homeland Security and Energy}

A closer linkage needs to be made between energy research and the burgeoning field of emergency preparedness and homeland security. The United States has numerous clear short- and long-term vulnerabilities. These can range from the threat posed to energy facilities by terrorist attacks or natural disasters to the challenges posed by transitions from one energy source to another. The specter of a full-fledged energy crisis, in which the country cannot meet its energy needs, also constitutes a threat to homeland security. Moreover, these threats will not affect American communities uniformly. Linking research on energy to the growing interest in community resiliency offers one area of immediate focus.

\section{We recommend the following study:}

- Assess the homeland security vulnerabilities posed by potential near-term or longer-term shortages of various energy sources, especially in the context of a possible inability to mitigate those shortages quickly.

\section{Promoting Public Support for Energy Solutions}

US policymakers have attended insufficiently to the ways that they might promote public support for energy solutions. Part of the problem is that ways to build support remain inadequately understood, at least insofar as energy generation, distribution, and consumption are concerned.

Examples abound of successful mobilization of public will. For example, consumer recycling in the United States has been successful as a voluntary movement, and in most states it does not rely on public incentives or penalties. Such examples provide a means for exploring how the "public mind" can be changed and motivated regarding energy options.

\section{We recommend the following initiatives:}

- Develop an integrated knowledge database drawn from all the results of the research initiatives proposed in the above sections.

- Formulate communication strategies that help to inform the US public on best energy practices that will lead to energy sufficiency and independence into the future.

- Formulate communication strategies that help to inform US policymakers on the public's perceptions about acceptable energy sources, practices, and technologies. 


\section{Reimagining the US Department of Energy's Identity and Scope}

In our view, the technological and economic dimensions of the energy challenge are necessary, although not sufficient, conditions for defining and implementing America's energy future. The societal dimension supplies a necessary, and also the required sufficient condition, for enabling future improvements in the US energy infrastructure. In this endeavor, the US Department of Energy's scope of interests could fruitfully expand further into the social dimensions of the energy challenge, as recommended in the recent report of the President's Council of Advisors on Science and Technology. ${ }^{86}$

\section{To foster this goal, we recommend the following steps:}

- Expand the US Department of Energy's formal scope to include societal factors when developing long-range sustainable solutions for meeting America's future needs.

- Incorporate science-based societal information gathered from research outlined in the above sections into the decision making process.

\section{Conclusion}

What unites each of these avenues for future research is a common theme: the need to advance our understanding of the societal contexts in which energy decisions are made. Given the "three-dimensional" nature of the energy conundrum, deeper understanding requires the simultaneous considerations of energy technologies, energy economics, and societal factors. It also calls for cross-disciplinary efforts to break the traditional limiting boundaries between these dimensions and to identify and harness their synergies.

Of course, we cannot lay out here a detailed research agenda that takes account of the many social science fields that can contribute to this goal. We also have not attempted to specify the many different study designs, modes of data collection, or analytic and statistical approaches that might be employed. Rather, we hope that our narrative will motivate a more holistic and multidisciplinary conversation about energy and help charter a research agenda that can provide practical, yet sustainable, long-term solutions to the energy needs of our society. 


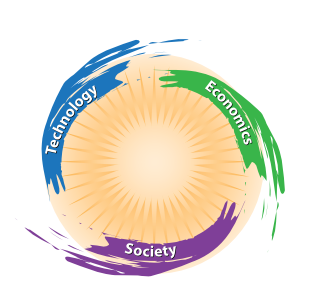

\section{References}

1. Smalley RE. Our energy challenge [slides]. New York: Columbia University; 2003 Sep 23. [cited 2010 Oct 2]. Available from: http://www.americanenergyindependence.com /library/pdf/smalley/OurEnergyChallenge.pdf

2. Committee on America’s Energy Future; National Academy of Sciences; National Academy of Engineering; National Research Council. America's energy future: technology and transformation. Summary edition. Washington: National Academies Press; 2009.

3. Committee for the National Academies Summit on America's Energy Future, National Research Council. The National Academies Summit on America's Energy Future: summary of a meeting. Washington: National Academies Press; 2008.

4. Committee on America’s Energy Future; National Academy of Sciences; National Academy of Engineering; National Research Council. Real prospects for energy efficiency in the United States. Washington: National Academies Press; 2009.

5. Committee on Health, Environmental, and Other External Costs and Benefits of Energy Production and Consumption, National Research Council. Hidden costs of energy: unpriced consequences of energy production and use. Washington: National Academies Press; 2010.

6. Lawrence Livermore National Laboratory. Energy flow charts [illustration]. Livermore (CA): Lawrence Livermore National Laboratory; 2010 [cited 2010 May 30]. Available from: https://publicaffairs.llnl.gov/news/energy/energy.html

7. American Physical Society. American Physical Society energy units. College Park (MD): American Physical Society; 2010 [cited 2010 May 30]. Available from: http://www.aps.org/policy/reports/popa-reports/energy/units.cfm

8. Lawrence Livermore National Laboratory. Estimated US energy use in 2008: 99.2 quads [illustration]. Energy flow charts. Livermore (CA): Lawrence Livermore National Laboratory; 2009 [cited 2010 May 30]. Available from: https://flowcharts.llnl. gov/index.html 
9. US Energy Information Administration. Independent statistics and analysis. Washington: US Dept of Energy; [date unknown] [cited 2010 May 30]. Available from: http://www.eia.doe.gov

10. US Energy Information Administration. Nuclear issues paper: nuclear power and the environment. Washington: US Dept of Energy; 2010.

11. Ground Water Protection Council; ALL Consulting. Modern shale gas development in the United States: a primer. US Department of Energy, Office of Fossil Energy and National Energy Technology Laboratory. 2009 Apr [cited 2010 Aug 28]. Available from: http://www.netl.doe.gov/technologies/oil-gas/publications/EPreports/Shale_ Gas_Primer_2009.pdf

12. Colorado School of Mines. Potential Gas Committee reports unprecedented increase in magnitude of US natural gas resource base [news release]. Golden (CO): Potential Gas Committee; 2010 Jun 18.

13. World Nuclear Association. World nuclear power reactors and uranium requirements. [data file]. London: World Nuclear Association; 2010 [cited 2010 July 30]. Available from: http://www.world-nuclear.org/info/reactors.html

14. US Committee on the Internationalization of the Civilian Nuclear Fuel Cycle, Committee on International Security and Arms Control, National Academy of Sciences and National Research Council. Internationalization of the nuclear fuel cycle: goals, strategies, and challenges. Washington: National Academies Press; 2008.

15. Rozon D, Lister D. Reprocessing versus direct disposal of spent CANDU nuclear fuel: a possible application of fluoride volatility. Toronto: Nuclear Waste Management Organization; 2008 [cited 2010 Sep 10]. Available from: http://www.nwmo.ca /uploads_managed/MediaFiles/82_ReprocessingCANDUSpentFuel.pdf

16. World Nuclear Association. Uranium: sustaining the global nuclear renaissance? London: World Nuclear Association; 2005 [cited 2010 Jul]. Available from: http://www.world-nuclear.org/reference/position_statements/uranium.html

17. Guth RA, Wakabayashi D. Bill Gates start-up in talks on small nuclear reactor. The Wall Street Journal. 2010 Mar 22 [cited 2010 Sep 21]. Available from: http://online. wsj.com/article/SB10001424052748704841304575138530498037398.html

18. van Loon J, Morales A. Small nuclear reactors are becoming big business. Business Week. 2010 May 20 [cited 2010 Sep 24]. Available from: http://www.businessweek. com/magazine/content/10_22/b4180020375312.htm 
19. World Nuclear Association. Small nuclear power reactors [Internet]. London: World Nuclear Association; 2010 Sep [cited 2010 Sep 24]. Available from: http://www.worldnuclear.org/info/inf33.html

20. NASA Earth Observatory. The carbon cycle. Greenbelt (MD): The Earth Observatory; 2010 [cited 2010 Jul 30]. Available from: http://earthobservatory.nasa.gov/Features /CarbonCycle/carbon_cycle4.php

21. Lawrence Livermore National Laboratory. Estimated US carbon dioxide emission in 2008: 5991 million metric tons. Energy flow charts [illustration]. Livermore (CA): Lawrence Livermore National Laboratory; 2009 [cited 2010 May 30]. Available from: https://flowcharts.llnl.gov/carbon.html\#2008

22. National Academy of Sciences. Understanding climate change-highlights of National Academies reports. Washington: National Academy of Sciences; 2008.

23. Walter K. Narrowing uncertainties. Livermore (CA): Lawrence Livermore National Laboratory. Science \& Technology Review. 2010 Jul/Aug; [cited 2010 Aug 28]. Available from: https://str.llnl.gov/JulAug10/klein.html

24. Intergovernmental Panel on Climate Change. IPCC fourth assessment report: climate change 2007, A2 scenario. [cited 2010 May 30]. Available from: http://www.ipcc.ch /publications_and_data/publications_and_data_reports.shtml\#1

25. Litos Strategic Communications. The smart grid: an introduction. Washington: US Dept. of Energy, Office of Electricity Delivery and Energy Reliability; 2009 [cited 2010 Sep 10]. Available from: http://www.oe.energy.gov/DocumentsandMedia/DOE_SG_ Book_Single_Pages(1).pdf

26. Hess G. Obama’s energy plan stirs mixed reaction. Chem Eng News. 2010;88(18):30-3.

27. US Energy Information Administration. Table 1.5 energy consumption, expenditures, and emission indicators, 1949-2009. Washington: US Energy Information Administration. [data file]. [date unknown] [cited 2010 Sep 10]. Available from: http://www.eia.doe.gov/emeu/aer/txt/ptb0105.html

28. US Energy Information Administration. Coal reserves current and back issues. Washington: US Energy Information Administration; 2010 [cited 2011 Feb 26]. Available from: http://www.eia.doe.gov/cneaf/coal/reserves/reserves.html 
29. US Energy Information Administration. Annual coal report 2009. Washington: US Energy Information Administration; 2010 [cited 2011 Feb 26]. Available from: http://www.eia.doe.gov/cneaf/coal/page/acr/acr_sum.html

30. US Energy Information Administration. Annual energy outlook 2010. Washington: US Energy Information Administration; 2010 [cited 2011 Feb 26]. Available from: http://www.eia.doe.gov/oiaf/archive/aeo10/index.html

31. US Energy Information Administration. Annual energy review: coal [data file]. Washington: US Energy Information Administration; 2010 [cited 2010 Sep 10]. Available from: http://www.eia.doe.gov/emeu/aer/coal.html

32. US Energy Information Administration. US crude oil proved reserves, reserves changes, and production [data file]. Washington: US Energy Information Administration; 2009 [cited 2010 Sep 10]. Available from: http://www.eia.gov/dnav/ pet/xls/PET_CRD_PRES_DCU_NUS_A.xls

33. Williams JL. Oil price history and analysis (updating). London (AR): WTRG Economics; c2006-2009 [cited 2010 Sep 10]. Available from: http://wtrg.com /prices.htm

34. US Energy Information Administration. Monthly US field production of crude oil [data file]. Washington: US Energy Information Administration; 2010 [cited 2010 Sep 10]. Available from: http://www.eia.gov/dnav/pet/hist/LeafHandler. ash $x ? \mathrm{n}=$ PET $\& \mathrm{~s}=$ MCRFPUS $1 \& \mathrm{f}=\mathrm{M}$

35. US Energy Information Administration. Weekly US imports of crude oil [data file]. Washington: US Energy Information Administration; 2010 [cited 2010 Sep 10]. Available from: http://www.eia.gov/dnav/pet/hist/LeafHandler. ash $\mathrm{x} ? \mathrm{n}=\mathrm{PET} \& \mathrm{~s}=\mathrm{WCRIMUS} 2 \& \mathrm{f}=\mathrm{W}$

36. US Energy Information Administration. Natural gas navigator [data file]. Washington: US Energy Information Administration. [date unknown] [cited 2010 Sep 10]. Available from: http://www.eia.gov/dnav/ng/hist/n9190us3m.htm

37. Wikipedia. List of countries by uranium reserves. [date unknown] [cited 2010 Sep 10]. Available from: http://en.wikipedia.org/wiki/Uranium_reserves

38. Arm ST. Nuclear energy: a vital component of our energy future. Chemical Engineering Progress. 2010;106(7):28. 
39. Sovacool BK, Agostino A. Nuclear renaissance: a flawed proposition. Chemical Engineering Progress. 2010;106(7):29.

40. Forsberg C. Nuclear power: energy to produce liquid fuels and chemicals. Chemical Engineering Progress. 2010;106(7):41-4.

41. Ux Consulting Company. UxC historical Ux price charts: UxU308 price-full history [data file]. Roswell, GA: Ux Consulting Company. [date unknown] [cited 2010 Sep 10]. Available from: http://www.uxc.com/review/uxc_PriceChart.aspx?chart=spot-u3o8full

42. Lawrence MJ. Nuclear renaissance? Think globally, act locally. Proceedings of the Symposium on Waste Management; 2001 Tucson (AZ). Report no. PNNL-SA-34212. Richland (WA): Pacific Northwest National Laboratory; 2001.

43. Nuclear Energy Institute. Nuclear energy: the renaissance revealed-a strategic direction for the 21st century. Washington: Nuclear Energy Institute; 2000.

44. US Department of Energy. Strategic petroleum reserve-quick facts and frequently asked questions. Washington: US Department of Energy; 2010 [cited 2011 Feb 26]. Available from: http://www.fossil.energy.gov/programs/reserves/spr/spr-facts.html

45. US Environmental Protection Agency. Economic analyses. Washington: US Environmental Protection Agency; 2010 [cited 2011 Feb 26]. Available from: http://www.epa.gov/climatechange/economics/economicanalyses.html

46. National Defense Council Foundation. The hidden cost of oil, an update. Paper presented to new congressional staff members by NDCF President Milt Copulos. Washington: National Defense Council Foundation; 2007 [cited 2010 Sep 10]. Available from: http://www.ndcf.org/

47. Greene DL, Ahmad S. Costs of US oil dependence: 2005 update. Oak Ridge (TN): Oak Ridge National Laboratory; 2005.

48. Link A. Benefit cost analysis of USDOE's energy efficiency and renewable energy vehicle technology program. Washington: US Office of Energy Efficiency and Renewable Energy; 2010.

49. Gillingham K, Newell RG, Palmer K. Energy efficiency economics and policy [Internet] [RFF Discussion Paper 09-13]. Washington: Resources for the Future; 2009 [cited 2010 Aug 28]. Available from: http://www.rff.org/documents/RFF-DP-09-13.pdf

50. Fairley P. Nuclear waste land. IEEE Spectrum. 2007 Feb:38-44. 
51. Fawcett A, Calvin K, de la Chesnaye F, Reilly M, Weyant J. Overview of EMF 22 US transition scenarios. Energy Economics. 2009;31 Suppl 2:S198-S211.

52. US Environmental Protection Agency. Integrated planning model (IPM). Washington: US Environmental Protection Agency; 2010 [cited 2011 Feb 26]. Available from: http://www.epa.gov/airmarkt/progsregs/epa-ipm/index.html

53. Goettle RJ, Ho MS, Jorgenson DW, Slesnick DT, Wilcoxen PJ. IGEM, an Inter-temporal general equilibrium model of the US economy with emphasis on growth, energy and the environment. Washington: US Environmental Protection Agency, Office of Atmospheric Programs, Climate Change Division; 2007. EPA Contract EP-W-05-035. Available from http://www.economics.harvard.edu/faculty/jorgenson/files/IGEM\%20 Documentation.pdf

54. RTI International. RTI Applied Dynamic Analysis of the Global Economy (ADAGE) model. Research Triangle Park, NC: RTI International; 2010 [cited 2011 Feb 26]. Available from: http://www.rti.org/adage

55. Woody T. Desert vistas vs. solar power. The New York Times. 2009 Dec21;Sect. B1.

56. Goodnough A. For Cape Cod wind farm, new hurdle is spiritual. The New York Times. 2010 Jan 5;Sect. A11.

57. Hubbert MK. Nuclear energy and the fossil fuels [Publication No. 95]. Houston (TX): Shell Development Company; 1956 [cited 2010 Oct 18]. Available from: http://www. hubbertpeak.com/hubbert/1956/1956.pdf

58. Jackson PM. The future of global oil supply: understanding the building blocks. IHS Cambridge Energy Research Associates; 2009 [cited 2010 Oct 18]. Available from: http://www.cera.com/aspx/cda/client/report/report.aspx?KID=5\&CID=10720

59. Lin S, Munsie JP, Hwang SA, Fitzgerald E, Cayo MR. Childhood asthma hospitalization and residential exposure to state route traffic. Environ Res. 2002;88(2):73-81.

60. Cornell University. Pollution causes 40 percent of deaths worldwide, study finds [Internet]. ScienceDaily; 2007 Aug 14 [cited 2010 Aug 28]. Available from: http://www.sciencedaily.com/releases/2007/08/070813162438.htm 
61. US Department of Transportation. National Transportation Statistics. Table 4-23 [data file]. Washington: US Department of Transportation. [date unknown] [cited 2010 Sep 10]. Available from: http://www.bts.gov/publications/national_ transportation_statistics/

62. US Environmental Protection Agency. Trends in greenhouse gas emissions, inventory of US greenhouse gas emissions and sinks: 1990-2007. Washington: US Environmental Protection Agency; 2009.

63. The Gallup Organization. Attitudes on issues related to EU energy policy. Analytical report. Washington: The Gallup Organization; 2007 [cited 2010 Aug 28]. Available from: http://ec.europa.eu/public_opinion/flash/fl206a_en.pdf

64. Tierney J. Poll finds generation gap on nukes. The New York Times. 2008 Oct 8.

65. Ansolobehere S. Public attitudes toward America's energy options: insights for nuclear energy. Cambridge (MA): Massachusetts Institute of Technology, MIT Center for Advanced Nuclear Energy Systems; 2007.

66. Van Liere KD, Dunlap RE. Environmental concern: does it make a difference how it's measured? Environment \& Behavior. 1981;13:651-76.

67. Arcury TA, Christianson EH. Rural and urban differences in environmental knowledge and actions. J Environ Edu. 1993;25:19-25.

68. Berenguer J, Corraliza JA, Martin R. Rural-urban differences in environmental concern, attitudes, and actions. Eur J Psychol Assess. 2005;1(2):128-38.

69. Bittle S, Rochkind J, Ott A. The energy learning curve: coming from different starting points, the public sees similar solutions. New York: Public Agenda; 2009 [cited 2010 Sep 9]. Available from: http://www.publicagenda.org/pages/energy-learning-curve

70. Mouawad J. Wind power grows 39\% for the year. The New York Times. 2010 Jan 26.

71. Solar Energy Industries Association. US solar industry year in review 2008. Washington: Solar Energy Industries Association. [updated 2009 Mar 31] Available from: http://www.seia.org/galleries/pdf/2008_Year_in_Review-small.pdf

72. CleanEdge, Co-op America. Utility solar assessment (USA) study: Reaching ten percent solar by 2025. Washington: Co-op America; 2008 [cited 2010 Sep 9]. Available from: http://myecoproject.org/wp-content/uploads/2009/03/cleanedge-coop-amerutilities-study-2008.pdf 
73. Katz C. Public attitudes and support for solar power: a survey of likely voters in California [Internet]. Los Angeles: Environment California Research \& Policy Center; 2004 [cited 2010 Sep 10]. Available from: http://cdn.publicinterestnetwork.org/assets/ JoiZa4yQT-yf6xXH-Pht7w/Public_Attitudes_and_Support_for_Solar_Power.pdf

74. Barbose G, Darghouth N, Wiser R. Tracking the sun III: the installed cost of photovoltaics in the US from 1998-2009. Berkeley, CA: Lawrence Berkeley National Laboratory; 2010 [cited 2010 December]. Available from: http://eetd.lbl.gov/ea/ems /re-pubs.html

75. Wiser R, Barbose G, Peterman C, Darghouth N. Tracking the sun II: the installed cost of photovoltaics in the US from 1998-2008. Berkeley, CA: Lawrence Berkeley National Laboratory; 2009 [cited 2010 Sep 10]. Available from: http://eetd.lbl.gov/ea/emp/ reports/lbnl-2674e.pdf

76. World Wind Energy Association. World wind energy report 2008. Bonn, Germany: World Wind Energy Association; 2009 [cited 2010 Sep 10]. Available from: http://www.wwindea.org/home/images/stories/worldwindenergyreport2008_s.pdf

77. Farhar B. Willingness to pay for electricity from renewable resources: a review of utility market research. Washington: US Dept of Energy, National Renewable Energy Laboratory; 1999.

78. US Energy Information Administration. Energy perspectives. Annual energy review 2009 [Internet]. 2008 [cited 2010 Oct 18]. Available from: http://www.eia.doe.gov /emeu/aer/pdf/perspectives_2009.pdf

79. International Energy Agency. World energy outlook: 2008. Paris: International Energy Agency; 2009 [cited 2010 Oct 18]. Available from: http://www.worldenergyoutlook. org/docs/weo2008/WEO2008.pdf

80. American Coalition for Clean Coal Electricity [Internet]. [Alexandria (VA)]: American Coalition for Clean Coal Electricity; 2007-2010 [cited 2010 Sep 10]. Available from: http://www.cleancoalusa.org

81. Jevons WS. The coal question: an inquiry concerning the progress of the nation, and the probable exhaustion of our coal-mines. London: Macmillan and Co.; 1866 [cited 2011 February 6]. Available from: http://www.econlib.org/library/YPDBooks/Jevons/ jvnCQ.html 
82. US Energy Information Administration. US imports by country of origin [data file]. Washington: US Energy Information Administration; 2010 [cited 2010 Sep 29]. Available from: http://www.eia.gov/dnav/pet/pet_move_impcus_a2_nus_ep00_im0_ mbbl_m.htm

83. Hurst C. The terrorist threat to liquefied natural gas: fact or fiction? Washington: Institute for the Analysis of Global Security; 2008.

84. Glod M. Court halts W. Va. wind farm to protect bats. The Washington Post. 2009 Dec 10.

85. Tech Blog Romow [Internet]. Japanese train station powered by kinetic energy. 2009 [cited 2010 Sep 10]. Available from: http://www.romow.com/tech-blog/japanese-trainstation-powered-by-kinetic-energy/

86. President's Council of Advisors on Science and Technology. Report to the President on accelerating the pace of change in energy technologies through an integrated federal energy policy. Washington: Executive Office of the President. November 2010. Available from: http://www.whitehouse.gov/sites/default/files/microsites/ostp/pcastenergy-tech-report.pdf 



\section{America's Energy Future: Technology and Transformation EXCERPTS OF INTEREST FOR SOCIETAL RESEARCH}

The following excerpts come from America's Energy Future: Technology and Transformation. ${ }^{2}$

"The report's aim is to inform policy makers about technology options for transforming energy production, distribution, and use to increase sustainability, support long-term economic prosperity, promote energy security, and reduce adverse environmental impacts" (p. 1).

"Mobilization of the public and private sectors, supported by sustained long-term policies and investments, will be required for the decades-long effort to develop, demonstrate, and deploy these technologies" (p. 1).

"A number of current barriers are likely to delay or even prevent the accelerated deployment of the energy-supply and end-use technologies described in this report. Policy and regulatory actions, as well as other incentives, will be required to overcome these barriers" (p. 6).

"[M]any uncertainties remain on the scientific, technological, and policy frontiers and in energy markets" (p. 6).

"[T]he committee will evaluate energy technologies with respect to:

- Estimated times to readiness for deployment

- Current and projected costs (e.g., per unit of energy production or savings)

- Current and projected performance (e.g., efficiency, emissions per unit of output)

- Key technological, environmental, economic, policy, and societal factors that would enhance or impede development and deployment

- Key environmental (including $\mathrm{CO}_{2}$ mitigation), economic, energy security, societal, and other life-cycle impacts arising from deployment

- Key research and development (R\&D) challenges" (p. 10). 
"In many cases, energy-efficiency gains that could have further moderated per-capita energy demand have instead been used to support new demands for energy, for example, through increased size and performance of light-duty vehicles" (p. 11).

"The committee uses the term 'energy security' to mean protection against disruptions to the energy supply chain" (p. 12).

“These market costs often did not account for 'externality' costs such as those stemming from the environmental and health impacts of producing, distributing, and consuming energy" (p. 14).

"The use of fossil fuels to generate energy has a number of deleterious impacts on land resources, water supplies, and the well-being of citizens" (p. 16).

"[Regarding $\mathrm{CO}_{2}$ capture and storage,] substantial new regulations would have to be formulated to address safety, ownership, and liability issues" (p. 16).

"While the development and widespread deployment of both evolutionary and new technologies will play a central role in transforming the energy system, so too will new public policies and international collective actions that are equitable, efficient, and effective. Such collaborations will be needed not only because of the inherently global nature of the challenges but also because of the differing priorities and capacities of other countries" (p. 29).

"[T]he transformation must engage the routine attention of the public itself" (p. 29).

"The committee did not, however, conduct an integrated assessment of how these technologies might compete in the marketplace and how that competition and other external factors could affect actual deployment rates and outcomes over time. For example, the successful deployment of energy efficiency technologies could reduce the demand for electricity and the need to deploy additional electricity-generation capacity" (pp. 31-32).

"The committee has not made judgments about the relative desirability of the supply options described in this report or about their appropriate pace and scale of deployment. Such decisions are beyond the committee's charge and are the responsibility of policy makers, investors, consumers, and, indeed, all citizens" (p. 32).

"The report does not provide an evaluation of the full range of options for reducing energy use. Such reductions are generally understood to be obtainable in two ways: (1) deploying technologies to improve the efficiency of energy production and use and (2) conserving energy through behavioral or lifestyle changes" (p. 32). 
"A study on energy conservation would require, for example, an in-depth understanding of how societal, economic, and policy factors affect energy consumption" (p. 33).

"Society is giving more attention to the environment and other externalities as exemplified, for example, by concerns about the impacts of carbon dioxide $\left(\mathrm{CO}_{2}\right)$ emissions on global climate change" (p. 40).

"To achieve such benefits, however, the efficiency savings must translate into actual reductions in energy consumption. This has been a particular issue in the transportation sector, where efficiency improvements that could have been used to raise vehicle fuel economy were instead offset by higher vehicle power and increased size" (p. 40).

"Substantially greater energy-efficiency savings could likely be obtained with a more aggressive mix of policies, regulations, and incentives to encourage an even wider deployment of energy-efficiency technologies. However, it should be noted that businesses and consumers have historically been resistant to making even modest upfront investments in such technologies.... New approaches may be required to break these patterns" (p. 49).

"A key finding of the present report is that there are substantial opportunities to reduce energy use through the widespread deployment of energy-efficiency technologies in buildings, industry, and transportation. The costs of deploying many of these technologies are much less than the costs to purchase energy; in fact, in these cases deployment saves money as well as energy. In spite of such advantages, many consumers are reluctant to make the necessary investments to deploy these technologies. Why the apparent dichotomy persists is the subject of ongoing research, which has already identified several reasons.

"One reason for the behavioral gap between economically optimal technology choices and actual choices is the low salience of energy efficiency for consumers. That is, consumers in this case do not reflect the neoclassical economic model of the optimizing consumer. Although real-world consumers may recognize that purchasing an energyefficient technology would be economically beneficial, the net benefits are usually so small relative to family budgets that individuals do not take the time to gather and analyze the requisite information.

"Another reason for the gap has to do with the difficulty of changing consumers' purchasing and use habits. Preferences learned from parents, neighbors, and friends may change only very slowly, if at all. Also, most consumers do not calculate lifecycle costs 
when making purchases but instead focus primarily on first-purchase costs. Producers, who understand this bias, may be reluctant to design and market energy-efficient products unless forced to do so by governmental regulation.

"Part of the behavioral gap is also based on economic-incentive issues-e.g., landlords of residential rental units are not motivated to pay for more efficient technologies when their tenants pay the utility bills. There are also historical path dependencies. For example, many existing building codes were developed when energy costs were not seen as important; these codes were optimized for safety, not for minimum lifecycle costs. Consumers also pay attention to product characteristics that tend to be ignored by analysts. They resisted buying early- generation compact fluorescent lamps, for instance, because they did not like the color of the light produced.

"Continuing research is needed to more fully understand these and other reasons for the behavioral gap and to devise appropriate strategies for closing it" (p. 50, Box 2.2).

"[C]orn ethanol is likely to serve only as a transition fuel to more sustainable biofuels production, given the societal and environmental concerns about using corn for fuel” (p. 63).

"R\&D in other scientific fields that are not addressed in this report will likely provide important support for the development and deployment of new energy supply and end-use technologies. ... Additionally, social science research on how households and businesses make decisions could lead to more effective measures to encourage energy efficiency" (p. 75).

"In the buildings sector, regulatory policies do not usually reward utility investments in energy efficiency; building owners in rental markets and builders are not responsible for paying energy costs and thus lack incentives to make investments that reduce energy use; information about the energy costs of specific appliances and equipment is often not readily available; and access to capital for such investments is limited. Drivers for greater efficiency - that is, for overcoming these barriers-could include rising energy costs, growing environmental awareness, improved and publicized building codes and appliance efficiency standards, and state and local-utility programs" (pp. 87-88).

"However, at a high level of renewable technology deployment, land use and other local impacts would become quite important. In the past, such impacts have provoked local opposition to the sitting of renewable electricity-generating facilities and associated transmissions lines, and opposition is likely to occur in the future" (p.101). 
"About 12 percent of US petroleum resources and 20 percent of US natural gas resources are believed to lie in areas that, for a variety of policy reasons, are currently offlimits" (p. 103).

"The issue for policy makers is to balance the energy security and economic benefits of developing these currently off-limits resources against the potentially negative environmental impacts" (p. 103).

"Public opinion about nuclear power has improved in recent years, at least in part because of the safe and reliable performance of existing plants, but it would likely become more negative if safety or security problems arose. The absence of a policy decision regarding the disposal of long-lived nuclear wastes, while not technically an impediment to the expansion of nuclear power, is still a public concern. 18 new reactor constructions have been banned in 13 states as a result, although several of these states are reconsidering their bans" (pp. 113-114).

"And the prospects for the Yucca Mountain repository are substantially diminished by the declared intent of the Obama Administration not to pursue this disposal site" (p. 115).

"[L]egislative and regulatory changes are needed to provide utilities and customers with adequate incentives to invest in modernization" [of the electricity transmission and delivery systems] (p. 117). 



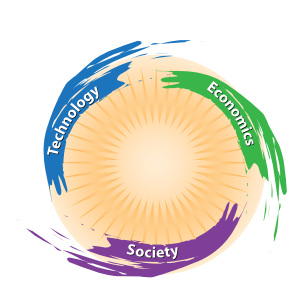

\section{About the Authors}

Robert H. Beach, $\mathrm{PhD}$, is a senior economist at RTI International with more than 10 years of applied economics research experience covering a broad range of policy issues. Dr. Beach specializes in the development and application of economic models to analyze agricultural, environmental, and natural resources regulations, programs, and policies. Recent applications have focused on analysis of the economic and environmental impacts of bioenergy and climate policy. Dr. Beach received his $\mathrm{PhD}$ in economics from North Carolina State University and a BSE in biomedical engineering from Duke University.

Philip C. Cooley, MS, is an RTI Fellow in bioinformatics. For more than 40 years he has focused on computer modeling research. He has developed models that examine the feasibility of evaluating policies for meeting air, water, and solid waste standards for the US Environmental Protection Agency, as well as disease transmission models involving malaria, HIV/AIDS, tuberculosis, and influenza. His current research focus is agent-based models, which are spatially orientated processes that simulate the movements of agents within social networks. Mr. Cooley received a master of science degree in operations research from the University of North Carolina and a BS in mathematics from Northwestern University.

Allen Duffer, BA, director of business and proposal development for RTI's Survey Research Division, has been with RTI since 1974. In this position he coordinates the business development plans and activities of the division for multiple agencies, institutes, and centers of the federal government as well as for commercial clients. His survey research experience includes the management of complex, large-scale cross-sectional, longitudinal, and sitebased data collection projects. These projects have involved the collection of data on sensitive health, quality of life, and behavioral topics. Mr. Duffer has a BA in English and political science from North Carolina State University.

Michael P. Gallaher, PhD, is the director of RTI International's Environmental, Technology, and Energy Economics Program and has more than 15 years of experience leading projects for the National Institute of Standards and Technology, the US Environmental Protection Agency, and other federal agencies modeling the economic impact of new technologies. Dr. Gallaher specializes in developing baseline/counterfactual scenarios from which incremental costs and benefits can be measured and has conducted both retrospective and prospective assessments of energy technologies and infrastructures. Dr. Gallaher received his $\mathrm{PhD}$ in economics from Boston College and has BS degrees in aerospace engineering from the University of Notre Dame and computer science from Southern Illinois University at Edwardsville.

L. Louis Hegedus, $\mathrm{PhD}$, is an advisor and a Visiting Distinguished Fellow at RTI International. He retired in 2006 as the Senior Vice President, Research and Development, of Arkema Inc., a global chemicals manufacturer. His nearly 40 years of industrial experience span chemicals (Arkema, W.R. Grace), oils (Elf Aquitaine, Total), and automobiles (Mercedes-Benz, General Motors). Dr. Hegedus earned his $\mathrm{PhD}$ in chemical engineering 
from the University of California, Berkeley, and is a member of the US National Academy of Engineering. He has 75 publications and patents, mainly in the areas of catalysis and chemical reaction engineering.

Markus Lesemann, $\mathrm{PhD}$, is the director for business development in the Center for Energy Technology at RTI International, where he is responsible for technology commercialization and licensing, commercial contracts, and intellectual property management. Previously Dr. Lesemann worked with catalyst manufacturer W.R. Grace, where he held positions in marketing management, with a focus on fluid catalytic cracking (FCC), and strategic $R \& D$, developing sorbents and membranes for oil refining applications. Dr. Lesemann received a $\mathrm{PhD}$ in physical chemistry from the University of Cologne, Germany, and an MBA from Georgetown University. He has published numerous articles in peer-reviewed journals, as well as industry publications, and is an inventor on several patents.

Toby H. Moore, $\mathrm{PhD}$, was a senior researcher in RTI's Survey Research Division at the time of the writing of this monograph. Prior to joining RTI in 2007, he was the redistricting expert of the Department of Justice's Civil Rights Division for the reapportionment that followed the 2000 Census, supporting voting rights enforcement through map drawing and demographic and electoral analysis. During his employment at RTI, he directed a major regional development study in South Carolina. Dr. Moore received a $\mathrm{PhD}$ in geography from the University of Iowa, Iowa City, an MA in geography from the University of North Carolina-Charlotte, and a BA in English and the Curriculum of Peace, War and Defense from the University of North Carolina-Chapel Hill.
Edo D. Pellizzari, PhD, is an RTI Fellow Emeritus. Dr. Pellizzari had nearly 40 years of scientific and executive leadership and accomplishments at RTI. $\mathrm{He}$ is nationally and internationally known for major contributions in the environmental health sciences, specifically in chemical and aerosol exposure analysis, and for developing and applying personal exposure methodology to populationbased studies on toxic chemicals. Dr. Pellizzari has served on several National Research Council committees, as chair of the Environmental Health Sciences Committee for the National Institute of Environmental Health Sciences from 2006 to 2008, and as a member of the US Environmental Protection Agency's Science Advisory Board (Drinking Water Committee) from 1987 to 1997. $\mathrm{He}$ received his $\mathrm{PhD}$ in biochemistry from Purdue University.

Dorota S. Temple, $\mathrm{PhD}$, is an RTI Senior Fellow in electronics and energy technologies and the director of RTI's Microsystem Integration and Flexible Electronics programs. She has more than 20 years of experience in the development of electronic materials and processes for applications in integrated circuits, sensors, displays, and solar cells. She is internationally known for her research on field emission electron sources and for her contributions to the development of threedimensional integration technologies for "smart" focal plane imaging arrays. Dr. Temple has authored or coauthored more than 130 scientific and technical publications and holds six US patents. She received her $\mathrm{PhD}$ in solid-state physics from the $\mathrm{AGH}$ University of Science and Technology, Cracow, Poland. 


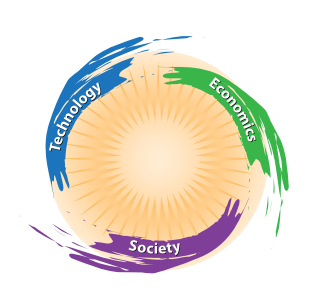

\section{Index}

A

ADAGE Integrated Model Structure, 44-45

electric vehicles, 18, 21, 79

American Coalition for Clean Electricity, 64

American Gas Association, 65

America's Energy Future: Summary of a Meeting

(National Academies), 2

America's Energy Future: Technology and

Transformation (National Academies), 2, 101-105

B

Barnett Shale, 13

behavioral energy economics, 36-37, 85-86

behavioral failure, 27

biomass

about, 9

public preferences for, 61-62

2008 usage, $5-7$

bounded rationality, 37

breeder reactors, 14,49

C

CAFE (corporate average fuel efficiency) standards, 40

Carnot cycle, 12, 21

Fischer-Tropsch chemistry, 19

methanol-to-gasoline (MTG) technology, 19

cement production, 15

Chernobyl, 53

Clean Air Acts (1955, 1963, 1967, 1970, 1977, 1990), 54

climate change, $1,17,43-44,51,54,62,74,86-87$

closed fuel cycle, 13

$\mathrm{CO}_{2}$ emissions, 15-17, 55 coal

about, 10-11, 15, 17

consumption, 5-7, 26-27

as global anthropogenic $\mathrm{CO} 2$ contributor, 15, 17

peak coal production, 52

pollution from mining of, 53

prices, $26-27$

production, 26-27, 69

public preferences for, 63-64

reserves, 26-27

community resiliency, 77

conservation (energy), 67-68

construction materials technologies, 83

consumption

coal, 5-7, 26-27

natural gas, 5-7, 31

nuclear energy, 5-7, 32-33

oil, 28-30

Copenhagen Summit, 74

corn-based ethanol, 61-62

crude oil. See oil

D

Deepwater Horizon offshore drilling rig explosion (2010), 33, 50, 73

deforestation, 15

Department of Energy. See US Department of Energy

Department of Transportation, 19

E

economics

behavioral energy, 36-37, 85-86

of primary energy sources, 25-34

EIA. See US Energy Information Administration (EIA)

electric grid, 8, 18, 21, 68, 73, 83

electricity generation, 18 
electricity-transportation boundary, 21

electrolysis, 20

EMF (Stanford Energy Modeling Forum), 43

emissions $\left(\mathrm{CO}_{2}\right), 15-17,55$

Endangered Species Act (1973), 54

energy

future options, 75-76

generation, distribution, and storage, 18-19

relationship with Homeland Security, 89

Richard Smalley on, 1

social justice and, 74-75

energy carriers, 18

energy conservation, 67-68

energy consumption, 85-86. See also specific energy sources

energy economics, $25-46$

behavioral, 36-37, 85-86

externalities, 34-36, 84

modeling energy markets and policies, 43-46

of primary energy sources, 26-34

role of government, 38-42

energy efficiency, 22, 36

Energy Information Administration. See US Energy

Information Administration (EIA)

energy infrastructure, 5-7

"energy literacy," 81-82

energy markets, modeling, 43-46

Energy Modeling Forum (EMF), 43

energy politics, $68-74,87,88$

energy sources

fossil, 5-7, 10-15, 17, 26-33, 48-49, 62-71

economics of primary, 25-34

public preferences for, $58-66$

sustainable, 5-9, 47-48, 59-62, 72-73, 76, 82-83

energy subsidies, 39

energy technologies, 5-23. See also energy sources

energy generation, distribution, and storage, 18-19

energy infrastructure, 5-7

energy utilization, 19-22

energy utilization, $19-22$

environmental impact, 51-54

of hydroelectric power, 60-61

of solar energy, 59-60

of wind energy, 60

EPA (US Environmental Protection Agency), 43-44

Eurobarometer survey (2007), 56

externalities, 34-36, 84
F

Fischer-Tropsch chemistry, 19

fluorescent light bulbs, 20, 23

fossil fuels

coal, 5-7, 10-11, 15, 17, 26-27, 52-53, 69-70

combustion, 15

natural gas, $5-7,12-13,31,52,65,70-71$

oil, 11-12, 28-30, 63-64, 68-69

production, $35,53,54$

public preferences for, $62-66$

2008 usage of, 5-7

fuel efficiency, in vehicles, 55

fuel-cell technology, 75

Fukushima Daiichi reactor crisis, 13-15

fusion project, 15

future research needs, 79-90

multidisciplinary energy research, 80-81

potential research topics, $81-90$

G

gas. See natural gas

geopolitics, 88 . See also energy politics

geothermal energy

about, 7-8

public preferences for, 62

2008 usage of, 5-7

Global Nuclear Energy Partnership (GNEP), 13-14

Global Trade Analysis Project (GTAP), 44

GNEP (Global Nuclear Energy Partnership), 13-14

Government Accountability Office, 70-71

government roles, 38-42

energy subsidies, 39

regulation, $39-40$

technology development, 40-42

GTAP (Global Trade Analysis Project), 44

$\mathrm{H}$

Hidden Costs of Energy: Unpriced Consequences of Energy Production and Use (National Research Council), 2, 35

Homeland Security, 89

Hubbert, M. King, 52

hydroelectric energy

environmental impact of, 60-61

2008 usage of, 5-7

hydrogen, 19

hydrogen fuel-cell vehicles, 75 
I

incandescent lighting, 20, 22

industrial utilization, 20

infrastructure (US energy), 5-7

instability of supply, 51-52

Integrated Planning Model of electricity production, 43-44

International Energy Agency, 33-34

International Thermonuclear Experimental Reactor (ITER) project, 14

Intertemporal General Equilibrium model, 43-44

Iraq War (2003), 33

ITER (International Thermonuclear Experimental Reactor), 14

J

Jevons Paradox, 67-68

L

Lawrence Berkeley National Laboratory, 59

Lawrence Livermore Laboratory, 5, 6, 15, 22

light-emitting diode (LED) technology, 20, 23

LNG (liquefied natural gas), 70-71

M

Marcellus Shale, 12-13

market failure, 40-42

methanol-to-gasoline (MTG) technology, 19

modeling energy markets and policies, 43-46

Mojave Desert, 47

MTG (methanol-to-gasoline) technology, 19

$\mathrm{N}$

National Academies, 2, 7, 15, 101-105

National Defense Council Foundation, 36

National Energy Modeling System (NEMS), 43

National Research Council, 33-34

natural gas

about, $12-13$

consumption, 5-7, 31

peak, 52

prices, 31

production, 31

reserves, 31

2008 usage of, 5-7

US Foreign politics, 70-71

natural gas-based fuels, 19 natural gas-transportation boundary, 21-22

NEMS (National Energy Modeling System), 43

nuclear energy

about, 13-15

breeder reactors, 14,49

consumption, 5-7, 32-33

history of US, $48-49$

prices, $32-33$

production, 32-33

public preferences for, $65-66$

reprocessing, 13-14, 49

reserves, $32-33$

2008 usage of, $5-7$

0

Oak Ridge National Laboratory, 36

ocean thermal energy conversion (OTEC), 76

offshore drilling, 50

oil

about, 11-12

consumption, $28-30$

major exporters to US, 69

prices, $28-30$

production, $28-30$

public preferences for, 63-64

reserves, 28-30

US Foreign politics, 68-69

OPEC oil embargo (1973), 33, 51-52

OTEC (ocean thermal energy conversion), 76

P

patents, 41

peak coal production, 52

peak natural gas, 52

peak oil, 52

petroleum usage (2008), 5-7

petroleum-based fuels, 19

photovoltaic electricity, 18

pipelines (natural gas), 70

plug-in hybrid vehicles, 18, 21

policies, modeling, 43-46

politics, $1,68-74,87,88$

pollution

from coal mining, 53

from fossil fuel production, 53, 54

health impact of, 53

Potential Gas Committee, 12 
prospect theory, 37

Public Agenda cluster analysis (2009), 57-58

public knowledge, inadequacy of, 81-82

public opinion

agreements in, 51-54

divisions in, 55-57

public preferences, 58-66

\section{R}

\section{Real Prospects for Energy Efficiency in the United} States (National Academy of Sciences), 2 rechargeable lithium batteries, 18

regulation and taxation, government role in, 39-40

renewable energy sources. See also specific renewable energy sources

public preferences for, 58-62

2008 usage of, 5-7

reprocessing (nuclear fuel), 13-14, 49

reserves

coal, 26-27

natural gas, 31

nuclear energy, 32-33

oil, 28-30

residential construction, 20,83

residential utilization, $19-20$

role of government, $38-42$

energy subsidies, 39

regulation, $39-40$

technology development, 40-42

RTI International Energy Grand Challenge Working Group, v

RTI's Applied Dynamic Analysis of the Global Economy (ADAGE) model, 43-45

\section{S}

savings (energy), 22-23

scarcity, 51, 52-53

shale gas technology, 12-13

Smalley, Richard, 1

smart electric grid, 83

social justice, $74-75$

societal factors, $47-77$

agreements in public opinion, 51-54

divisions in public action, $57-58$

divisions in public opinion, 55-57 energy and social justice, 74-75

energy conservation, 67-68

energy politics and geopolitics, $68-74$

environmental movement, 54-55

impact of, 48-51

prospects of energy success and failure, $75-77$

public's preferences for energy sources, 58-66

public's willingness to pay, 66-67

societal research, 101-105

solar energy

about, 8

environmental impact of, 59-60

large-scale deployment of, 82-83

Mojave Desert site, 47

public preferences for, 59-60

2008 usage of, 5-7

US Foreign politics, 72-73

Solar Energy Industries Association, 59

sources. See energy sources

Stanford Energy Modeling Forum (EMF), 43

Strategic Petroleum Reserve (SPR), 33-34

subsidies (energy), 39

sustainability, 1

sustainable energy sources

biomass, 5-7, 9, 61-62

geothermal, 5-8, 62

hydroelectric, 5-7, 60-61

solar, 5-8, 47, 59-60, 72-73, 82-83

tidal and wave, 9,76

wind, 5-9, 47-48, 59-60, 72-73, 82-83

syngas, 19

\section{$\mathrm{T}$}

taxation. See regulation and taxation

technology development, 1, 40-42

terrorism, 33

tidal energy, 9, 76

transportation

all-electric vehicles, $18,21,79$

corn-based ethanol, 61-62

hydrogen fuel-cell vehicles, 75

research on, 83

utilization, 21-22

vehicle emissions, 53

vehicle fuel efficiency, 55 
U

United Nations Climate Change Conference (2009), 74

uranium. See nuclear energy

US Department of Energy

about, 5

Energy Information Administration database, 7

Energy Star program, 67

identity and scope, 90

review of US shale gas developments, 12-13

US Department of Transportation, 19

US Domestic politics, 73-74

US Energy Information Administration (EIA)

about, 43

on coal resources, 26

energy savings, 6, 22

National Energy Modeling System (NEMS), 43

2010 Annual Energy Outlook, 27

US Environmental Protection Agency (EPA), 43-44

US Foreign politics, 68-73

US Government Accountability Office, 70-71

US National Academies Committee on America's Energy Future, 1-3

US National Academies Panel on Energy Efficiency

Technologies, 23
V

vehicles

all-electric, 18, 21, 79

corn-based ethanol, 61-62

emissions, 53

fuel efficiency, 55

hydrogen fuel-cell, 75

W

wave energy, 9

wind energy

about, 8-9

capacity of, 59

Cape Cod wind farm, 48, 72-73

environmental impact of, 60

large-scale deployment of, 82-83

Mojave Desert site, 47

political geography of, 73

public preferences for, 60

2008 usage of, 5-7

World Nuclear Association, 14

World Wind Energy Association, 60

Y

Yucca Mountain, 50 


RTI International is an independent, nonprofit research organization dedicated to improving the human condition by turning knowledge into practice. RTI offers innovative research and technical services to governments and businesses worldwide in the areas of health and pharmaceuticals, education and training, surveys and statistics, advanced technology, international development, economic and social policy, energy and the environment, and laboratory testing and chemistry services. 